QA: QA

Page i

000-3YD-VI00-00100-000-003

March 2005

BECHTEL

SAIC COMPANYLC

\title{
Surface Industrial HVAC System Description Document
}

Prepared for:

U.S. Department of Energy

Office of Civilian Radioactive Waste Management

Office of Repository Development

1551 Hillshire Drive

Las Vegas, Nevada 89134-6321

Prepared by:

Bechtel SAIC Company, LLC

1180 Town Center Drive

Las Vegas, Nevada 89144

Under Contract Number

DE-AC28-01RW12101 


\section{DISCLAIMER}

This report was prepared as an account of work sponsored by an agency of the United States Government. Neither the United States Government nor any agency thereof, nor any of their employees, nor any of their contractors, subcontractors or their employees, makes any warranty, express or implied, or assumes any legal liability or responsibility for the accuracy, completeness, or any third party's use or the results of such use of any information, apparatus, product, or process disclosed, or represents that its use would not infringe privately owned rights. Reference herein to any specific commercial product, process, or service by trade name, trademark, manufacturer, or otherwise, does not necessarily constitute or imply its endorsement, recommendation, or favoring by the United States Government or any agency thereof or its contractors or subcontractors. The views and opinions of authors expressed herein do not necessarily state or reflect those of the United States Government or any agency thereof. 


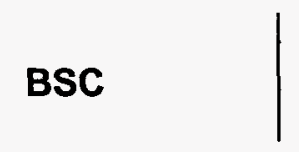

System Description Do cu
Signature Page
Complete only applicable it

1. $Q A: Q A$

2. Page iii of $11 \bar{\phi}^{4}$ 作 $10^{5}$

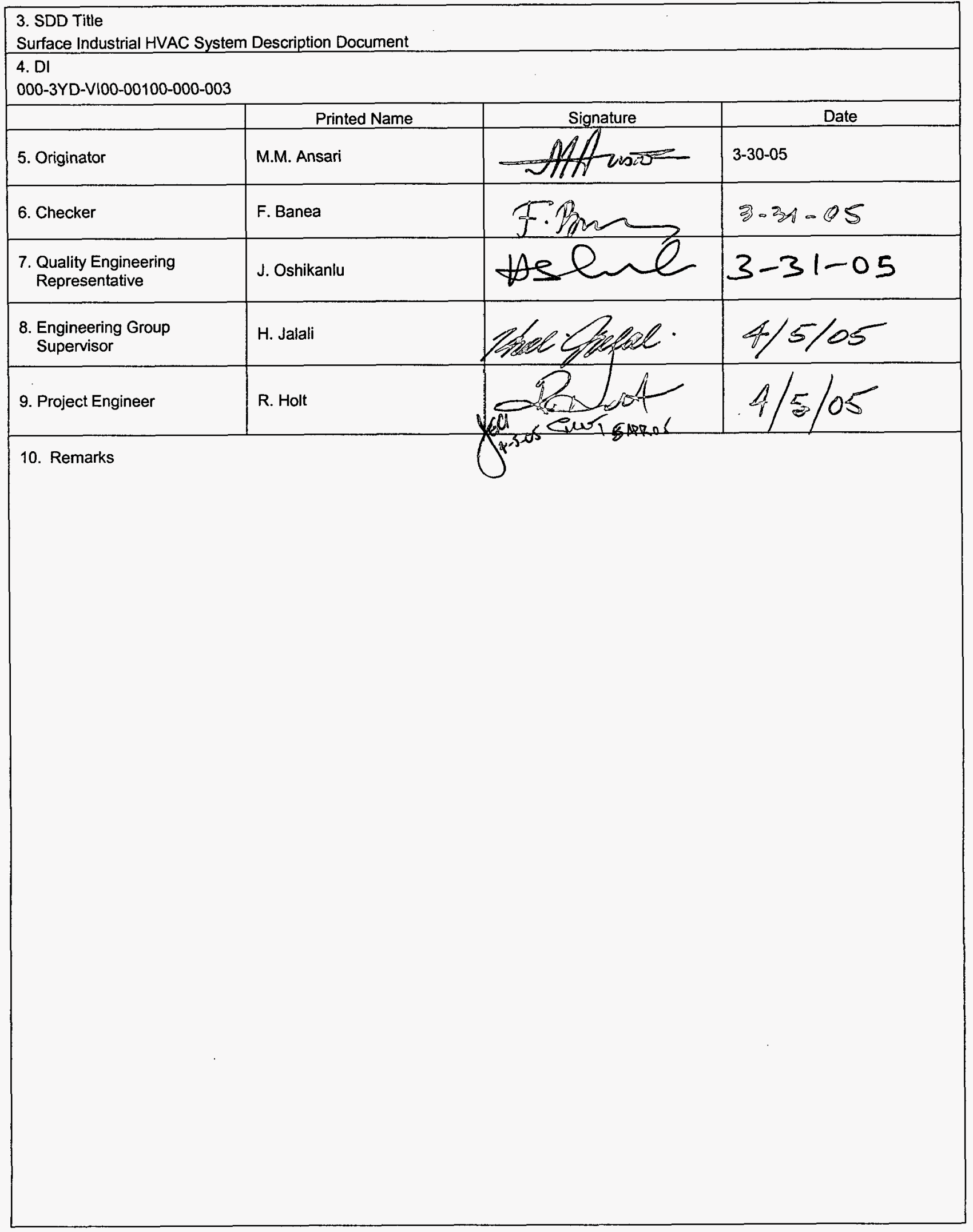




\section{System Description Document Change History \\ Complete only applicable items}

12. SDD Title

Surface Industrial HVAC System Description Document

13. $\mathrm{DI}$

000-3YD-V100-00100-000-003

14. Revision No.

15. Description of Change

000

Initial Issue. This issue supersedes previously issued System Description Document 000-3YD-VSI0-00100-000-000 due to change in system designation, reformatting, and additional information in Sections 3 and 4. This issue of the

System Description Document presents a preliminary description of the system to guide the License Application design development.

Issued for License Application.

002

Issue for LA Application with addition of FHF and CCCF. Major revision due to procedure LP-3.26Q-BSC, Rev. 1 ICN 4 and new template. Revision bars not used.

Issue for LA Application to incorporate revisions in preclosure safety analysis documents (Q-list, Nuclear Design Basis and Classification of SSCs), PDC, and the F\&OR. Revision bars mark revisions. 


\section{CONTENTS}

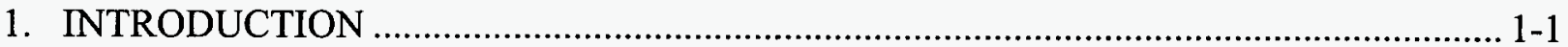

1.1 SYSTEM IDENTIFICATION.......................................................................... 1-1

1.2 LIMITATIONS OF THIS SYSTEM DESCRIPTION DOCUMENT …………........... 1-3

1.3 OWNERSHIP OF THIS SYSTEM DESCRIPTION DOCUMENT ............................ 1-3

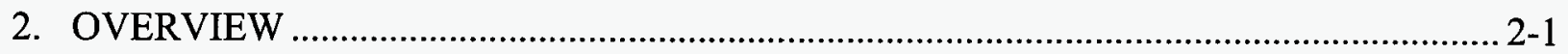

2.1 STRUCTURE, SYSTEM, OR COMPONENT FUNCTIONS................................. 2-1

2.2 STRUCTURE, SYSTEM, OR COMPONENT CLASSIFICATION N.......................... 2-1

2.3 OPERATIONAL OVERVIEW ……………………......................................... 2-2

3. REQUIREMENTS AND BASES ……........................................................................

3.1 GENERAL REQUIREMENTS ................................................................ 3-1

3.2 SPECIAL REQUIREMENTS AND BASES ………............................................... 3-9

3.3 ENGINEERING DISCIPLINARY REQUIREMENTS AND BASES....................... 3-16

3.4 TESTING AND MAINTENANCE REQUIREMENTS AND BASES..................... 3-21

3.5 OTHER REQUIREMENTS AND BASES ............................................................. 3-22

4. SYSTEM DESCRIPTION .............................................................................................. 4-1

4.1 CONFIGURATION INFORMATION............................................................ 4-1

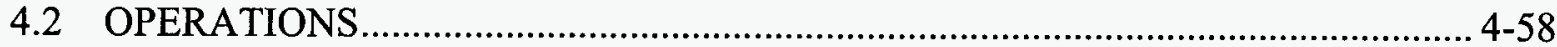

4.3 TESTING AND MAINTENANCE ………………........................................... 4-61

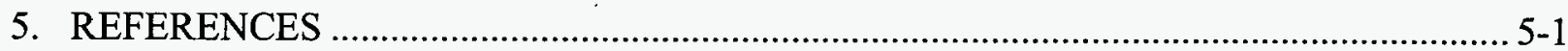

5.1 DOCUMENTS CITED .........................................................................................

5.2 CODES, STANDARDS, REGULATIONS, AND PROCEDURES ............................. 5-2

5.3 DATA TRACKING NUMBERS …………………................................................. 5-5

5.4 SOFTWARE CODES .................................................................................... 5-5

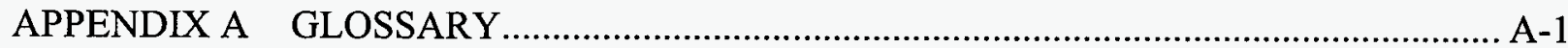

APPENDIX B LIST OF KEY SYSTEM CHARTS, DIAGRAMS, DRAWINGS, AND

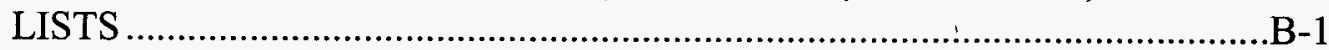

APPENDIX C $\quad$ LIST OF SYSTEM PROCEDURES …………............................................ 


\section{FIGURES}

Page

4-1. DTF 1 Electrical Equipment Room HVAC Subsystem............................................. 4-5

4-2. DTF 1 and Remediation Facility Support Room and Offices HVAC Subsystem .......... 4-7

4-3. DTF 1 Fuel Element and Canister Staging Area HVAC Subsystem............................. 4-9

4-4. CHF Electrical Equipment Room HVAC Subsystem ............................................... 4-15

4-5. CHF Support Areas and HVAC Equipment Rooms HVAC Subsystem ..................... 4-17

4-6. CHF Control System Rooms HVAC Subsystem...................................................... 4-19

4-7. CHF Canister Staging Area HVAC Subsystem........................................................... 4-21

4-8. Transportation Cask Receipt/Return Facility HVAC Subsystem................................. 4-27

4-9. WNNRF Warehouse Area and HVAC Equipment Area HVAC Subsystem ............... 4-29

4-10. WNNRF Office Area HVAC Subsystem .......................................................... 4-31

4-11. WNNRF Electrical Room HVAC Subsystem ...................................................... 4-33

4-12. FHF Electrical Room HVAC Subsystem ............................................................... 4-39

4-13. FHF Support Rooms and Offices HVAC Subsystem .............................................. 4-43

4-14. CCCF, Central Control Center HVAC Subsystem .................................................. 4-47

4-15. CCCF, Safeguard Area HVAC Subsystem.......................................................... 4-51

\section{TABLES}

Page

2-1. Determination of ITS, ITWI, and SC.......................................................... 2-2

3-1. Nominal Indoor Design Temperatures and Humidity .............................................. 3-3

3-2. Ambient Relative Humidity ........................................................................ 3-13

3-3. Ambient (Outdoor) Environmental Condition......................................................... 3-14

3-4. System Monitoring, Status, and Alarms Requirements .......................................... 3-19

4-1. DTF 1 Nonconfinement HVAC Subsystem Design Data.......................................... 4-12

4-2. CHF Nonconfinement HVAC Subsystem Design Data ....................................... 4-24

4-3. TCRRF and WNNRF HVAC Subsystem Design Data ............................................ 4-36

4-4. FHF HVAC Subsystem Design Data.................................................................. 4-45

4-5. CCCF HVAC Subsystem Design Data.................................................................. 4-53 


\section{ACRONYMS}

ALARA as low as is reasonably achievable

BOP Balance of Plant

CCCF

$\mathrm{CHF}$

DBGM

DCMIS

DOE

DTF

FDD

FHF

F\&OR

HVAC

HEPA

ITS

ITWI

LLW

NFPA

PDC

PRD

SC

SDD

SNF

SSC

TCRRF

WNNRF
Central Control Center Facility

Canister Handling Facility

design basis ground motion

digital control and management information system

U.S. Department of Energy

Dry Transfer Facility

facility description document

Fuel Handing Facility

Functional and Operational Requirements

heating, ventilation, and air-conditioning

high-efficiency particulate air

important to safety

important to waste isolation

low-level radioactive waste

National Fire Protection Association

Project Design Criteria Document

Project Requirements Document

safety category

system description document

spent nuclear fuel

structure, system, or component

Transportation Cask Receipt and Return Facility

Warehouse and Non-Nuclear Receipt Facility 
Surface Industrial HVAC System Description Document

INTENTIONALLY LEFT BLANK 


\section{INTRODUCTION}

The purpose of this system description document (SDD) is to establish requirements that drive the design of the surface industrial heating, ventilation, and air-conditioning (HVAC) system and its bases to allow the design effort to proceed to license application. This SDD will be revised at strategic points as the design matures. This SDD identifies the requirements and describes the system design, as it currently exists, with emphasis on attributes of the design provided to meet the requirements. This SDD is an engineering tool for design control; accordingly, the primary audience and users are design engineers. This SDD is part of an iterative design process. It leads the design process with regard to the flowdown of upper tier requirements onto the system. Knowledge of these requirements is essential to performing the design process. The SDD follows the design with regard to the description of the system. The description that provided in this SDD reflects the current results of the design process.

Functional and operational requirements applicable to this system were obtained from Project Functional and Operational Requirements (F\&OR) (Curry 2004 [DIRS 170557]). Other requirements that support the design process were taken from documents such as Project Design Criteria Document (PDC) (BSC 2004 [DIRS 171599]), the fire hazards analyses, and Nuclear Safety Design Bases for License Application (BSC 2005 [DIRS 171512]). These documents address requirements in Project Requirements Document (PRD) (Canori and Leitner 2004 [DIRS 166275]).

This SDD includes several appendices. Appendix A is a glossary; Appendix B is a list of key system charts, diagrams, drawings, lists, and additional supporting information; and Appendix $\mathrm{C}$ is a list of system procedures that will be used to operate the system.

\subsection{SYSTEM IDENTIFICATION}

The surface industrial HVAC system provides and maintains proper environmental conditions in the nonconfinement areas (clean areas) and supporting areas of the waste processing facilities like the Dry Transfer Facility with integrated Remediation Area (DTF 1 and DTF 2), Canister Handling Facility (CHF), and Fuel Handling Facility (FHF).

The surface industrial HVAC system also provides and maintains the proper environmental conditions in the other non-processing facilities like the Warehouse and Non-Nuclear Receipt Facility (WNNRF), Central Control Center Facility (CCCF), Balance of Plant (BOP), and other miscellaneous facilities.

The surface industrial HVAC system consists of the following major independent subsystems serving the facilities as shown below:

- DTF 1

- DTF 1 Electrical Equipment Room HVAC Subsystem

- DTF 1 and Remediation Area Support Room and Offices HVAC Subsystem

- DTF 1 Fuel Element and Canister Staging Area HVAC Subsystem 
- DTF 2

- DTF 2 Electrical Equipment Room HVAC Subsystem

- DTF 2 and Remediation Facility Support Room and Offices HVAC Subsystem

- DTF 2 Fuel Element and Canister Staging Area HVAC Subsystem

- $\mathrm{CHF}$

- CHF Electrical Equipment Room HVAC Subsystem

- CHF Control Systems Room HVAC Subsystem

- CHF Support Areas and HVAC Equipment Room HVAC Subsystem

- CHF Canister Staging Area HVAC Subsystem

- WNNRF

- Transportation Cask Receipt/Return HVAC Subsystem

- WNNRF Warehouse and HVAC Equipment Area HVAC Subsystem

- WNNRF Office Area HVAC Subsystem

- WNNRF Electrical Room HVAC Subsystem

- FHF

- FHF Electrical and Support Areas HVAC Subsystem

- FHF Support Room and Offices Areas HVAC Subsystem

- $\mathrm{CCCF}$

- Central Control Center HVAC Subsystem

- Safeguard Area HVAC Subsystem

- BOP and other Miscellaneous Facilities

- Administration Facility HVAC Subsystem

- Central Security Station HVAC Subsystem

- Utilities Facility HVAC Subsystem

- Switchgear Facilities HVAC Subsystems

- Generator Facilities Heating and Ventilation Systems

- Fire Water Facilities Heating and Ventilation Systems

- Fire, Rescue, and Medical Facility HVAC Subsystem

- Warehouse/Central Receiving HVAC Subsystem

- Craft Shops HVAC Subsystem

- Heavy Equipment Maintenance Facility HVAC Subsystem

- Vehicle Maintenance and Motor Pool HVAC Subsystem

- Visitor Center HVAC Subsystem

- Cask Receipt Security Station HVAC Subsystem

- Gate 510 Facilities HVAC Subsystem. 
Each of the above subsystems might be broken down further into supply system, and exhaust system as the applicable design warrants during the detail design stage. In this revision of the $\mathrm{SDD}$, all of the above subsystems are addressed as the surface industrial HVAC system as their functional and performance requirements are identical. Any difference or unique requirement is identified individually as the design and other information matures.

\subsection{LIMITATIONS OF THIS SYSTEM DESCRIPTION DOCUMENT}

As noted above, surface industrial HVAC system serves only the nonconfinement (clean area). The confinement areas of nuclear facilities are served by surface nuclear HVAC system described in a separate SDD.

This SDD may include assumptions, preliminary information, and to be verified values, as appropriate, to the current level of design development. Additionally, requirements or descriptions that are stated as to be determined or are expected at a later phase of the design will be described as such.

When this version was approved, the design status was such that the conceptual design had been completed and the preliminary design had begun. As design documents (e.g., calculations, drawings, and specifications) are completed, this SDD will be updated.

\subsection{OWNERSHIP OF THIS SYSTEM DESCRIPTION DOCUMENT}

The Surface Industrial HVAC SDD is owned by the Mechanical-HVAC group of the Design and Engineering Organization. 
INTENTIONALLY LEFT BLANK 


\section{OVERVIEW}

This section lists the functions allocated to the surface industrial HVAC system that are traceable to the identified source requirements in the F\&OR (Curry 2004 [DIRS 170557]) and PRD (Canori and Leitner 2004 [DIRS 166275]). This section also documents a preliminary determination of the system classification and provides an overview of the system operation.

\subsection{STRUCTURE, SYSTEM, OR COMPONENT FUNCTIONS}

The surface industrial HVAC system is described in Section 1.4.1.2.7-2 of the F\&OR (Curry 2004 [DIRS 170557]) which states that the repository:

Shall provide ventilation to surface nuclear and industrial facilities. Independent HVAC system shall be used in nuclear and industrial areas of surface facilities to ensure operating conditions of the nuclear and non-nuclear facilities, and quality of air in general, are within design limits.

The following system function from the F\&OR (Curry 2004 [DIRS 170557]) is supported by the requirements contained in the subsection of the general requirements. The implementing performance and operational requirements are described in each subsection along with the section of the F\&OR from which they are taken.

2.1.1 The repository shall provide industrial HVAC system for non-contaminated and clean areas of the surface facilities. An HVAC system shall be provided in the clean areas of the surface facilities to assure proper environmental conditions for personnel comfort and equipment operation. [F\&OR 1.4.1.2.7.2-2]

\subsection{STRUCTURE, SYSTEM, OR COMPONENT CLASSIFICATION}

The surface industrial HVAC system includes structures, systems, or components (SSCs) important to safety (ITS). They are not important to waste isolation (ITWI) as identified in the Table 2-1. The surface industrial HVAC system is categorized as safety category (SC).

Additional information regarding system classification is presented in Q-List (BSC 2005 [DIRS 171190]) and Nuclear Safety Design Bases for License Application (BSC 2005 [DIRS 171512]).

Based on Q-List (BSC 2005 [DIRS 171190]), the classification of systems is presented in Table 2-1. 
Table 2-1. Determination of ITS, ITWI, and SC

\begin{tabular}{|l|l|l|c|c|}
\hline \multicolumn{1}{|c|}{ Name } & \multicolumn{1}{|c|}{ Component or Function } & ITS & ITWI & Safety Category (SC) \\
\hline $\begin{array}{l}\text { Surface Industrial } \\
\text { HVAC System }\end{array}$ & $\begin{array}{l}\text { Inlet, outlet dampers, and ventilation } \\
\text { ducting (including stack) for Fuel } \\
\text { Element Staging Areas. (DTF only). }\end{array}$ & Yes & No & SC \\
\hline & $\begin{array}{l}\text { Structures, systems, and components } \\
\text { other than Inlet, outlet dampers, and } \\
\text { ventilation ducting (including stack) } \\
\text { for Fuel Element Staging Areas. (DTF } \\
\text { only). }\end{array}$ & No & No & Non-SC \\
\hline
\end{tabular}

\subsection{OPERATIONAL OVERVIEW}

The surface industrial HVAC system provides conditioned air for cooling, heating, and ventilation to ensure proper room temperatures and minimum air quality standards required for the safety, health, and comfort of the occupational workers.

The system provides pressure differentials that are maintained slightly positive relative to ambient, to minimize infiltration of unconditioned air and dust during the system operation. The surface industrial HVAC system, that interfaces with or is adjacent to contamination confinement areas, also provides positive pressure differentials relative to the ventilation confinement zones to preclude cross-contamination from those areas.

The surface industrial HVAC system consists of major independent subsystems identified in Section 1.1.

The exhaust fan bypass dampers for DTF HVAC subsystems that serve the fuel element staging areas are designed to fail open upon loss of power or upon fan failure. The related ductwork is designed to remain intact to allow natural airflow. This portion of the surface industrial HVAC system is designed not to collapse and to be operational with a design basis ground motion (DBGM)-1 event sequence.

The surface industrial HVAC subsystem's configuration normally consists of outside air intakes, supply air-handling units (with integral air filters, heating coils, cooling coils, humidifiers if required, and supply fans), exhaust fans, return fan in the recirculating systems, air distribution ductwork, and accessories including balancing, control, and instrument devices.

Fan-coil units are provided when supplemental cooling is required in an area served by the related subsystem.

The battery rooms are provided with explosion proof exhaust fans (one operating and one backup) that exhaust the air to the atmosphere to prevent hydrogen buildup in the battery rooms.

In certain areas where inside design temperature is higher than outside, natural ventilation is provided along with unit heaters for heating.

The central plant heating and cooling system provides hot water and chilled water to the air-handling unit heating and cooling coils of all the facilities. 
During loss of normal electrical power or when the central plant heating and cooling system is not available, the backup air-cooled water chiller and related chilled water pump which are powered from the emergency supplies the required backup chilled water to the supply airhandling unit cooling coils of CCCF, FHF, and DTF electrical equipment room HVAC subsystems.

The controls for HVAC system interface with the digital control and management information system (DCMIS). The electrical system provides electrical power to the HVAC components. 
Surface Industrial HVAC System Description Document

INTENTIONALLY LEFT BLANK 


\section{REQUIREMENTS AND BASES}

All requirements are classified as Engineering requirements and are located in Section 3.1. The remaining requirements and associated bases are classified as external compliance unless noted within the appropriate comment section.

Throughout Section 3, references are made to numerous source documents. Please note that in each case, PRD refers to Project Requirements Document (Canori and Leitner 2003 [DIRS 166275]), PDC refers to Project Design Criteria Document (BSC 2004 [DIRS 171599]), and F\&OR refers to Project Functional and Operational Requirements (Curry 2004 [DIRS 170557]).

\subsection{GENERAL REQUIREMENTS}

\subsubsection{System Functional Requirements}

\subsubsection{Safety Requirements}

The safety requirements presented in this section are nuclear design bases from Nuclear Safety Design Bases for License Application (BSC 2005 [DIRS 171512]). Other requirements that address safety issues, such as personnel protection from industrial hazards or nuclear criticality safety requirements are presented in the special requirements or other sections below.

3.1.1.1.1 Requirement: The system and its SSCs shall include design provisions based on its safety classification to enhance reliability and availability, such as diversity and redundancy, and features to place the system in a fail-safe state upon failure. Supports Function 2.1.1.

\section{Performance Acceptance Criteria:}

1. The inlet and outlet dampers and ventilation ducting for the fuel element staging areas (DTF only) shall be designed for loading conditions associated with a DBGM-1 seismic event and demonstrate sufficient seismic design margin to a "no failure" safety function ${ }^{\mathrm{a}}$.

2. The ventilation stack for the fuel element staging areas (DTF only) shall be designed for loading conditions associated with a DBGM-1 seismic event and demonstrate sufficient seismic design margin to a "controlled failure" safety function ".

3. A loss of HVAC for up to 30 days in areas where SNF or HLW is handled or staged shall not cause waste form temperatures to exceed allowable limits.

Note: ${ }^{\text {a }}$ See Glossary in Appendix A

Basis: Nuclear Safety Design Bases for Licensing Application (BSC 2005 [DIRS 171512]) takes credit for the passive portion of the ventilation system to provide airflow and ensure the temperature in the staging areas remains below the safe limits until active ventilation is restored. [PDC 5.1.3.2, PDC 6.3.2, PDC 4.8.2.2.33, PDC 4.8.2.2.34, and PRD-002/T-012] 
Other requirements that address safety issues such as personnel protection from process industrial hazards or nuclear criticality safety requirements are contained in the Special Requirements section or other topical section below.

\subsubsection{Environmental Requirements}

No environmental requirements for the system have been identified at this stage of the design. Environmental requirements for the system may be developed as the design progresses and will be applied as needed.

There are several environmental requirements that limit total site land disturbance, water usage, and air emissions. These have not been subdivided and allocated to individual facilities or systems. It is necessary, however, in the design of each facility or system, to predict the impact of facility and system construction and operation of these elements. A requirement for this is included in Section 3.2.7.4.

\subsubsection{Mission-Critical Requirements}

None have been identified at this stage of the design.

\subsubsection{General Requirements}

3.1.1.4.1 Requirement: The system shall provide no less than the minimum quantity of outdoor air to maintain the air quality standard in the clean areas of the facilities. Supports Function 2.1.1.

\section{Performance Acceptance Criteria:}

1. The system shall provide outdoor air of no less than 10 percent of the total system airflow, or as required to maintain proper indoor air quality.

2. The system shall maintain a slight positive differential pressure in the nonconfinement (clean) areas relative to atmosphere, or to adjacent confinement areas. The range could be between atmospheric and +0.15 inches water gauge.

Basis: This requirement supports PRD-022/P-001, which states that all repository SSCs shall be designed in accordance with the applicable industry codes, standards, engineering principles and practices with particular attention to those that incorporate system safety, human factors, and habitability standards. The required outdoor air is also to meet the requirements in ANSI/ASHRAE 62-2001, Ventilation for Acceptable Indoor Air Quality [DIRS 164296], Table 3-1. 2001 ASHRAE Handbook, Fundamentals (ASHRAE 2001 [DIRS 157789], Chapter 26, Ventilation and Infiltration) states that the conventional air handling systems utilizing the recirculation systems provide approximately 10 percent to 40 percent outside air fraction for ventilation purposes. This requirement also supports PDC 4.8.2.3.4. Controlling pressures between confinement zones will limit the spread of radioactive or hazardous materials into the clean area. [[PRD-022/P-001, PDC 4.8.2.3.4, and PRD-002/T-012]

3.1.1.4.2 Requirement: The system shall provide sufficient quantity of conditioned air to maintain proper indoors environmental condition. Supports Function 2.1.1. 


\section{Performance Acceptance Criteria:}

1. The system shall provide a circulation air change frequency of four to ten air changes per hour to the normally occupied areas of the facilities. The actual air change rate shall be based on the heating and cooling load calculations.

2. The system shall maintain the indoor design temperature and relative humidity (where required) as defined in Table 3-1.

Table 3-1. Nominal Indoor Design Temperatures and Humidity

\begin{tabular}{|c|c|c|}
\hline \multirow[b]{2}{*}{ Area } & \multicolumn{2}{|c|}{ Summer/Winter } \\
\hline & $\begin{array}{c}\text { Dry Bulb } \\
\text { Temperature }\left({ }^{\circ} \mathrm{F} \mathrm{DB}\right)^{\mathrm{a}} \\
\end{array}$ & Relative Humidity $(\% \mathbf{R H})^{\mathbf{a}}$ \\
\hline $\begin{array}{l}\text { Normally Occupied Areas (e.g., Offices, Corridors, } \\
\text { Conference Rooms, Records Room, Training } \\
\text { Rooms, etc.) }\end{array}$ & $75^{\circ} \mathrm{F}+/-2^{\circ} \mathrm{F} / 72^{\circ} \mathrm{F}$ & $30 \%-60 \% / 30 \%-60 \%{ }^{b}$ \\
\hline $\begin{array}{l}\text { Mechanical and Electrical Equipment Rooms, } \\
\text { Warehouses, Shops, Vehicle Maintenance Areas) }\end{array}$ & $\begin{array}{l}90^{\circ} \mathrm{F} / 65^{\circ} \mathrm{F}^{\mathrm{e}} \\
\text { See Note a }\end{array}$ & $\begin{array}{l}\text { Humidity Control Not } \\
\text { Required }^{c}\end{array}$ \\
\hline $\begin{array}{l}\text { Sensitive Electronics Equipment Areas (e.g., Central } \\
\text { Control Center, Computer Rooms, Monitoring } \\
\text { Rooms, etc.) }\end{array}$ & $72^{\circ} \mathrm{F} / 72^{\circ} \mathrm{F}$ & $45 \%-55 \% / 45 \%-55 \%{ }^{a, b, c, d}$ \\
\hline Battery Rooms & $77^{\circ} \mathrm{F} / 77^{\circ} \mathrm{F}^{f}$ & Humidity Control Not Required \\
\hline Switchgear Rooms & $104^{\circ} \mathrm{F} / 65^{\circ} \mathrm{F}$ & Humidity Control Not Required \\
\hline Canister Staging Area & $\begin{array}{c}140^{\circ} \mathrm{F} \text { (design) } / \\
150^{\circ} \mathrm{F}^{\mathrm{g}} \text { (maximum) }\end{array}$ & Humidity Control Not Required \\
\hline Diesel Generator Rooms & $120^{\circ} \mathrm{F} / 50^{\circ} \mathrm{F}^{\mathrm{h}}$ & Humidity Control Not Required \\
\hline
\end{tabular}

NOTES: ${ }^{a}$ Temperature and humidity are not controlled during event sequence conditions such as loss of power or equipment failure. The system shall be designed to achieve temperatures for normally occupied areas and within acceptable range required by ACGIH for workers occupancy during maintenance, operation, and inspection cycles.

${ }^{b}$ Recommended dew point temperature for occupied spaces shall be not less than $36^{\circ} \mathrm{F}$.

${ }^{\mathrm{c}}$ Special provisions may be provided for components with special humidity requirements.

${ }^{d}$ Further study is required to evaluate the impact of humidity on sensitive electronic equipment.

e Temperature for the warehouse and other shop facilities needs to be evaluated on the basis of expected usage and occupancy.

${ }^{f}$ Temperature is based on the recommendation of IEEE STD. 484-2002 [DIRS 169128].

${ }^{\mathrm{g}}$ The maximum surface temperature of $150^{\circ} \mathrm{F}$ in staging area is based on concrete temperature limit and is necessary to protect fuel cladding.

${ }^{h}$ The upper value is when the diesel generator is operating and the lower value is to prevent freezing condition during winter based on acceptable industry practices. 
Basis: This requirement supports PRD-022/P-001, which states that all repository SSCs shall be designed in accordance with the applicable industry codes, standards, engineering principles and practices with particular attention to those that incorporate system safety, human factors, and habitability standards. This requirement defines the interior ambient temperature and humidity for various types of room applications based on the applicable human comfort criteria in ANSI/ASHRAE 55(55a)-1995 [DIRS 157791]. This indoor environmental condition for human comfort is also in accordance with 2001 ASHRAE Fundamentals Handbook (ASHRAE 2001 [DIRS 157789], Chapter 8), and 2004 ASHRAE $B$ Handbook, Heating, Ventilating, and Air-Conditioning Systems and Equipment (ASHRAE 2004 [DIRS 171799], Chapter 16). The requirement to provide sufficient air movement in the occupied areas is to maintain proper air quality standards. The range of the air change frequency is based on Chapter 3 (ASHRAE 2003 [DIRS 171798]). The actual number of air changes will be determined during the design process and will be compared with the actual cooling requirements for adequacy. [PRD-022/P-001, PDC 4.8.2.3.1, PDC 4.8.2.3.2, PDC 4.8.2.3.5]

3.1.1.4.3 Requirement: The system shall maintain an acceptable thermal environment as defined in Table 3-1 in the fuel assembly and canister staging areas inside waste processing facilities.

\section{Performance Acceptance Criteria:}

1. The system shall remove the decay heat dissipated from the nuclear waste materials that are staged in the staging area inside nonconfinement areas of the waste processing facilities.

2. The design of airflow in the nonconfinement staging area shall include consideration of the additional heat dissipation from spent fuels in the related HVAC thermal analysis calculations in order to maintain fuel cladding at temperatures that will maintain its integrity.

Basis: This requirement supports PRD-014/T-008, which requires maintaining spent nuclear fuel (SNF) cladding at temperatures that will maintain its integrity.

\subsubsection{Subsystems and Major Components}

Section 1.1 lists all of the subsystems of surface industrial HVAC system. Functional and performance requirements listed in this section are identical to all the subsystems and are listed once as surface industrial HVAC system. Requirements unique to each subsystem or major component and related details are identified when they differ.

3.1.2.1 Requirement: The system shall be provided with supply air-handling units with filters to clean the supply air into the facilities. Supports Function 2.1.1.

Performance Acceptance Criteria:

1. The prefilter elements used in air-handling units shall have an efficiency of 25 percent to 30 percent.

2. High efficiency filter elements shall have an average dust spot efficiency of 80 percent to 90 percent. 
Basis: This requirement supports the requirement PDC 4.8.2.3.2. It is also based on ANSI/ANS-57.7-1988, American National Standard Design Criteria for an Independent Spent Fuel Storage Installation (Water Pool Type) ([DIRS 102564], Section 6.6.2.1). Quality of outdoors is a key factor in the design that can affect employee safety and health. In addition adequate filtration of the inlet air is required to prevent accumulation of dust and external particles within the facility environment. [PRD-022/P-001]

\subsubsection{Boundaries and Interfaces}

Formal detailed requirements based on the interfaces shown below will be developed in the later revision of this SDD after the detailed system design is completed. The relevant SDD/facility description document (FDD) document identifier number is listed in the related comments. The document identifier number does not include three digits revision designation.

3.1.3.1 Requirement: The system shall interface with DTF 1 to assure that the surface industrial HVAC system will perform adequately. Supports Function 2.1.1.

Performance Acceptance Criterion: The system shall interface with the DTF 1 to allocate space and means to support the system equipment and components serving the nonconfinement areas of the facility. Duct shafts, duct penetrations and related penetration seals, confinement barriers, and airlocks shall be provided where required.

Basis: This interface requirement ensures that the system design objective as well as general performance requirements will be met.

Comment: FDD 110-3YD-CD00-00100-000.

3.1.3.2 Requirement: The system shall interface with DTF 2 to assure that the surface industrial HVAC system will perform adequately. Supports Function 2.1.1.

Performance Acceptance Criterion: The system shall interface with DTF 2 to allocate space and means to support the system equipment and components serving the nonconfinement areas of the facility. Duct shafts, ducts penetrations and related penetration seals, confinement barriers, and airlocks shall be provided where required.

Basis: This interface requirement ensures that the system design objective as well as general performance requirements will be met.

Comment: FDD 110-3YD-CD00-00100-000.

3.1.3.3 Requirement: The system shall interface with the Remediation Facility to assure that the surface industrial HVAC system will perform adequately. Supports Function 2.1.1.

Performance Acceptance Criterion: The system shall interface with the Remediation Facility to allocate space and means to support the system equipment and components serving the nonconfinement areas of the facility. Duct shafts, duct penetrations and related penetration seals, confinement barriers, and airlocks shall be provided where required.

Basis: This interface requirement ensures that the system design objective as well as general performance requirements will be met. 
Comment: FDD 130-3YD-CR00-00100-000.

3.1.3.4 Requirement: The system shall interface with CHF to assure that the surface industrial HVAC system will perform adequately. Supports Function 2.1.1.

Performance Acceptance Criterion: The system shall interface with the CHF to allocate space and means to support the system equipment and components serving the nonconfinement areas of the facility. Duct shafts, duct penetrations and related penetration seals, confinement barriers, and airlocks shall be provided where required.

Basis: This interface requirement ensures that the system design objectives, as well as general performance requirements will be met.

Comment: FDD 190-3YD-CH00-00100-000.

3.1.3.5 Requirement: The system shall interface with the Transport Cask Receipt and Return Facility (TCRRF) and WNNRF to assure that the surface industrial HVAC system will perform adequately. Supports Function 2.1.1.

Performance Acceptance Criterion: The system shall interface with the TCRRF and WNNRF to allocate space and means to support the system equipment and components serving the nonconfinement areas of the facility. Duct shafts, duct penetrations and related penetration seals, confinement barriers, and airlocks shall be provided as needed.

Basis: This interface requirement ensures that the system design objectives as well as general performance requirements will be met.

Comment: FDD 140-3YD-CC00-00100-000. (TCRRF FDD)

FDD 230-3YD-CW00-00100-000. (WNNRF FDD).

3.1.3.6 Requirement: The system shall interface with the FHF to assure that the surface industrial HVAC system will perform adequately. Supports Function 2.1.1.

Performance Acceptance Criterion: The system shall interface with the FHF to allocate space and means to support the system equipment and components serving the nonconfinement areas of the facility. Duct shafts, duct penetrations and related penetration seals, confinement barriers, and airlocks shall be provided where required.

Basis: This interface requirement ensures that the system design objectives as well as general performance requirements will be met.

Comment: FDD 210-3YD-FH00-00100-000.

3.1.3.7 Requirement: The system shall interface with the CCCF, BOP, and miscellaneous facilities as listed in Section 1.1 to assure that the surface industrial HVAC system will perform adequately. Supports Function 2.1.1.

Performance Acceptance Criterion: The system shall interface with the CCCF, BOP, and miscellaneous facilities to allocate space and means to support the system equipment and 
components serving the CCCF, and miscellaneous facilities. Duct shafts, duct penetrations and related penetration seals shall be provided where required.

Basis: This interface requirement ensures that the system design objective as well as general performance requirements will be met.

Comment: FDD 600-3YD-SB00-00100-000.

3.1.3.8 Requirement: The HVAC system shall interface with the HVAC plant heating and cooling system. Supports Function 2.1.1.

Performance Acceptance Criterion: The HVAC system shall interface with the HVAC plant heating and cooling system to ensure that sufficient chilled water and hot water will be provided to the heat exchangers of the surface industrial HVAC system for the safety, comfort, and health of the occupational workers.

Basis: This interface requirement ensures that the system design objectives as well as general performance requirements will be met.

Comment: SDD 000-3YD-VP00-00100-000.

3.1.3.9 Requirement: The HVAC system shall interface with the electrical power system. Supports Function 2.1.1.

Performance Acceptance Criterion: The HVAC system shall interface with the electrical power system to ensure that that the power demands of the surface industrial HVAC system electrical components are provided.

Basis: This interface requirement ensures that the system design objectives as well as general performance requirements will be met.

Comment: SDD 000-3YD-EE00-00100-000.

3.1.3.10 Requirement: The HVAC system shall interface with the plant services system. Supports Function 2.1.1.

\section{Performance Acceptance Criteria:}

1. The HVAC system shall interface with the plant services system for the supply of service and instrument air to the pneumatic operated components of the surface industrial HVAC system.

2. The HVAC system shall interface with the plant services system for the supply of deionized water to the system humidifiers, where required, to maintain the level of humidity as indicated in Table 3-1.

Basis: This interface requirement ensures that the system design objectives, as well as general performance requirements, will be met.

Comment: SDD 000-3YD-PS00-00100-000. 
3.1.3.11 Requirement: The HVAC system shall interface with the fire protection system. Supports Function 2.1.1.

Performance Acceptance Criterion: The HVAC system shall interface with the fire protection system for appropriate fire protection, fire detection, and interlocks with the fire alarm system.

Basis: This interface requirement ensures that the system design objectives, as well as general performance requirements, will be met.

Comment: SDD 000-3YD-PF00-00100-000.

3.1.3.12 Requirement: The HVAC system shall interface with the DCMIS. Supports Functions 2.1.1 and 2.1.2.

Performance Acceptance Criterion: The HVAC system shall interface with the DCMIS to provide control and monitored status of system and equipment operation, and to provide operating parameters, status, and related alarms.

Basis: This interface requirement ensures that the system design objective as well as general performance requirements will be met.

Comment: SDD 000-3YD-JD00-00100-000.

3.1.3.13 Requirement: The HVAC system shall interface with the surface nuclear HVAC system. Supports Function 2.1.1.

Performance Acceptance Criterion: The HVAC system shall interface with the surface nuclear HVAC system to ensure that the required confinement zone differential pressures are maintained.

Basis: This interface requirement ensures that the system design objective as well as general performance requirements will be met.

Comment: SDD 000-3YD-VN00-00100-000.

3.1.3.14 Requirement: The system shall interface with the safeguard and security system. Supports Function 2.1.1.

Performance Acceptance Criterion: The system shall interface with the safeguard and security system, as determined by the physical protection plan developed during detail design.

Basis: This interface requirement is needed to ensure the interfaces between this system and the safeguards and security system are addressed during the design. [PRD-022/P-001, PRD-005/T-008, and PRD-014/T-022]

Comment: SDD 000-3YD-ES00-00200-000.

3.1.3.15 Requirement: The system shall interface with the low-level radioactive waste (LLW) management system to assure that waste generated by the surface industrial HVAC system is managed and dispositioned by LLW. Supports Function 2.1.1. 
Performance Acceptance Criterion: The system shall interface with the LLW management system in order to manage and dispose of waste generated by the surface industrial HVAC system during operation and maintenance. The LLW can be high-efficiency particulate air (HEPA) filter units, HVAC components being replaced, condensate drains from HVAC units, and other waste generated during the maintenance activities in the radiological areas.

Basis: This interface requirement ensures that the system general operation and maintenance requirements will be met.

Comment: SDD 100-3YD-MR00-00100-000.

\subsubsection{Codes, Standards, and Regulations}

The surface nuclear HVAC system shall be designed in accordance with the codes, standards, and regulations identified in Section 4.8.2 of the PDC (BSC 2004 [DIRS 171599]) and in the bases of the requirements in this document. The materials used in the construction of the major HVAC system SSCs are described in Section 4.1.1 of this SDD. The materials shall be consistent with the recommendations of the industry codes and standards identified in Section 4.8.2 of the PDC (BSC 2004 [DIRS 171599]).

\subsubsection{Operability}

The section provides the operability requirements for the system. This includes technical specification requirements, if applicable, and other operating requirements from modes and conditions such as startup, normal operations, shutdown, emergency operation, and other system operations.

\subsection{SPECIAL REQUIREMENTS AND BASES}

All scenarios relating to the surface industrial HVAC system are presented in Preliminary Hazards Analysis for License Application Study (BSC 2004 [DIRS 167313]) and have been screened for applicability. Existing design requirements have been found to capture all necessary requirements for mitigation control of applicable scenarios.

\subsubsection{Radiation and Other Hazards}

Not applicable.

\subsubsection{As Low As Is Reasonably Achievable (ALARA)}

3.2.2.1 Requirement: The surface industrial HVAC system shall be designed and operated to meet ALARA principles.

Performance Acceptance Criterion: The performance requirements for ALARA considerations will be developed during subsequent design.

Basis: The surface industrial HVAC system may involve potential worker exposure to ionizing radiation during operation and when maintenance activities are performed. The surface industrial HVAC system may become contaminated during normal and event sequences. The maintenance and replacement activities on this system will 
consider ALARA in the design and the maintenance and replacement determinations. An ALARA assessment will be applied in all stages of the facility design and construction where there is potential for worker exposure to ionizing radiation. Preliminary emphasis in the ALARA process shall be to incorporate ALARA design considerations throughout the design process. Personnel performing work at Yucca Mountain have a potential of receiving occupational doses while performing tasks associated with the disposal of high-level radioactive waste and SNF. PRD-015/P-015 contains dose limits for general employees. [PRD-015/P-015, PRD-015/P-015-010]

\subsubsection{Nuclear Criticality Safety}

Not applicable.

\subsubsection{Industrial Hazards}

3.2.4.1 Requirement: The surface industrial HVAC system shall be designed and operated to assure compliance with Occupational Safety and Health requirements. Supports Function 2.1.1.

Performance Acceptance Criterion: The performance requirements of the surface industrial HVAC system will be ascertained from the evaluation performed per AP-ESH-004, Occupational Safety and Health Program to comply with hazards common to industry. The performance requirements of the surface industrial HVAC system will be ascertained from the evaluation performed per AP-EM-007, Hazardous Material Approval and Tracking to comply with hazardous materials approval and tracking.

Basis: The surface industrial HVAC system will be screened for hazards common to industry per AP-ESH-004, Occupational Safety and Health Program, and AP-EM-007, Hazardous Material Approval and Tracking. The surface industrial HVAC system is required to comply with federal and state laws, regulations, standards, and U.S. Department of Energy (DOE) directives applicable to safety and health and ensure compliance with federal and state of Nevada regulatory requirements for hazardous material use and storage. [PRD-015/P-020, PRD-015/P-021, PDC 4.8.2.3.6]

3.2.4.2 Requirement: The surface industrial HVAC system shall be designed and operated to comply with federal and state laws, regulations, standards, and DOE directives applicable to safety and health.

Performance Acceptance Criterion: The performance requirements of the surface industrial HVAC system will be ascertained from the evaluation performed per AP-ESH-004, Occupational Safety and Health Program, to comply with hazards common to industry.

Basis: The surface industrial HVAC system is required to comply with federal and state laws, regulations, standards, and DOE directives applicable to safety and health. [PRD-015/P-020, PRD-015/P-021]

3.2.4.3 Requirement: The surface industrial HVAC system shall be designed and operated to assure high-energy safety.

Performance Acceptance Criterion: The performance requirements of the surface industrial HVAC system will be defined in the safety analysis per LP-3.30Q-BSC to assure high energy safety.

Basis: The effect of failure of high energy SSCs on other SSCs shall be performed for the surface industrial HVAC system in accordance with safety analysis in LP-3.30Q-BSC and documented in a report per AP-3.11Q. Highenergy safety will be evaluated per LP-3.30Q-BSC. Protection against high energy hazards (electrical, chemical, 
high pressure, etc.) shall be controlled by designing SSCs (e.g., vessels which contain pressure hazards) to appropriate consensus codes, standards (e.g., ASME Boiler and Pressure Vessel Code (ASME 2004 [DIRS 171846]), piping codes, Occupational Safety and Health Administration requirements), and the design documents. The design should be reviewed for the presence of high energy sources and the identification of any high energy source shall be made to the environmental compliance organization. This requirement also supports PRD-022/P001, which states that all repository SSCs shall be designed in accordance with the applicable industry codes, standards, engineering principles and practices with particular attention to those that incorporate system safety, reliability, and availability. [PRD-022/P-001]

3.2.4.4 Requirement: The surface industrial HVAC system shall be designed and operated to minimize fire hazards.

Performance Acceptance Criterion: This system shall be designed to include those design features identified in the various fire hazard analyses of the facilities.

Basis: Required design features for the fire protection will be based on the fire hazard analysis. Fire hazard analysis will be performed either for various facilities or the site.

3.2.4.5 Requirement: The surface industrial HVAC system shall be designed and operated to assure compliance with explosives hazard requirements.

Performance Acceptance Criterion: The performance requirements will be established for addressing explosives hazards associated with or potentially affected by the surface industrial HVAC system as part of the integrated safety assessment.

Basis: Explosives hazards associated with or potentially affected by the surface industrial HVAC system will be evaluated as part of the integrated safety assessment. Explosives hazards requirements are contained in PRD002/T-004. [PRD-002/T-004, PRD-015/P-021]

3.2.4.6 Requirement: The surface industrial HVAC system shall be designed and operated to limit and control employee exposures to crystalline silica (including quartz, cristobalite, and tridymite) consistent with the risk.

Performance Acceptance Criterion: The performance requirements of the surface industrial HVAC system will be defined in the analysis per LP-ESH-019-BSC, Silica Protection, to assure limiting of silica dust.

Basis: The requirements to limit and control employee exposures to crystalline silica (including quartz, cristobalite, and tridymite) are defined in LP-ESH-019-BSC. [PRD-015/P-020]

3.2.4.7 Requirement: The surface industrial HVAC system shall be designed and operated in coordination with Emergency Management Plan (DOE 2003 [DIRS 167254]).

Performance Acceptance Criterion: The performance requirements of the surface industrial HVAC system will be developed during design in conjunction with the development of the respective emergency plans for repository and nonrepository activities to assure coordination and compliance with Emergency Management Plan (DOE 2003 [DIRS 167254]) for repository and nonrepository activities.

Basis: Emergency Management Plan (DOE 2003 [DIRS 167254]) will evaluate the surface industrial HVAC system for appropriate information to be included in the Emergency Management Plan for repository activities. The 
emergency preparedness plans for nonrepository activities will be documented per the Emergency Management Plan and implemented by LP-ESH-010-BSC, Onsite Emergency Management, and LP-ESH-037-BSC, Emergency Preparedness and Response. An emergency plan for repository activities is required by PRD-002/P-017. [PRD-002/P-017]

3.2.4.8 Requirement: The surface industrial HVAC system shall be designed and operated consistent with the facility hazard category. It is anticipated that this system may be located in facilities classified as Hazard Category 1, 2, 3, and industrial facilities.

Performance Acceptance Criterion: The performance requirements will be developed consistent with the categorization of the facilities in which they are located.

Basis: DOE-STD-1027-92 [DIRS 150357] specifies the criteria for determining radiological hazard characterization of a facility. It identifies the classification as Hazard Category 1-Potential for significant offsite consequences; Hazard 2-Potential for significant onsite consequences; or Hazard 3-Potential for significant localized consequences or industrial facilities. [PRD-002/P-013]

3.2.4.9 Requirement: As changes are made to the surface industrial HVAC system, these changes shall be evaluated for impact on the safety basis and the safety basis shall be updated to reflect new information on existing hazards, new hazards, and changes in inventory of radiological and chemical inventories. Supports Function 2.1.1.

Performance Acceptance Criterion: The performance requirements for the surface industrial HVAC system will be evaluated when changes are identified that will impact the safety basis.

Basis: As changes are made to the surface industrial HVAC system, these changes are to be evaluated for impact on the safety basis, and the safety basis is to be updated to reflect new information. [PRD-022/P-001]

3.2.4.10 Requirement: The activities involving tracers, fluids, and materials shall be evaluated in accordance with LP-SA-001Q-BSC, Determination of Importance and Site Performance Protection Evaluations.

Performance Acceptance Criterion: The performance requirements on the surface industrial HVAC system with regard to tracers, fluids, and materials will be developed in conjunction with safety assurance and performance assessment in accordance with LP-SA-001Q-BSC, Determination of Importance and Site Performance Protection Evaluations.

Basis: The activities involving tracers, fluids, and materials are evaluated in accordance with LP-SA-001Q-BSC, Determination of Importance and Site Performance Protection Evaluations. Performance assessment has considered all applicable features, events, and processes that are related to the tracers, fluids, and materials use and calculate limiting (i.e., in quantity or location) the use of certain tracers, fluids, and materials at the site. [PRD-002/P-024, PRD-002/T-017]

\subsubsection{Operating Environment and Natural Phenomena}

3.2.5.1 Requirement: The surface industrial HVAC system shall be designed and operated to minimize radon exposure, consistent with the risk to personnel. Supports Function 2.1.1.

Performance Acceptance Criterion: The performance requirement for Radon hazards considerations will be developed during subsequent design. 
Basis: For the radon hazard, the surface nuclear HVAC system will be evaluated against AP-ESH-006, Protection Program for Radon. Workers associated with the surface nuclear HVAC system may be exposed to radon while performing normal and event sequence functions. The maintenance and replacement activities on this system will consider radon exposure in the design and the maintenance and replacement determinations. [PRD-015/P-020, AP-ESH-006]

3.2.5.2 Requirement: The system components shall be designed to withstand and operate in the applicable environmental conditions. Supports Function 2.1.1.

\section{Performance Acceptance Criteria:}

1. The system components located within the confines of the facilities shall be designed to operate in the environmental conditions (temperature and humidity) as defined under Functional Requirement Number 3.1.1.4.2.

2. The system components located outdoors shall be designed for the extreme outside temperature range of $2^{\circ} \mathrm{F}$ to $116^{\circ} \mathrm{F}$.

3. The system components located outdoors shall be designed for an external environment with a maximum daily snowfall of $6 \mathrm{in} .(15 \mathrm{~cm})$, and maximum monthly snowfall accumulation of $6.6 \mathrm{in} .(17 \mathrm{~cm})$.

4. The system components located outdoors shall be designed for an external environment with the maximum annual precipitation of $20 \mathrm{in} . / \mathrm{year}(51 \mathrm{~cm})$ and maximum daily precipitation expected in the area.

5. The system components located outdoors shall be designed for an ambient relative humidity in accordance with Table 3-2.

Table 3-2. Ambient Relative Humidity

\begin{tabular}{|l|c|}
\hline \multicolumn{1}{|c|}{ Environment Parameter } & Value \\
\hline Annual mean value & $30 \%$ \\
\hline Minimum summer monthly mean value (June) & $11 \%$ \\
\hline Maximum winter monthly mean value & $58 \%$ \\
\hline
\end{tabular}

6. The system shall be designed based on the outdoors environmental condition at Mercury, Nevada. The ambient (outdoor) design condition for this site shall be as defined in Table 3-3.

7. The system components located outdoors shall be designed for the basic wind speed of $90 \mathrm{mph}$. 
Table 3-3. Ambient (Outdoor) Environmental Condition

\begin{tabular}{|c|c|c|c|c|}
\hline Parameters & \multicolumn{4}{|c|}{ Design Data } \\
\hline \multirow{3}{*}{ Site: Mercury, Nevada } & \multicolumn{4}{|c|}{$\begin{array}{cc}\text { Latitude: } & 36.62^{\circ} \\
\text { Longitude: } & 116.02^{\circ} \\
\text { Elevation: } & 3310 \text { feet }\end{array}$} \\
\hline & \multicolumn{2}{|c|}{$\begin{array}{l}\text { Use for Personnel } \\
\text { Comfort System }\end{array}$} & \multicolumn{2}{|c|}{$\begin{array}{l}\text { Use where Close Temperature } \\
\text { or Humidity is Required }\end{array}$} \\
\hline & $\begin{array}{c}\text { Frequency of } \\
\text { Occurrence }\end{array}$ & Temperature & $\begin{array}{c}\text { Frequency of } \\
\text { Occurrence }\end{array}$ & Temperature \\
\hline Heating Dry-Bulb & $99 \%$ & $28^{\circ} \mathrm{F}$ & $99.6 \%$ & $24^{\circ} \mathrm{F}$ \\
\hline Cooling Dry-Bulb & $1 \%$ & $100^{\circ} \mathrm{F}$ & $0.4 \%$ & $102^{\circ} \mathrm{F}$ \\
\hline Cooling Mean Coincident Wet Bulb & $1 \%$ & $64^{\circ} \mathrm{F}$ & $0.4 \%$ & $65^{\circ} \mathrm{F}$ \\
\hline Wet Bulb & $1 \%$ & $67^{\circ} \mathrm{F}$ & $0.4 \%$ & $69^{\circ} \mathrm{F}$ \\
\hline Dew Point & $1 \%$ & $60^{\circ} \mathrm{F}$ & $0.4 \%$ & $64^{\circ} \mathrm{F}$ \\
\hline Mean Coincident Dry-Bulb & $1 \%$ & $77^{\circ} \mathrm{F}$ & $0.4 \%$ & $72^{\circ} \mathrm{F}$ \\
\hline Range of Dry-Bulb & & $25.9^{\circ} \mathrm{F}$ & & $25.9^{\circ} \mathrm{F}$ \\
\hline
\end{tabular}

NOTE: Frequency of occurrence is explained in the ASHRAE Handbook (ASHRAE 2001 [DIRS 157789]). Frequency level for a specific temperature is its annual percentile value the temperature is expected to exceed, e.g., $0.4 \%$ means that values are expected to exceed, on an average, 35 hours per year for the period.

Basis: This functional and performance requirement supports PDC 4.8.2.2.3, PDC 4.8.2.3.7, PDC 4.8.2.3.8, PDC 4.8.2.3.9, PDC 6.1.1.1, PDC 6.1.1.2, PDC 6.1.1.5, and PDC 6.1.1.6. These values were obtained from Tables 1A and 1B in Chapter 26 ASHRAE Handbook, Fundamentals (ASHRAE 2001 [DIRS 157789]). The values of Mercury, Nevada are selected as the most representative and appropriate because they represent long-term data record of conditions for a location close to the North Portal area of the Yucca Mountain Project. This requirement establishes the environmental conditions in which the system components are expected to operate to ensure the system's continued operation and readiness in accordance with the equipment manufacturer recommendations. [PRD-022/P-001, PDC 4.8.2.3.7, PDC 4.8.2.3.8, PDC 4.8.2.3.9, PDC 6.1.1.1, PDC 6.1.1.2, PDC 6.1.1.5, PDC 6.1.1.6]

\subsubsection{Human Interface Requirements}

3.2.6.1 Requirement: The system design shall include provisions to enhance the interface between the system operation and system operator. Supports Function 2.1.1.

\section{Performance Acceptance Criteria:}

1. The system shall be provided with indicators, recorders, readable displays, gauges, and control devices to show the status of system operation and to control equipment operation, and shall be located such that they are readily visible and accessible.

2. Indication of system operation shall be provided in the central control center via the interface with the DCMIS.

Basis: This requirement supports PRD-022/P-001, which states that all repository SSCs shall be designed in accordance with the applicable industry codes, standards, engineering principles and practices with particular attention to those that incorporate system safety, reliability, and availability. This requirement will ensure that human error will be minimized in the operation of the systems and its components. This will also ensure the continuous operation of the system and the system's readiness to perform its function. [PRD-022/P-001] 


\subsubsection{Environmental Management}

3.2.7.1 Requirement: The system shall be designed to include provisions and interfaces to achieve the maximum practicable improvement in efficiency in the use of renewable and clean sources of energy and water conservation.

\section{Performance Acceptance Criteria:}

1. The system shall be designed with the goal of reducing energy consumption per gross square foot through life cycle cost effective measures. The industrial HVAC system design shall comply with the requirements of Sections 4.1.1.1, 4.1.1.3, 4.1.1.4, and 4.1.1.5 of the PDC (BSC 2004 [DIRS 171599]).

2. The design of the industrial HVAC system shall consider the requirements of the Energy Conservation Compliance Design Guide for Yucca Mountain Project Surface and Subsurface Facilities (BSC 2003 [DIRS 163179]).

Basis: This requirement supports PRD-018/P-021, which is required to comply with the federal energy and environmental laws and executive order for greening the government through efficient energy management. Federal buildings and associated building energy-using systems are required to lead to efficient energy management to include greater use of clean and renewable energy sources to comply with the national environmental and energy plans and policies. [PRD-018/P-021, PDC 4.1.1.1, PDC 4.1.1.3, PDC 4.1.1.4, PDC 4.1.1.5, and PDC 4.8.2.3.10]

3.2.7.2 Requirement: The surface industrial HVAC system shall be designed and operated for compliance with land access agreements, applicable permits and support compliance with applicable environmental, regulatory, monitoring, and mitigation requirements.

Performance Acceptance Criterion: The performance requirements of the surface industrial HVAC system will be developed during design in conjunction with the development and maintenance of the evaluations performed per the Environmental Management Plan (YMP 2000 [DIRS 154039]), applicable permits, land access and environmental compliance, and the environmental baseline to assure compliance with environmental hazard impacts.

Basis: Environmental hazards (impacts) associated with the surface industrial HVAC system will be evaluated and controlled in accordance with Environmental Management Plan (YMP 2000 [DIRS 154039]). AP-EM-002, Land Access and Environmental Compliance, will be utilized to establish compliance with land access agreements and support compliance with applicable environmental regulatory, monitoring, and mitigation requirements. AP-EM010, Environmental Baseline Review will review the surface industrial HVAC system design against the environmental baseline established by the Final Environmental Impact Statement for a Geological Repository for the Disposal of Spent Nuclear Fuel and High-Level Radioactive Waste at Yucca Mountain, Nye County, Nevada, (DOE 2002 [DIRS 155970]). The surface industrial HVAC system is required to comply with federal and state laws, regulations, standards, and DOE directives applicable to environmental hazard impacts, land access and environmental compliance, and the environmental baseline review. [PRD-014/P-038, PRD-015/P-075, and PRD-002/T-004]

3.2.7.3 Requirement: The surface industrial HVAC system shall be designed and operated to meet pollution prevention and sustainable design and decommissioning goals.

Performance Acceptance Criteria: The performance requirements of the surface industrial HVAC system will be ascertained from the evaluations performed per the assessments for 
pollution prevention and sustainable design to assure compliance with pollution prevention and sustainable design and decommissioning goals.

Basis: Pollution prevention and sustainable design assessments associated with the surface industrial HVAC system will be evaluated and controlled in accordance with AP-EM-009, Pollution Prevention Assessments and Sustainable Design. PRD-018/P-017, Program and Project Management for the Acquisition of Capital Assets, requires the identification of requirements to meet sustainable design principals and PRD-018/P-021, departmental energy and utility management, provides requirements for sustainable design. [D-018/P-017, PRD-018/P-021]

3.2.7.4 Requirement: The repository shall be designed with pollution prevention systems to control air emissions and effluents, minimize water use, and reduce or eliminate discharges to the environment.

Basis: DOE Order 450.1 [DIRS 161567] establishes DOE policy to conduct its operations in an environmentally safe and sound manner, and to perform its activities in compliance with applicable environmental protection requirements. The design shall comply with applicable environmental requirements set forth by federal and state regulations, executive orders, and DOE directives, and requirements derived from environmental permits and corresponding permit conditions. [PDC 4.1.1.9]

3.2.7.5 Requirement: The repository shall be designed with a goal to reduce energy and water consumption while increasing the use of clean energy sources.

Basis: To meet or exceed the goals of the laws, executive orders and federal regulations for energy efficiency, use of renewable energy, and water conservation at DOE facilities. This requirement pledges compliance with 10 CFR Part 434, 2002 Energy: Energy Code for New Federal Commercial and Multi-Family High Rise Residential Buildings [DIRS 158912], that provides the minimum standards for energy efficiency goals in the design of new federal buildings. 10 CFR 434 provides design requirements for building envelopes, electrical distribution systems, and equipment for electric power, lighting, heating, ventilation, air-conditioning, service water heating, and energy management. This is also in conformance with DOE O 430.2A, Departmental Energy and Utilities Management [DIRS 158913], and with 64 FR 30851 [DIRS 104026], Executive Order 13123, that provides the goals for the reduction of greenhouse gas emissions attributed to the energy use of federal buildings. [PDC 4.1.1.1]

\subsection{ENGINEERING DISCIPLINARY REQUIREMENTS AND BASES}

\subsubsection{Civil and Structural}

3.3.1.1 Requirement: The industrial HVAC system shall be provided with means to support the system equipment and components serving the nonconfinement areas of the facility. Supports Function 2.1.1.

Performance Acceptance Criterion: The industrial HVAC system equipment and components shall be supported, anchored, and braced as required from the building structure. Wall, floor, roof openings, and floor drains for the HVAC system shall be provided where required.

Basis: This interface requirement ensures that the system design objectives as well as general performance requirements will be met. Appropriate supports are required to prevent damage to equipment and injury to personnel. 


\subsubsection{Mechanical and Materials}

3.3.2.1 Requirement: The industrial HVAC system air-conditioning units shall be provided with heating and cooling coils to condition the supply air to the nonconfinement areas of the surface facilities. Supports Function 2.1.1.

\section{Performance Acceptance Criteria:}

1. The cooling coils shall be arranged for counter flow design for cooling the supply air with chilled water.

2. The heating coils shall be designed for heating the supply air with hot water.

3. The cooling coils and preheat coils shall be sized at a face velocity in the range of 400 to 500 feet per minute and the reheat coil in the range of 700 to 1000 feet per minute.

Basis: This requirement supports PRD-022/P-001, which states that all repository SSCs shall be designed in accordance with the applicable industry codes, standards, engineering principles and practices, with particular attention to those that incorporate system safety, human factors, and habitability standards. The provision of heating and cooling coils ensures habitable conditions exist in the surface facilities by providing acceptable indoors environmental conditions for the comfort and protection of the occupational workers, and for proper functioning of the equipment. The velocity range through the heating and cooling coil is in accordance with acceptable industry practice and based on the recommendation from 2001 ASHRAE Handbook, Fundamentals (ASHRAE 2001 [DIRS 157789], Chapter 34, Table 10). Velocities over 500 feet per minute in the cooling coil may result in moisture carryover into the ductwork and affect indoor air quality. [PDC 4.8.2.3.1, PDC 4.8.2.3.2, PDC 4.8.5.8.1, PRD-022/P-001]

3.3.2.2 Requirement: The industrial HVAC system air-conditioning units shall be provided with prefilters and high-efficiency filters to prevent accumulation of dust in the facility. Supports Function 2.1.1.

\section{Performance Acceptance Criteria:}

1. The prefilter elements shall be high capacity pleated panel filters. The nominal size of each prefilter element shall be 24 " $\times 24$ " with a maximum depth of 4 ".

2. The high-efficiency filter elements shall be replaceable, extended (i.e., bag-type) media, dry-type filters made of glass fiber. The nominal size of each bag-type filter element shall be $24 " \times 24$ " with a maximum depth of 36 ".

Basis: This requirement supports PRD-022/P-001, which states that all repository SSCs shall be designed in accordance with the applicable industry codes, standards, engineering principles and practices with particular attention to those that incorporate system safety, human factors, reliability, availability, and habitability standards. The provision of the prefilters and high-efficiency filters ensures acceptable indoor air quality to protect the health and safety of the occupational workers. The quality of outdoor air is a key factor in the design that can affect employee safety and health. [PDC 4.8.2.3.2, PRD-022/P-001]

3.3.2.3 Requirement: The industrial HVAC system shall be provided with fans and ductwork to distribute HVAC air in noncontaminated areas of the surface process facilities, BOP, and other miscellaneous facilities. Supports Function 2.1.1. 


\section{Performance Acceptance Criteria:}

1. The system shall be provided with supply and exhaust/recirculation ductwork made of galvanized steel and shall be sized to maintain velocities with a range between 1500 and 2500 feet per minute.

2. Ductwork shall be provided with access doors or hatches at proper locations to allow cleaning of the accumulated dust and airborne particulate matter. Access doors shall be located upstream of the duct-mounted components.

3. Ductwork penetrating a barrier wall shall be provided with penetration seals to prevent leakage and maintain the ventilation boundary.

Basis: This functional requirement supports PRD-022/P-001, which states that all repository SSCs shall be designed in accordance with the applicable industry codes, standards, engineering principles and practices, with particular attention to those that incorporate system safety, human factors, and habitability standards. This requirement prevents accumulation of dust and particulate matter inside the ductwork, and minimizes noise. [PDC 4.8.2.3.13, PRD-022/P-001]

\subsubsection{Chemical and Process}

3.3.3.1 Requirement: The system shall provide proper environmental condition and safety features for the protection of the chemicals and the process functions inside the confines of the facility. Supports Function 2.1.1.

Performance Acceptance Criterion: The system design shall provide proper environmental condition and safety features for the protection of the chemicals and the process functions inside the confines of the facility. The system shall prevent the spread or release of any hazardous chemical during normal operation and during an event sequence. In addition, the system's integrity shall be protected from exposure to any deleterious effect due to any chemical or process function in order to minimize component contamination or degradation.

Basis: This requirement complies with ANSI/ANS-57.7-1988 [DIRS 102564], Section 1.2 and ANSI/ANS-57.91992, Design Criteria for an Independent Spent Fuel Storage Installation (Dry Type) [DIRS 103093], Section 1.1. This functional requirement supports PRD-022/P-001, which states that all repository SSCs shall be designed in accordance with the applicable industry codes, standards, engineering principles and practices. [PRD-022/P-001]

\subsubsection{Electrical Power}

3.3.4.1 Requirement: The system shall be provided with reliable electrical power to ensure continuous system operation during normal conditions and event sequence conditions where needed. Supports Function 2.1.1.

\section{Performance Acceptance Criteria:}

1. The system shall be provided with normal alternating current electrical power for the various motors operated fans and controls and instrumentation.

2. The electrically operated system components shall be provided with adequate grounding protection. 
3. The industrial HVAC system shall be provided with variable frequency speed drive to provide adjustment in the system airflow as needed.

Basis: This requirement supports PRD-022/P-001, which states that all repository SSCs shall be designed in accordance with the applicable industry codes, standards, engineering principles and practices with particular attention to those that incorporate system safety, reliability, and availability. This requirement will ensure that the system is provided with required electrical power for its reliable operation. [PRD-022/P-001]

\subsubsection{Instrumentation and Control}

3.3.5.1 Requirement: The system shall be designed to include the required instrumentation and control hardware to monitor the system operation and performance. Supports Function 2.1.1.

\section{Performance Acceptance Criteria:}

1. The systems monitoring and alarm function shall be located in the central control center via the interface with the DCMIS.

2. The system shall be provided with all the necessary monitoring, alarms, and equipment status indication for the parameters identified in Table 3-4.

3. All fire detection and suppression systems are monitored by the fire alarm system.

Table 3-4. System Monitoring, Status, and Alarms Requirements

\begin{tabular}{|l|l|}
\hline \multicolumn{1}{|c|}{ Requirements } & \multicolumn{1}{c|}{ Functions } \\
\hline Space temperature & Facility ventilation zone temperature indication and control \\
\hline Airflow rate & Filter trains and exhaust stacks \\
\hline Differential pressure & $\begin{array}{l}\text { Filters, moisture eliminators, and areas require specific pressure } \\
\text { differential control with respect to other areas or to the outside } \\
\text { atmosphere }\end{array}$ \\
\hline Radiation level indication and monitoring & $\begin{array}{l}\text { Indication of radiation levels at the HEPA filtration units and exhaust } \\
\text { stacks. }\end{array}$ \\
\hline Smoke and high heat detection & $\begin{array}{l}\text { Detection interface with the fire protection system for fire suppression } \\
\text { and fire alarm, as required }\end{array}$ \\
\hline On-off status & Status for electrically powered or controlled equipment \\
\hline Open-closed status & Status for motor control breakers, valves, and dampers \\
\hline Failure alarms & Alarm the failure of specific equipment and components \\
\hline
\end{tabular}

Basis: This requirement supports PRD-022/P-001, which states that all repository SSCs shall be designed in accordance with the applicable industry codes, standards, engineering principles and practices with particular attention to those that incorporate system safety, reliability, and availability. The provision for monitoring, control, and alarm capabilities are integral functional requirements that ensure the systems operation and alarming of unsafe conditions for the protection of equipment and safety of the occupational workers. This requirement will ensure that the system will provide the required environmental condition to protect the operation, accuracy, and reliability of the instrumentation and control hardware associated with the other interfacing SSCs in the facility so they can perform their intended functions. [PRD-022/P-00, PDC 4.8.2.3.11] 


\subsubsection{Computer Hardware and Software}

3.3.6.1 Requirement: The system design shall provide proper environmental conditions to the rooms housing computer hardware and software to protect their operation, accuracy, and reliability so that all interfacing SSCs can perform their intended function during normal operation and during an event sequence. Supports Function 2.1.1.

Performance Acceptance Criterion: The system design shall provide proper environmental conditions to the rooms housing computer hardware and software to protect their operation, accuracy, and reliability so that all interfacing SSCs can perform their intended functions during normal operation and during an event sequence. The system shall include the required computer hardware and software that is compatible and directly interface with DCMIS to provide the required environmental conditions in the facilities during normal operation and during an event sequence.

Basis: This requirement supports goals to protect the operation and reliability of the computer hardware and software to comply with NUREG 0800 (NRC 1987 [DIRS 103124], Chapter 7). [PDC 4.8.2.3.11]

\subsubsection{Fire Protection}

3.3.7.1 Requirement: The system shall be provided with fire rated features that function in conjunction with the specified fire rated barriers and fire detection systems for the protection of the workers and to limit the spread of fires. Supports Function 2.1.1.

\section{Performance Acceptance Criteria:}

1. The system ductwork penetrating a fire barrier shall be equipped with appropriate fire dampers, smoke dampers and detectors, and interlocks to prevent the spread of fire. The fire dampers should conform to the requirements of ANSI/UL-555-2001. 2002 [DIRS 161103].

2. The design and installation of the surface industrial HVAC system related to fire protection should conform to the requirements of NFPA 90A [DIRS 160955].

Basis: This requirement ensures that the system is designed and located so it can continue to perform its function effectively under a credible fire event to support goals for the protection of the workers and the SSC. The required design features will be identified in the fire hazard analysis. [PDC 4.8.2.3.13]

\subsubsection{Safeguards and Security}

3.3.8.1 Requirement: The surface industrial HVAC system shall be provided adequate safeguard and security to comply with physical security criteria applicable to the repository. Supports Function 2.1.1.

Performance Acceptance Criterion: The system shall be designed with adequate security protection. Physical barriers shall be provided at air intakes, exhaust openings through walls and roof, and large ductwork to prevent any unauthorized intrusion by the workers or members of the public into the protected or restricted access areas of the facility. 
Basis: This requirement is based on PDC 4.8.2.2.37. This complies with the requirements of Regulatory Guides 5.65 Vital Area Access Controls, Protection of Physical Security Equipment, and Key Lock Controls [DIRS 158858]. This requirement supports PRD-005/T-008, related to physical protection. [PRD-005/T-008, PDC 4.8.2.2.37]

\subsection{TESTING AND MAINTENANCE REQUIREMENTS AND BASES}

\subsubsection{Testability}

3.4.1.2 Requirement: The system design shall include features, components, and connections required to perform accurate and reliable inspection and testing of the subsystems and components. Supports Function 2.1.1.

\section{Performance Acceptance Criteria:}

1. Instrumentation, test ports for balancing and other necessary measuring instruments shall be provided at strategic locations of the system to test, collect data, and monitor system performance.

2. The system components shall be inspected prior to installation and startup testing shall be performed to verify that the system will function as designed.

Basis: This requirement supports PRD-014/P-011, which requires startup and periodic testing to be conducted to ensure that the SSCs function as designed. These functional and performance requirements will provide means in developing a testing program for the system. [PRD-014/P-011, PDC 4.8.2.3.15]

\subsubsection{Safety-Required Surveillance}

3.4.2.1 Requirement: The system design shall list and define the technical specifications for surveillance requirements, such as checks, inspection, calibrations, and functional testing that are deemed necessary and sufficient for safe operation of the system based on its safety classification.

Performance Acceptance Criteria: The fuel element canister staging HVAC subsystem in DTF shall list and define the technical specifications and surveillance requirements to check, inspect, calibrate, and functionally test operation of inlet and outlet dampers, ductwork and related instrumentation.

Basis: This requirement supports PRD-002/T-012, which specifies technical guidelines for design objectives, as well as general performance requirements that ensure the system's continuous operation and readiness to perform its safety function. This requirement supports goals to protect the operation and reliability of the instrumentation and control systems to comply with NUREG-0800 (NRC 1987 [DIRS 103124], Chapter 7).

\subsubsection{Non-Safety Inspections and Testing}

There is no system requirement identified for the surface industrial HVAC system at this stage of the design. Procedures will be developed to define and describe the inspections, and testing requirements. The procedures will be based on manufacturer recommendations and final system configuration. This section will be updated in the later revision of this SDD accordingly as the related requirements are identified as the design matures. 


\subsubsection{Maintenance}

3.4.4.1 Requirement: The system shall be provided with adequate spares and installed in such a manner to facilitate accessibility for maintenance, repair, replacement, and in-service inspection with consideration under which these activities are performed. Supports Function 2.1.1.

Performance Acceptance Criterion: The system preventive maintenance program shall include periodic calibration, lubrication, and the replacement of seals, belts, and other components due to wear to avoid system failure.

Basis: This requirement supports PRD-022/P-001, which states that all repository SSCs shall be designed and installed in accordance with the applicable industry codes, standards, engineering principles and practices with particular attention to those that incorporate system safety, reliability, and availability. This requirement supports general maintenance requirements that will ensure the system's continuous operation and readiness to perform its function. This requirement supports the maintenance activities required to comply with the manufacturer's recommendations to ensure continued reliability. [PRD-022/P-001, PDC 4.8.2.3.15]

\subsection{OTHER REQUIREMENTS AND BASES}

\subsubsection{Security and Special Nuclear Material Protection}

There is no special installation requirement identified for the surface industrial HVAC system at this stage of the design. This section will be updated in the later revision of this SDD accordingly as the related requirements are identified as the design matures.

\subsubsection{Special Installation Requirements}

There is no special installation requirement identified for the surface industrial HVAC system at this stage of the design. This section will be updated in the later revision of this SDD accordingly as the related requirements are identified as the design matures.

\subsubsection{Reliability, Availability, and Preferred Failure Modes}

3.5.3.1 Requirement: The system shall include design provisions that enhance reliability and availability, such as diversity and redundancy, and features to place the system in a fail-safe state upon failure. Supports Function 2.1.1.

Performance Acceptance Criterion: The system shall be provided with sufficient redundancy and standby units to ensure continued operation in the event of a failure of any of its components during normal operation or during maintenance.

Basis: This requirement supports PRD-022/P-001, which states that the SSCs shall be designed and installed in accordance with the applicable industry codes, standards, engineering principles and practices. This requirement supports general maintenance requirements that will ensure the system's continuous operation and readiness to perform its function. This requirement supports the maintenance activities required to comply with the manufacturer's recommendations to ensure continued reliability. 


\subsubsection{Quality Assurance}

The surface industrial HVAC system contain items categorized as ITS (SC) and, therefore, is subject to the requirements of Quality Assurance Requirement and Description (DOE 2004 [DIRS 171539]).

At this stage of initial design, no quality assurance is identified for the surface industrial HVAC system. This section will be updated in the revision of this SDD, accordingly, as the related requirements are identified as the design matures.

\subsubsection{Miscellaneous Requirements}

There is no miscellaneous requirement identified for the surface industrial HVAC system at this stage of the design. This section will be updated in the revision of this SDD, accordingly, as the related requirements are identified as the design matures. 
INTENTIONALLY LEFT BLANK 


\section{SYSTEM DESCRIPTION}

\subsection{CONFIGURATION INFORMATION}

The objective of Section 4 for this revision of the SDD is to describe the current status of the design activities in progress. The section describes design features currently under development to meet the requirements identified in Section 3.

\subsubsection{Description of System, Subsystems, and Major Components}

The surface industrial HVAC system consists of the subsystems serving nonconfinement or noncontaminated areas of the waste processing facilities and the BOP facilities. The subsystem are identified in section 1.1

Only portions of the DTF HVAC subsystems of the Surface Industrial HVAC system serving the fuel element staging areas providing the passive (natural) ventilation are classified as ITS and are designed to safety class requirements. The rest of the other subsystems under the surface industrial HVAC system are not required to operate during an event sequence and are classified as not ITS.

The non ITS Surface Industrial HVAC subsystems of the repository are provided with commercial quality, HVAC systems to ensure indoor environmental conditions for the health and safety of the facility workers and equipment opeartion. The surface industrial HVAC system is designed to maintain a slight positive pressure in the nonconfinement areas relative to atmosphere and adjacent confinement areas

The block flow diagrams for the subsystems are shown in figures as listed in the respective subsystem descriptions. Figures shown in this section of the SDD are diagrams for illustration purpose only. For general notes and other detailed information, refer to the related flow diagrams listed in Appendix B. These are issued separately to the Records Management and Document Control Center.

The surface industrial HVAC system typically consists of components dedicated to supply or exhaust air from the facility. The supply system components consist of air-handling units complete with filters, preheat coil, cooling coil, humidifiers where required, supply fan, and outdoors air intake louvers and supply air distribution. The supply air distribution consists of ductwork, reheat coils, pressure control dampers, air-balancing devices, and isolation dampers. The electrically operated components of the subsystem are powered from the normal alternating current electrical power systems. The recirculation system consists of return fan and related ductwork and air balancing dampers.

For facilities or areas where mechanical cooling is not required, ventilation is provided where air is introduced from the outside through a series of wall louvers equipped with automatic shutoff dampers and bird screens. The shutoff dampers are interlocked with the associated roof or wall exhaust fans and the space thermostats control the operation of the shutoff dampers and exhaust fans. If required, thermostatically controlled hot water unit heaters provide heating.

Surface industrial HVAC subsystems are described as follows: 


\subsubsection{DTF 1 HVAC System}

The DTF 1 HVAC subsystems serving the nonconfinement zones of DTF 1 (clean areas not served by the surface nuclear HVAC subsystems) are the support rooms and offices, and the electrical equipment rooms HVAC subsystems. The subsystems are provided with a recirculation type HVAC system. The subsystems provide conditioned air for cooling, heating, and ventilation to ensure air quality meets standards required for the safety, health, and comfort of occupational workers, and it is designed to maintain a slight positive pressure in the nonconfinement areas relative to atmosphere and adjacent confinement areas.

DTF 1 Electrical Equipment Room HVAC Subsystem-The electrical equipment room HVAC subsystem block flow diagram is shown in Figure 4-1. The HVAC subsystem serving the electrical equipment rooms (electrical motor control center rooms, battery rooms, and Train A and Train B electrical rooms) consists of two 100 percent recirculating supply air-handling units (one operating and one backup) and associated ductwork, dampers, registers, and controls. Each supply air-handling unit consists of prefilters, high-efficiency filters, heating coil, cooling coil, and supply fan. The central plant heating and cooling subsystem provides hot and chilled water to the air-handling unit heating and cooling coils. The electrically operated components of the electrical equipment room HVAC subsystem are powered from the normal and backup electrical power system from standby diesel generators.

The recirculating fan coil units provide supplemental cooling to the Train A and Train B electrical equipment rooms. Each fan coil unit, located within each electrical equipment room, consists of prefilters, high-efficiency filters, chilled water cooling coil, and a supply fan. The backup air-cooled water chiller and chilled water pump, powered from the backup electrical power system, will supply chilled water to the supplementary fan coil unit cooling coils when the central plant heating and cooling subsystem is not available.

The battery rooms are provided with exhaust fans with explosion proof motors (one operating and one backup) that exhaust to the atmosphere to prevent hydrogen buildup in the battery rooms.

DTF 1 and Remediation Facility Support Rooms and Offices HVAC Subsystem-The support rooms and offices HVAC subsystem block flow diagram is shown in Figure 4-2. The subsystem consists of six supply air-handling units, six return air fans, six exhaust fans with five operating and one as a backup exhaust fan, and associated ductwork, dampers, registers, and controls. Each supply air-handling unit consists of prefilters, high-efficiency filters, heating coil, cooling coil, and supply fan. The central plant heating and cooling subsystem provides hot and chilled water to the air-handling unit heating and cooling coils. The electrically operated components of the support rooms and offices HVAC subsystem are powered from the normal electrical power system.

\section{DTF 1 Fuel Element and Canister Staging Area HVAC Subsystem}

The fuel element and canister staging area in the waste transfer cell of DTF 1 is a nonconfinement area and is part of the surface industrial HVAC system. 
Tubular fuel and canister staging positions (tubes) are suspended from the floor into the room beneath to allow airflow around the tube exteriors. This heat transfer maintains SNF cladding temperatures at or below $400^{\circ} \mathrm{C}$ without active ventilation for up to 30 days.

DTF 1 Thermal Analysis of the Staging Cell (BSC 2004 [DIRS 171778]) used $230^{\circ} \mathrm{C}$ as target maximum temperature aimed at protecting cladding from oxidation. The analysis provides recommended constraints to be imposed on the fuel assembly that can be placed in the staging cell will be imposed to ensure that maximum cladding does not exceed the target maximum temperature.

The supply consists of outside air intake, supply ductwork, and supply plenum in the staging area. The exhaust for this area consists of two exhaust fans. The fans draw outside air and circulate the air around the fuel element and canister tubes prior to exhaust through a dedicated exhaust stack.

If a power or fan failure occurs, either event triggers the opening of a normally-closed/fail-open bypass damper providing an alternate ventilation path to the exhaust, and the normally open exhaust fan bypass dampers closes. This path creates sufficient stack-effect natural ventilation to maintain the design basis SNF cladding temperatures. The staging area HVAC subsystem flow diagram is shown in Figure 4-3.

Following a DBGM-1 seismic event the exhaust damper providing the passive (natural) ventilation to the DTF HVAC subsystems that serve the fuel element staging areas fail open upon loss of power or upon fan failure. The associated exhaust fan isolation dampers that isolate the non-ITS active ventilation from the ITS ventilation fail closes. During normal operation, the exhaust fan isolation dampers for SNF staging racks of the DTF HVAC subsystems remain open and the exhaust damper providing passive (natural) ventilation remain close.

The inlet and outlet dampers and ventilation ducting for the fuel element staging areas are designed for loading conditions associated with a DBGM-1 level seismic event and demonstrate sufficient margin to a "no failure" safety function.

The ventilation stack for the fuel element staging areas (DTF only) is designed for loading conditions associated with a DBGM-1 level seismic event and demonstrates sufficient margin to a "controlled failure" safety function"

The passive portion providing natural ventilation of the DTF HVAC staging area including the outside air intake, related ductwork, bypass outlet dampers, exhaust fan isolation dampers, and exhaust stack for fuel element staging area is ITS. The rest of the portion is not ITS.

\section{DTF 1 HVAC Subsystem Components Descriptions}

The DTF 1 HVAC subsystem serving nonconfinement zones of DTF 1 consists of components dedicated to supplying air to or exhausting air from the facility. The supply subsystem components consist of air-handling units with supply fan, outdoor air intake louvers, and supply air distribution. The supply air distributions consists of ductwork and reheat coils. 


\section{INTENTIONALLY LEFT BLANK}




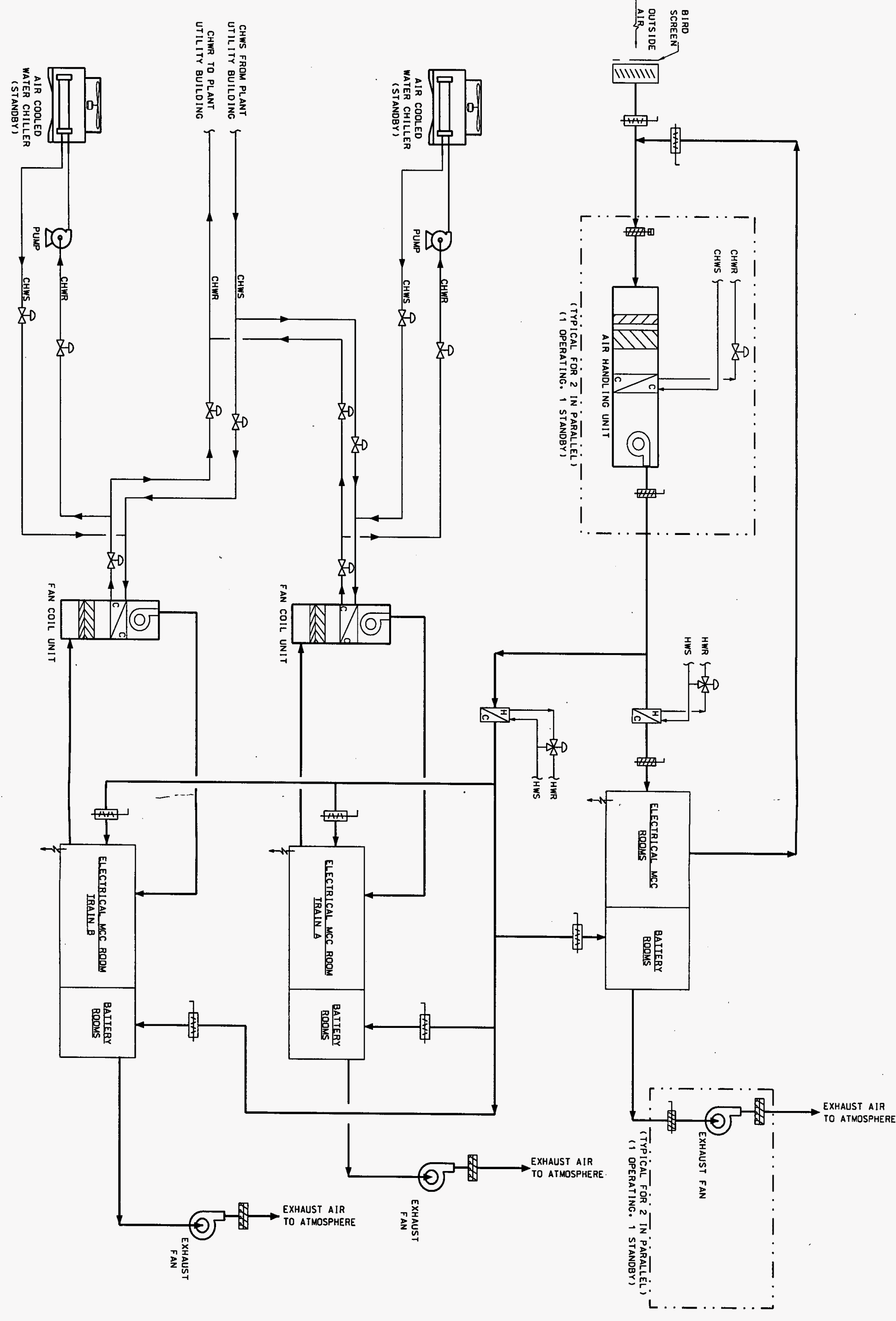




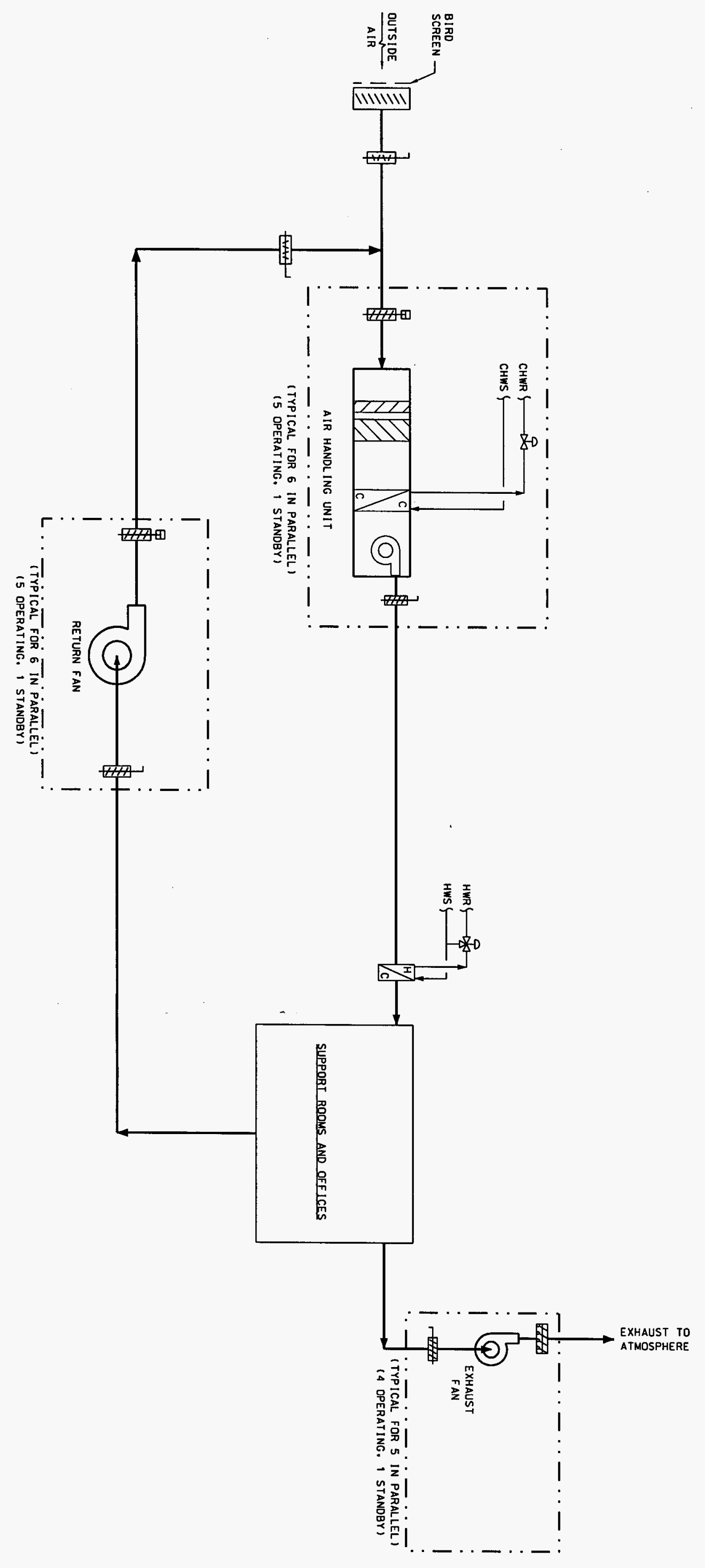

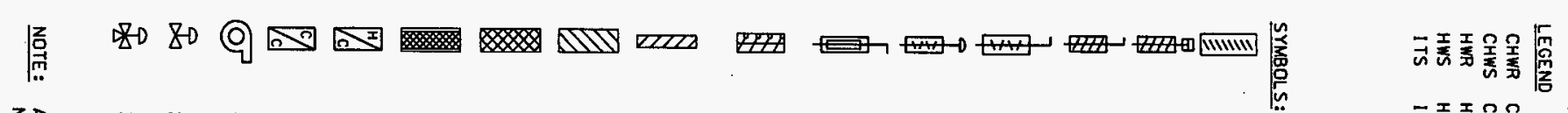

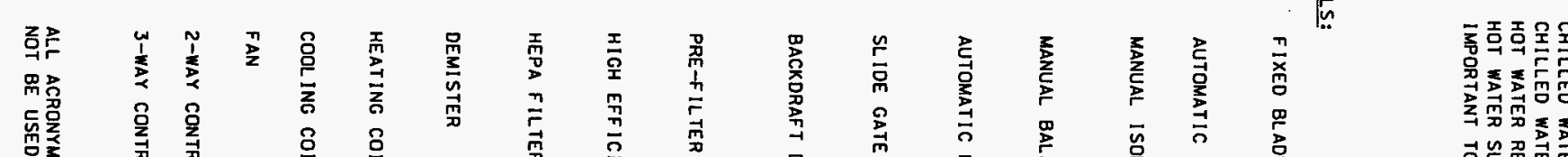




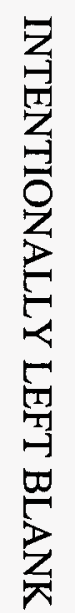




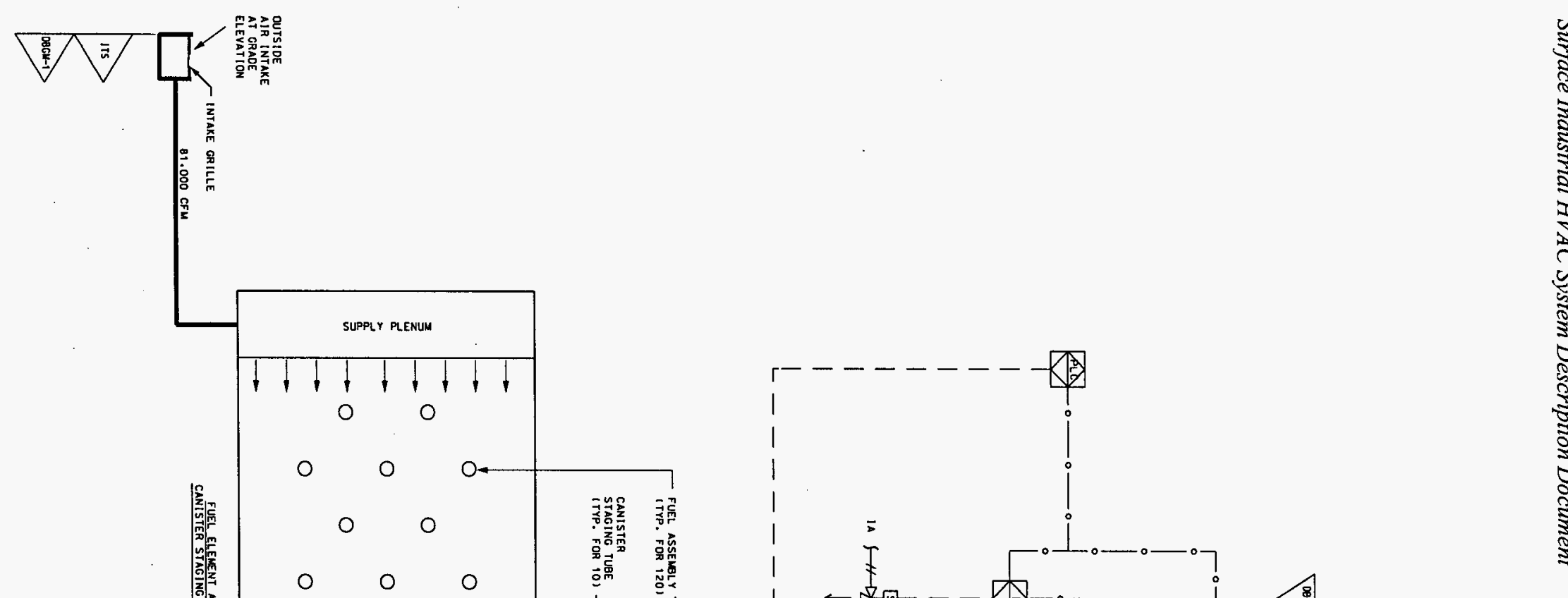


The major components of the DTF 1 HVAC subsystems and related design data are shown in Table 4-1. The major components are described below.

Supply Air-Handling Units-Each supply air-handling unit consists of filters, cooling coils, heating coils, and associated supply fans. The water coils and piping are located outside the moderator exclusion area.

The outdoor air intake filter section for the supply air-handling units consists of prefilters and high-efficiency filters. The prefilters elements are high capacity pleated panel filters and have an efficiency rating of 25 to 30 percent when evaluated in accordance with ANSI/ASHRAE 52.1-1992 [DIRS 164197]. The nominal size of each prefilter element is 24 " $\times 24$ " $\times 4$ ". The high-efficiency filters are replaceable, extended surface multipocket style filters made of microfine glass fiber media and have an efficiency rating of 80 to 90 percent when evaluated in accordance with ANSI/ASHRAE 52.1-1992 [DIRS 164197]. The nominal size of each high-efficiency filter element is $24 " \times 24 " \times 36 "$.

The cooling coils are constructed of copper tubes and fins mechanically bonded to the tubes. The tube bundles are enclosed in a steel frame with vent and drain connections. The coils are arranged for counter flow design using chilled water. The cooling coils are in accordance with ARI 4102001 [DIRS 164310].

The heating coils and reheat coils are constructed of copper tubes with helically wound, permanently bonded, smooth soldered, coated copper fins. The coils are designed for heating air with hot water. The reheat coils are duct-mounted to provide supplemental heat to areas where additional heating is required. The heating coils are in accordance with ARI 4102001 [DIRS 164310].

Supply Fans and Exhaust Fans-The supply fans for the air-handling units and the exhaust fans for the exhaust HEPA Filter Plenum are either directly driven or belt driven, heavy-duty centrifugal-type fans with backward inclined or airfoil blades. The fan performance testing is in accordance with ANSU/AMCA 21099 [DIRS 153079].

Dampers-The design and construction of the dampers are in accordance with ASME N509 [DIRS 115139] and ASME AG-1-2003 [DIRS 166908].

Isolation dampers are used where a means of isolating the system or portion of a system from a flow path is required. Butterfly dampers or parallel-blade-type dampers are used. These dampers are pneumatically operated and are designed to automatically fail in the safe position.

Volume (balancing) dampers, opposed-blade-type, are used as necessary to provide a means of system balancing. In general, these dampers are manually operated.

Backdraft dampers are used, where required, to maintain the proper direction of airflow or to prevent reversal of the airflow. Backdraft dampers are equipped with adjustable counterweights.

Fire dampers are curtain-type dampers located in fire barriers, as necessary, to maintain the fire ratings of the barriers. Fire dampers are equipped with fusible links to close the damper at elevated temperature. 


\begin{tabular}{|c|c|c|c|c|c|c|c|c|c|c|}
\hline 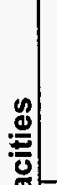 & 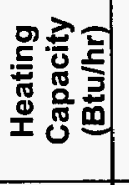 & $\begin{array}{l}8 \\
8 \\
8 \\
0 \\
-\end{array}$ & $\$$ & $\begin{array}{l}\text { ठ } \\
\text { Ñ } \\
\text { \& } \\
\text { - }\end{array}$ & $\frac{\$}{z}$ & $\frac{\hbar}{z}$ & $\overleftrightarrow{\mathbf{z}}$ & $\$$ & $\lesssim$ & 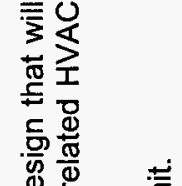 \\
\hline 잉 & 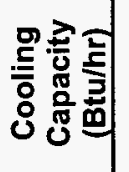 & $\begin{array}{l}\frac{8}{8} \\
\stackrel{N}{N} \\
\stackrel{-}{-}\end{array}$ & $\begin{array}{l}8 \\
8 \\
ٍ ్ \\
0\end{array}$ & $\begin{array}{l}8 \\
8 \\
0 \\
\text { स्̃ } \\
0\end{array}$ & 告 & 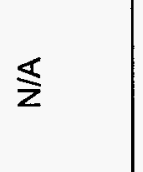 & $\lesssim$ & $\overleftarrow{\Sigma}$ & $\$$ & 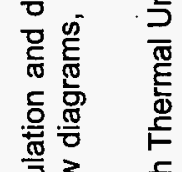 \\
\hline & 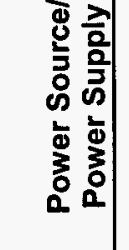 & 己े & 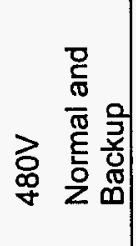 & 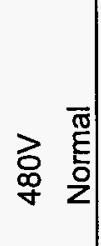 & 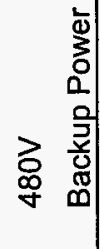 & 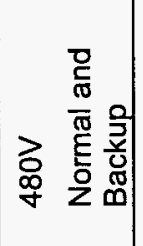 & 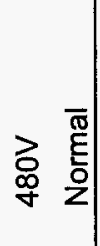 & 客 & 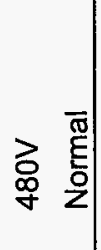 & 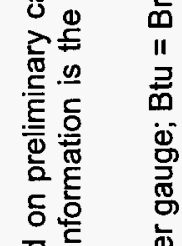 \\
\hline & 岳总这 & 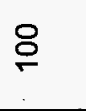 & 으 & $\stackrel{\circ}{\circ}$ & 吅主 & $\stackrel{\circ}{\dot{m}}$ & 80 & $\stackrel{\text { م) }}{\sim}$ & 요 & 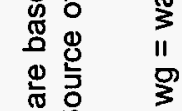 \\
\hline & 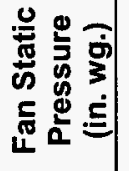 & $\stackrel{\circ}{\circ}$ & $\stackrel{\circ}{+}$ & $\stackrel{\circ}{\circ}$ & $\lesssim$ & 이 & is. & $m$ & $m$ & 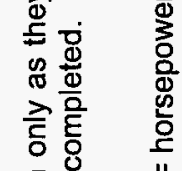 \\
\hline & 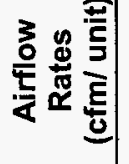 & $\begin{array}{l}8 \\
8 \\
5 \\
5\end{array}$ & $\begin{array}{l}\stackrel{8}{0} \\
\infty\end{array}$ & $\begin{array}{l}8 \\
8 \\
o \\
q\end{array}$ & 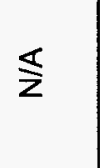 & $\begin{array}{l}8 \\
8 \\
15\end{array}$ & $\begin{array}{l}\text { ס } \\
\text { o }\end{array}$ & $\begin{array}{l}8 \\
8 \\
0\end{array}$ & $\begin{array}{l}8 \\
8 \\
\circ\end{array}$ & 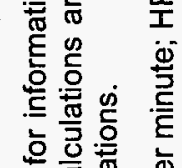 \\
\hline : & 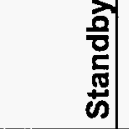 & $r$ & 0 & - & $r$ & - & - & - & 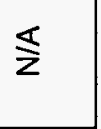 & 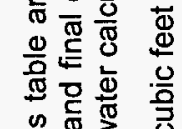 \\
\hline है & 気 & - & $N$ & ما & $\$$ & - & 10 & $\forall$ & $N$ & 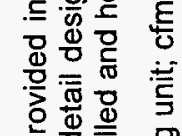 \\
\hline & 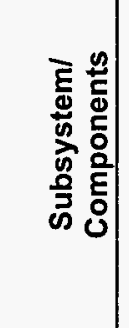 & 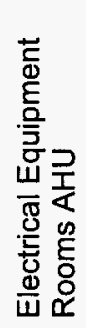 & 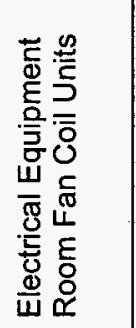 & 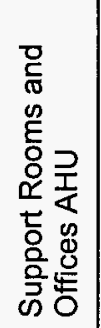 & 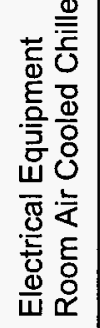 & 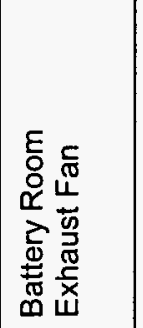 & 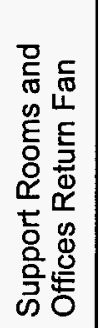 & 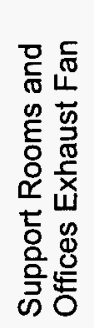 & 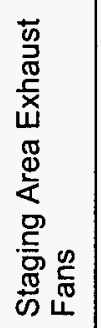 & 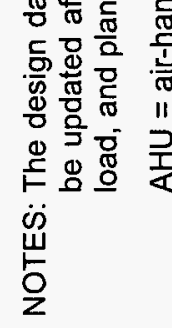 \\
\hline
\end{tabular}


Ductwork-The supply, return, and exhaust ductwork is fabricated and installed in accordance with SMACNA 1995 [DIRS 158927]. The supply and return ductwork is generally constructed of galvanized steel with outside thermal insulation. The exhaust ducts are made of galvanized steel and are uninsulated.

Controls and Instrumentation-The DTF HVAC subsystem parameters are monitored and controlled by temperature, pressure, and flow instrumentation. Temperature-indicating controllers automatically regulate the operation of the heating and cooling coils. Operations of the supply, exhaust, and return fans are controlled from the central control center.

\subsubsection{DTF 2 HVAC Subsystem}

This system serves the nonconfinement or clean areas of DTF 2 that are not served by the nuclear HVAC system. The system description and system components are considered the same as for DTF 1. Any deviation or unique features will be addressed in the later revision of the SDD after the design of the DTF 2 HVAC subsystem is developed.

\subsubsection{CHF HVAC System}

The CHF HVAC subsystems serve the nonconfinement zones (i.e., clean areas such as the canister staging pit support areas and offices, and the electrical equipment rooms) that are not being served by the surface nuclear HVAC subsystems. The subsystems provide conditioned air for cooling, heating, and ventilation to ensure air quality meets standards required for the safety, health, and comfort of the occupational workers and is designed to maintain a slight positive pressure in the nonconfinement areas relative to atmosphere or to adjacent tertiary confinement areas.

\section{CHF Electrical Equipment Room HVAC Subsystem}

The CHF electrical equipment room HVAC subsystem block flow diagram is shown in Figure 4-4. The HVAC subsystem serving the mechanical HVAC equipment room, electrical equipment rooms, uninterruptible power supply room, and battery area consists of a supply air-handling unit, exhaust fans, and associated ductwork, dampers, registers, and controls. The supply air-handling unit consists of prefilters, high-efficiency filters, heating coil, cooling coil, and supply fan. The central plant heating and cooling subsystem provides the hot water and chilled water to the air-handling unit heating and cooling coils. The electrically operated components of the electrical equipment room HVAC subsystem are powered from the normal electrical power system. The battery rooms in the electrical equipment rooms are provided with two exhaust fans, one operating, and one standby. The exhaust fan prevents hydrogen buildup by exhausting air at the ceiling and floor levels of the battery rooms, thereby maintaining combustible gas concentrations below the lower flammability limit of hydrogen.

\section{CHF Support Areas and HVAC Equipment Rooms HVAC Subsystem}

The CHF support area HVAC subsystem block flow diagram is shown in Figure 4-5. The HVAC subsystem serving the support areas consists of recirculating supply air-handling units, an exhaust fan, and associated ductwork, dampers, registers and controls. Each supply air-handling unit consists of prefilters, high-efficiency filters, heating coil, cooling coil, and supply fan. The 
central plant heating and cooling subsystem provides the hot water and chilled water to the air-handling unit heating and cooling coils. The electrically operated components of the subsystem are powered from the normal electrical power system.

\section{CHF Control Systems Room HVAC Subsystem}

The CHF control systems room block flow diagram is shown in Figure 4-6. The HVAC subsystem serving the control systems rooms and communication room consists of two recirculating supply air-handling units (one standby and one operating) and associated ductwork, dampers, registers, and controls. Each supply air-handling unit consists of prefilters, high-efficiency filters, heating coil, cooling coil, and supply fan. Reheat coil in supply ductwork is provided for better temperature controls based on the requirement of areas served. The central plant heating and cooling subsystem provides the hot water and chilled water to the air-handling unit heating and cooling coils. The electrically operated components of the subsystem are powered from the normal electrical power system.

CHF Canister Staging Area HVAC Subsystem-The canister staging area ventilation subsystem airflow diagram is shown in Figure 4-7.

The canister staging area ventilation subsystem is non ITS because forced ventilation is not required to maintain maximum canister surface temperature. Furthermore, the dampers and ductwork have high reliability and in the event of failure, will fail in the position that will allow natural ventilation to occur. The passive (natural) ventilation portion is also classified as non-ITS because their failure will not result in radioactive exposure of the public or site personnel as determined by the PCSA.

Thermal Analysis of the canister handling canister pits and staging area (BSC 2004 [DIRS 170938]) verified that the HVAC subsystem can maintain the bounding temperature requirement for the outer surface of the canister below $343.3^{\circ} \mathrm{C}$. This is taken from Section 3.2 .10 of the Preliminary Design Specification for Department of Energy Standardized Spent Nuclear Fuel Canister (DOE 1999 [DIRS 140225]).

The HVAC subsystem consists of outside air intake, supply ductwork, supply plenum in the staging area, and two exhaust fans to ventilate and maintain the area temperature at an acceptable level. One fan is normally operating and the other is in standby. The staging pit area outside of the canisters' storage tubes is considered clean and filtration of the exhaust air is not required. The exhaust fan draws outside air through the intake louver and circulates it around the canister staging tubes prior to exhausting through the normally open isolation damper via stack.

The exhaust duct is provided with a bypass ductwork equipped with a normally closed bypass damper. If a loss of power condition occurs, the normally open isolation damper closes and the normally closed bypass damper opens to initiate natural ventilation. Exhausts from this subsystem flow through a continuously monitored stack for data collection.. 

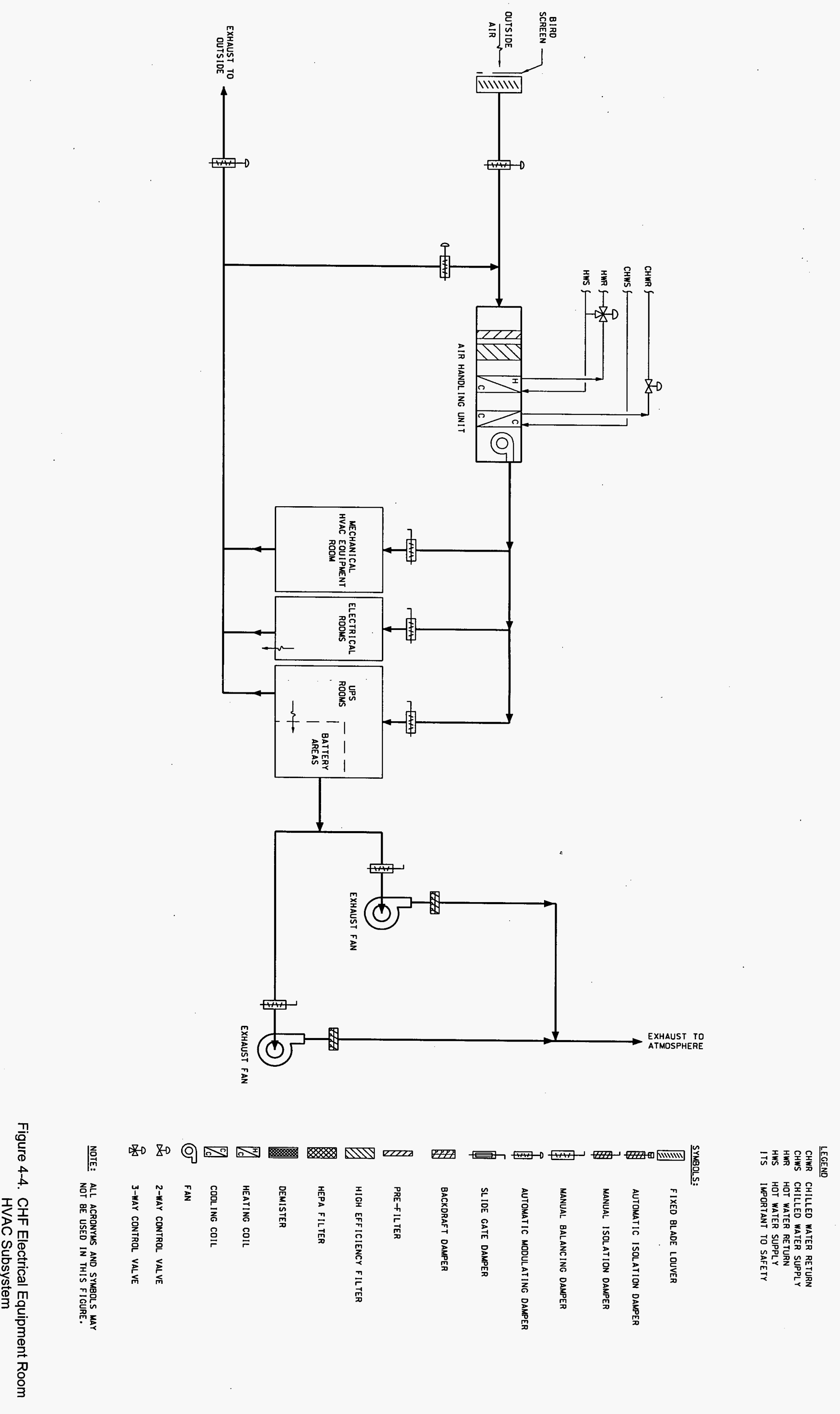
录 

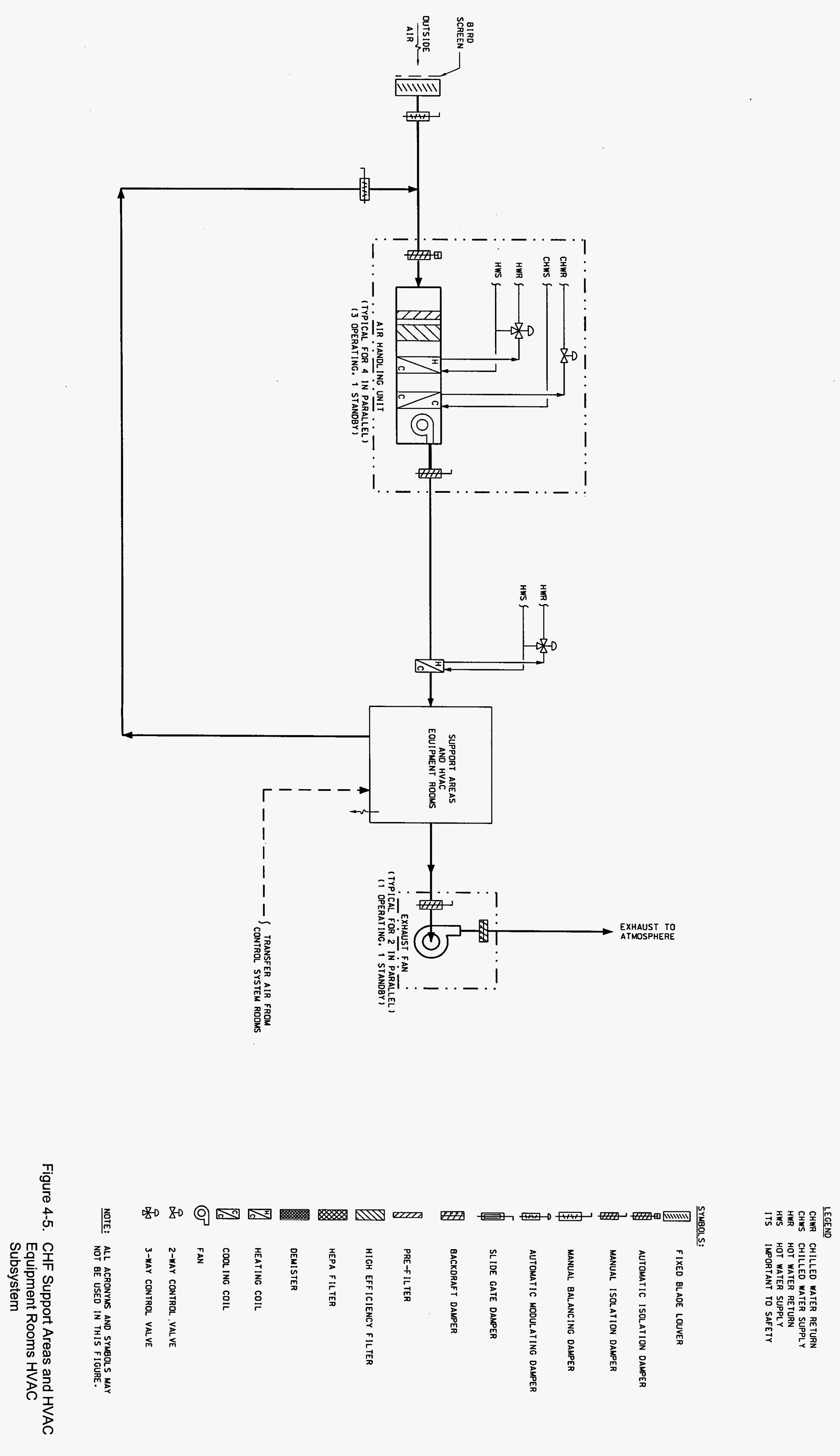
疍

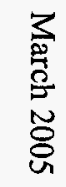




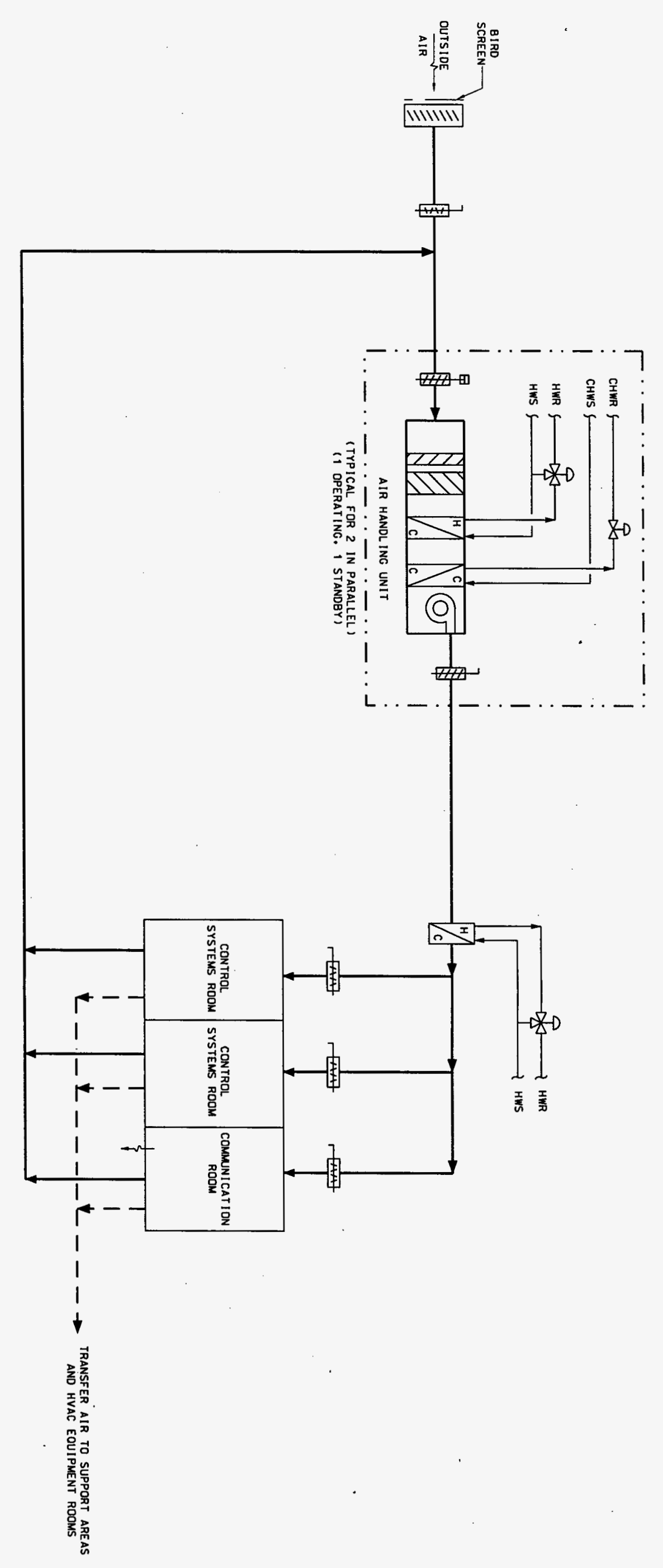




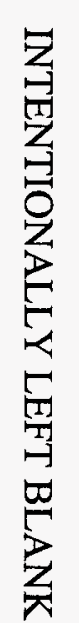




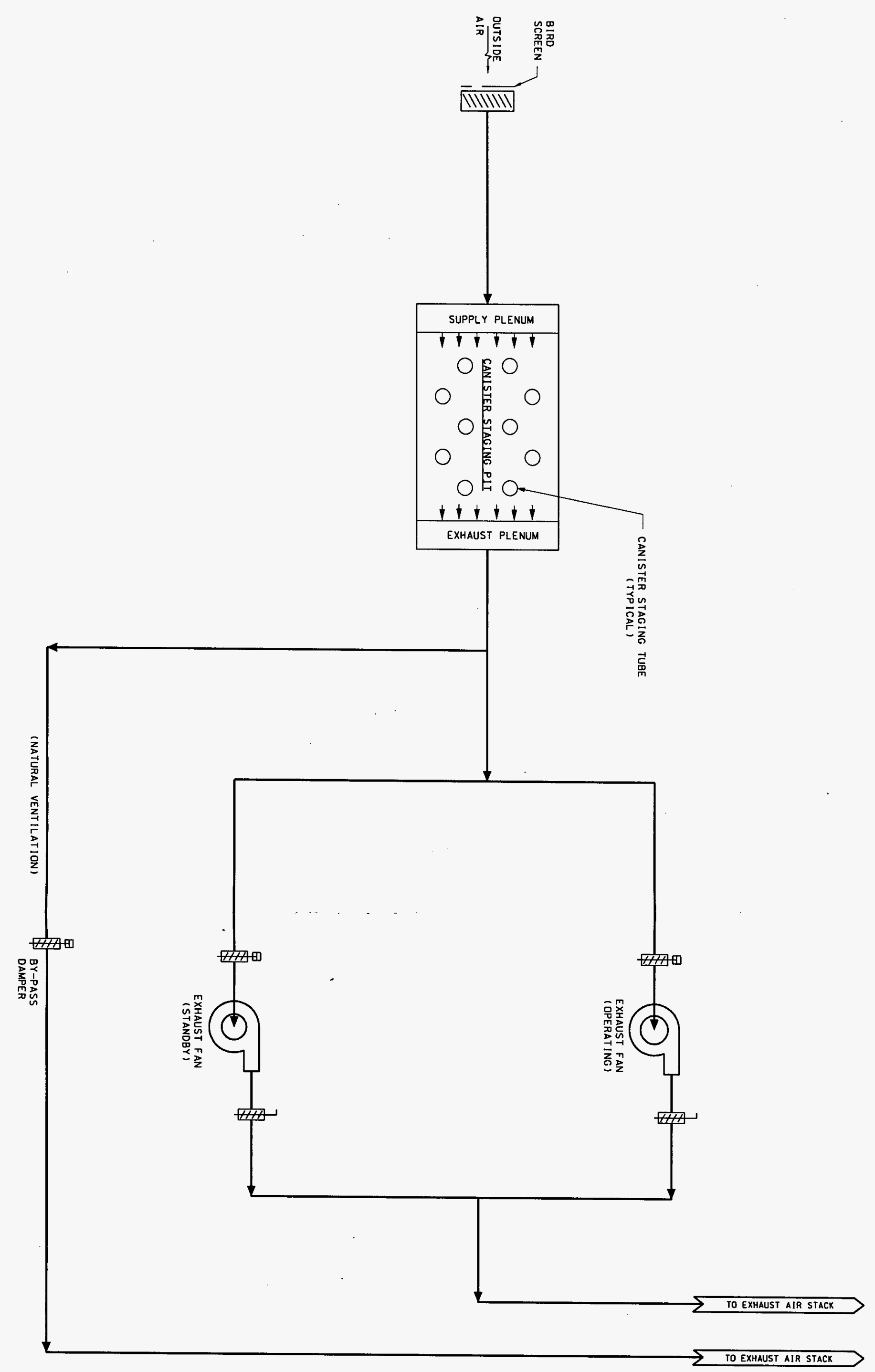

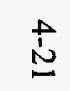
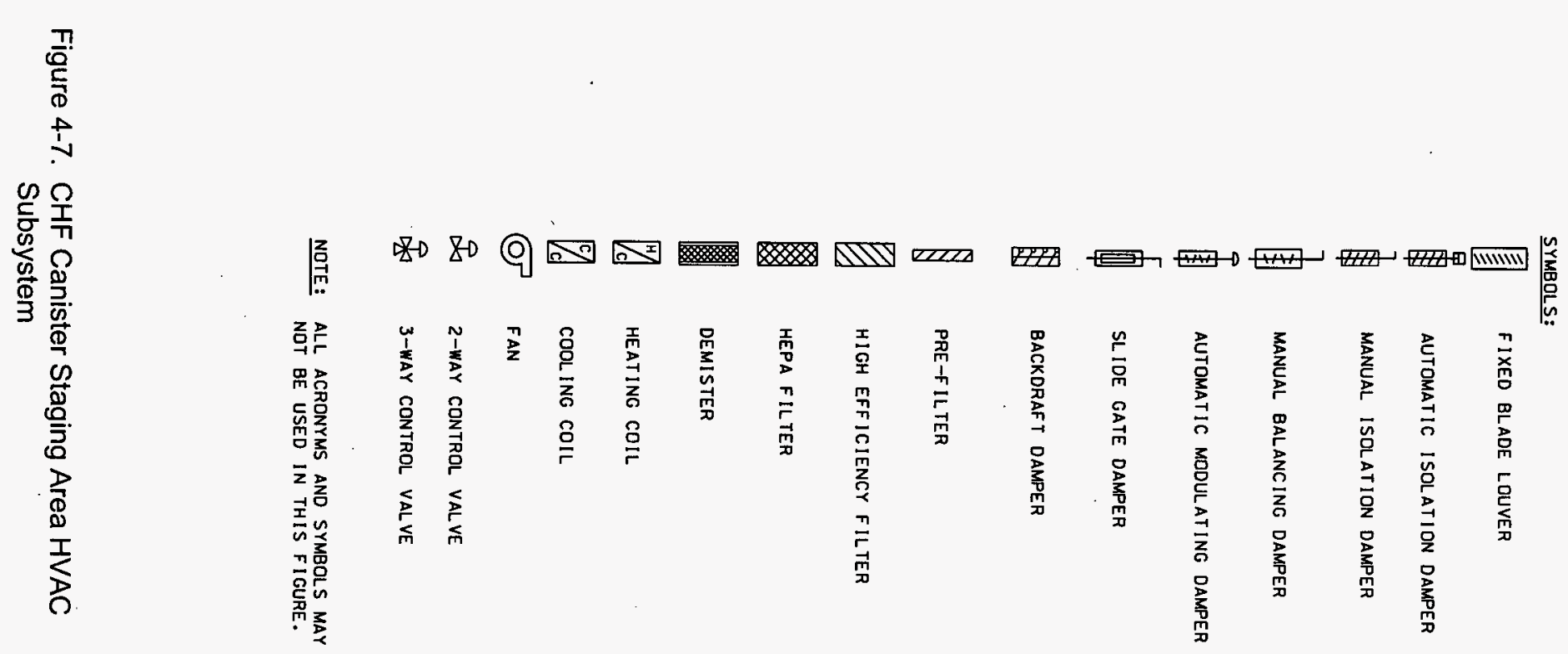

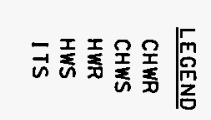

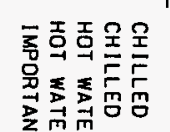

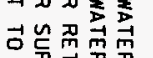

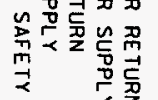




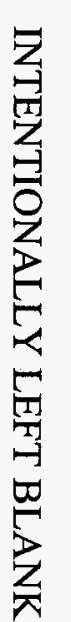


The passive portion providing natural ventilation of the CHF HVAC staging area including the outside air intake, related ductwork, bypass outlet dampers, exhaust fan isolation dampers, and exhaust stack for fuel element staging area is non-ITS. However, if needed, it will be designed with augmented quality conforming to DOE/RW-0565, Augmented Quality Assurance Program (AQAP) (DOE 2004 [DIRS 171341]) during the detail design.

The related ductwork is designed to remain intact to allow natural airflow. This portion of the surface industrial HVAC system is designed not to collapse and be operational with a DBGM-1 event sequence.

\section{HVAC Subsystem Components Description}

The CHF HVAC system consists of components dedicated to supply air to or exhaust air from the facility. The supply subsystem components consist of air-handling units with supply fan, outdoor air intake louvers, and supply air distribution. The supply air distribution consists of ductwork, reheat coils, pressure control dampers, air-balancing devices, and isolation dampers. The exhaust subsystem components consist of exhaust HEPA Filter Plenum, exhaust air fans, pressure control dampers, air-balancing devices, and isolation dampers. The CHF HVAC subsystems and the related design data are shown in Table 4-2. The major components are described below:

Supply Air-Handling Units-Each supply air-handling unit consists of outdoor air intake filters, heating coils, and cooling coils. The water coils and piping are located outside of the moderator exclusion area.

The outdoor air intake filter section for the supply air-handling units consists of prefilters and high-efficiency filters. The prefilters elements are high capacity pleated panel filters and have an efficiency rating of 25 to 30 percent when evaluated in accordance with ANSI/ASHRAE 52.1-1992 [DIRS 164197]. The nominal size of each prefilter element is $24 " \times 24 " \times 4 "$. The high-efficiency filters are replaceable, extended surface multipocket style filters made of microfine glass fiber media and have an efficiency rating of 80 to 90 percent when evaluated in accordance with ANSI/ASHRAE 52.1-1992 [DIRS 164197]. The nominal size of each high-efficiency filter element is $24 " \times 24 " \times 36^{\prime \prime}$.

The cooling coils are constructed of copper tubes and fin mechanically bonded to the tubes. The tube bundles are enclosed in a steel frame and include vent and drain connections. The coils are arranged for counterflow design using chilled water. The cooling coils are in accordance with ARI 410-2001 [DIRS 164310].

The heating coils and reheat coils are constructed of copper tubes with helically wound, permanently bonded, smooth soldered-coated copper fins. The coils are designed for heating air with hot water. The reheat coils are duct mounted to provide supplemental heat to areas where additional heating is required. The heating coils are in accordance with ARI 410-2001 [DIRS 164310]. 


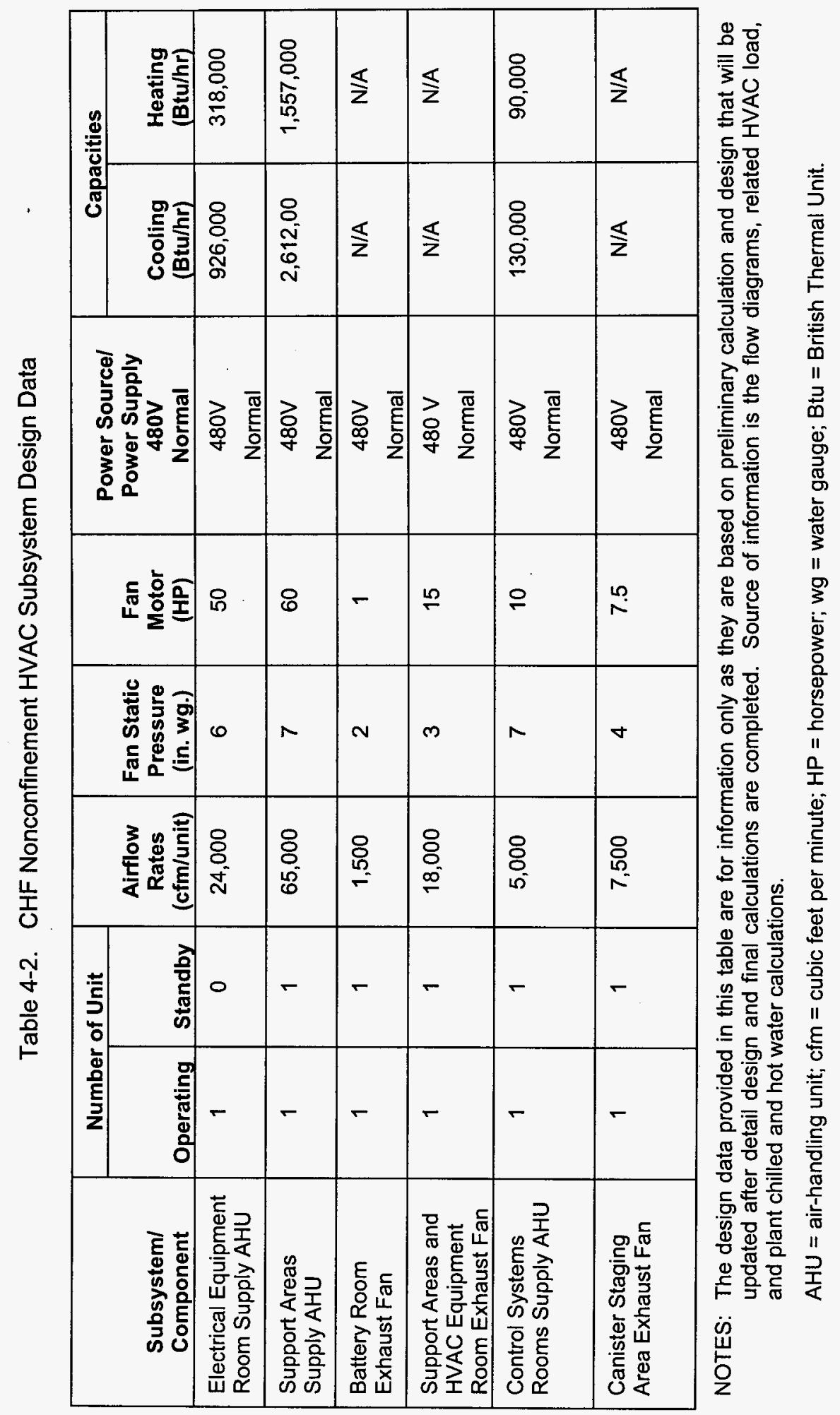


Supply Fans and Exhaust Fans-The supply fans for the air-handling units and the exhaust fans for the exhaust HEPA Filter Plenum are either directly driven or belt driven, heavy-duty centrifugal-type fans with backward inclined or airfoil blades. The fan performance testing is in accordance with ANSI/AMCA 210-99 [DIRS 153079].

Dampers-The design and construction of the dampers are in accordance with Article 5.9 of ASME N509 [DIRS 115139] and Section DA of ASME AG-1-2003 [DIRS 166908].

Isolation dampers are used where a means of isolating the system or portion of a system from a flow path is required, butterfly dampers or parallel-blade-type dampers are utilized. These dampers are pneumatically operated and are designed to automatically fail in the safe position.

Volume (balancing) dampers, opposed-blade-type, are utilized, as necessary, to provide a means of system balancing. In general, these dampers are manually operated.

Backdraft dampers are employed, where required, to maintain the proper direction of airflow, or prevent reversal of airflow. Backdraft dampers are equipped with adjustable counterweight.

Fire dampers are the curtain-type dampers located in fire barriers, as necessary, to maintain the fire ratings of the barriers. Fire dampers are equipped with fusible links to close the damper at elevated temperature.

Ductwork-The supply and exhaust ductwork is fabricated and installed in accordance with SMACNA 1995 [DIRS 158927]. The supply ductwork is generally constructed of galvanized steel with outside thermal insulation. The exhaust ducts are made of galvanized steel and are uninsulated.

\subsubsection{WNNRF HVAC Systems}

The WNNRF HVAC subsystems are based on a normally clean building with no loose or airborne contamination, and the casks that enter the facility will not have removable contamination that exceeds specified limits. Therefore, ventilation zoning of the facility is not required. Although not required, an exhaust HEPA filter plenum with HEPA filters is provided as defense-in-depth to mitigate the consequences of a release, should one occur during the life of the TCRRF portion of the building.

\section{Transportation Cask Receipt/Return Area HVAC Subsystem}

The HVAC subsystem for the cask receipt/return area is provided with a once-through design. This design includes two supply air-handling units with integral supply fans, two exhaust fans, associated ductwork, and accessories. Both air-handling units operate during normal conditions. The exhaust fans remove diesel exhaust that may be present inside the facility. A bypass duct is available with a locked-closed damper that can be opened to recirculate the air if required. 
The exhaust HEPA filter plenum with HEPA filters is manually started on demand. It consists of a demister, a prefilter, HEPA filtration, and an exhaust fan. The subsystem block flow diagram is shown in Figure 4-8.

\section{WNNRF HVAC Subsystems}

The WNNRF HVAC subsystems are based on a normally clean building with no loose or airborne contamination, and the casks that enter the facility will not have removable contamination that exceeds specified limits. WNNRF is served by the following subsystems.

\section{WNNRF Warehouse Area and HVAC Equipment Area HVAC Subsystem}

The HVAC subsystem that serves the warehouse area and HVAC equipment includes two recirculating supply air-handling units with integral supply fans, return/exhaust fans, and associated distribution ductwork, dampers, registers, and economizer controls. The air-handling units consist of prefilters, high-efficiency filters, heating coils, and cooling coils. The waste package storage area is provided with two return or exhaust fans with the ability to flush the building from any build-up of carbon monoxide and oxides of nitrogen generated from the vehicle diesel exhaust. A bypass duct is available with a locked-closed damper that can be opened to recirculate the air if required. The subsystem block flow diagram is shown in Figure 4-9.

\section{WNNRF Office Area HVAC Subsystem}

The HVAC subsystem serving the offices, contained in the WNNRF, consists of a supply air-handling unit with an integral supply fan, return or exhaust fan, and associated ductwork, dampers, registers, and economizer controls. The supply air-handling unit consists of prefilters, high-efficiency filters, heating coil, cooling coil, and supply fan. The subsystem block flow diagram is shown in Figure 4-10.

\section{WNNRF Electrical Room HVAC Subsystem}

The HVAC subsystem serving the electrical rooms consists of a recirculating supply air-handling unit with an integral supply fan, and associated ductwork, dampers, registers, and controls. The supply air-handling unit consists of prefilters, high-efficiency filters, heating coil, cooling coil, and supply fan. The subsystem block flow diagram is shown in Figure 4-11. 


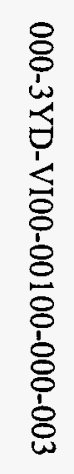

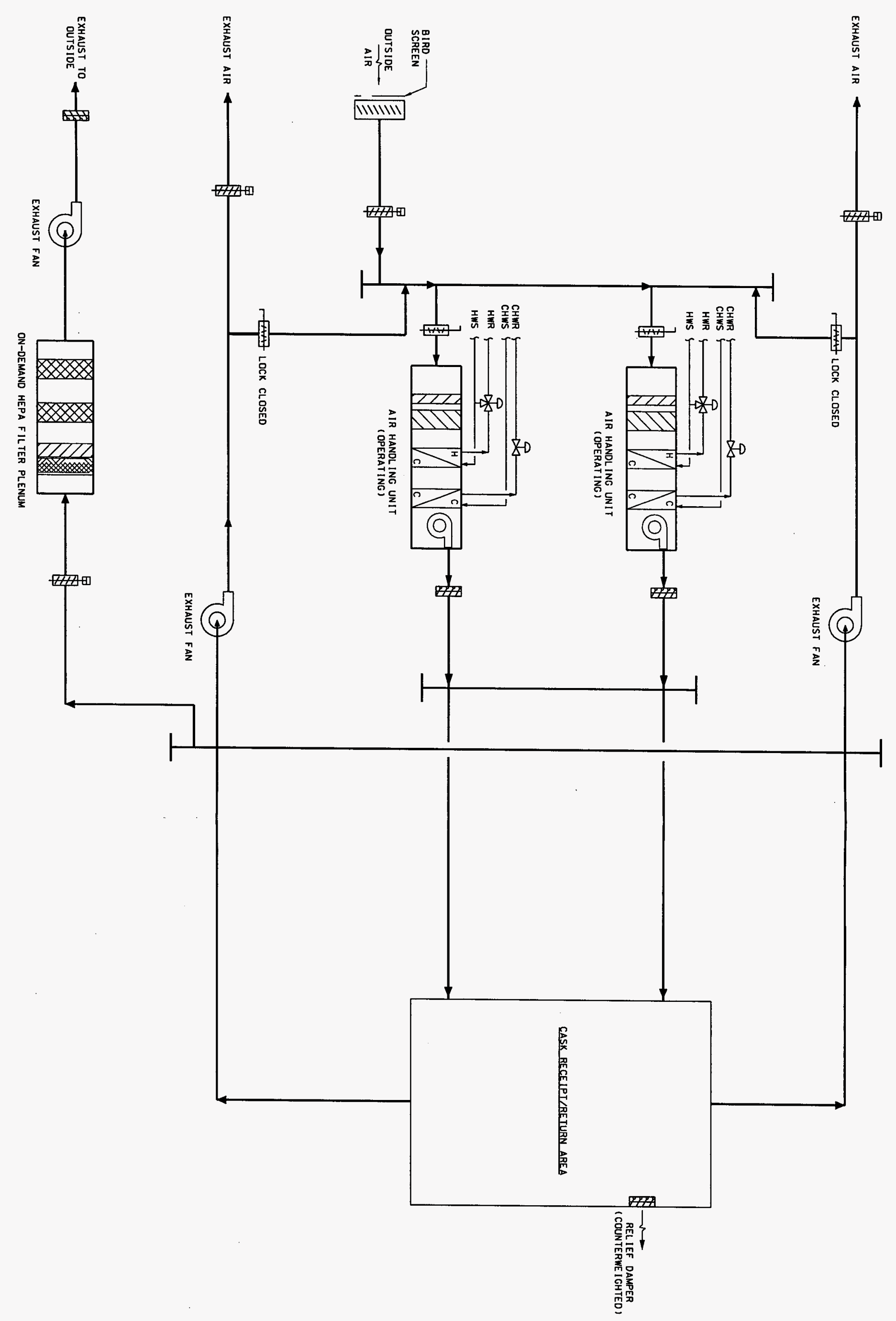

要

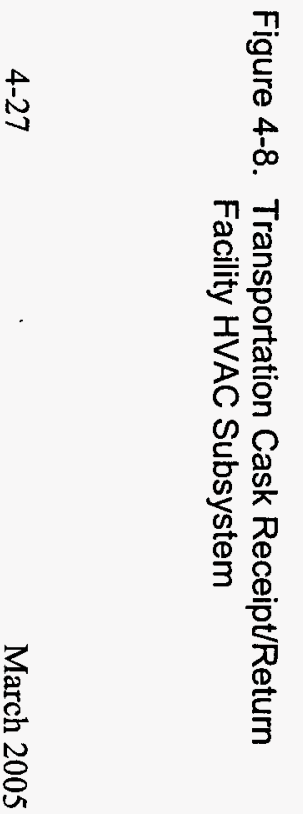

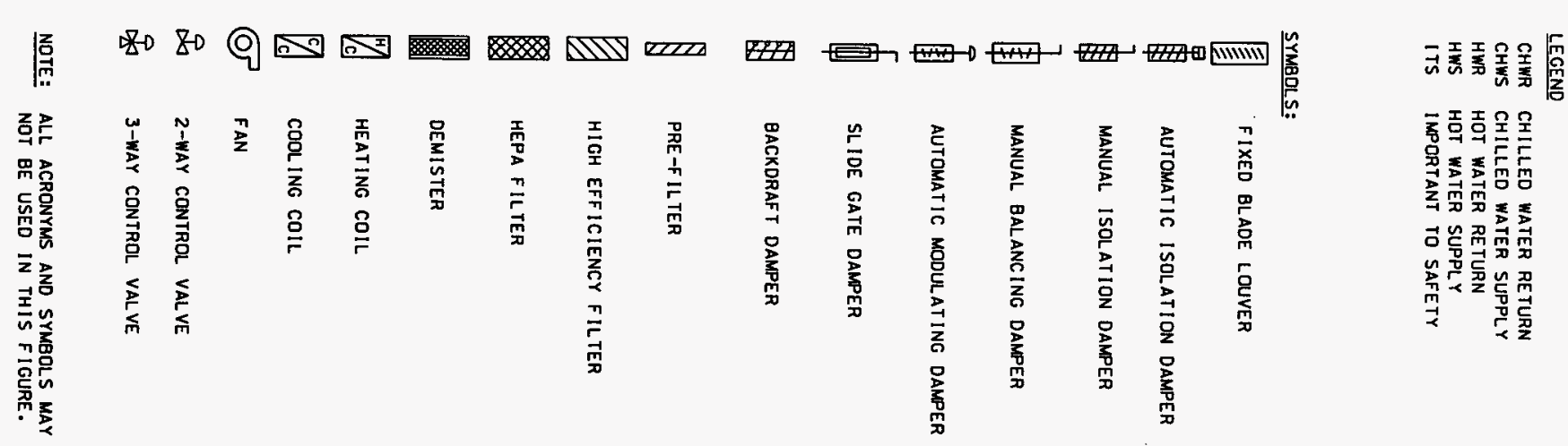




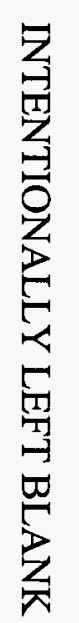

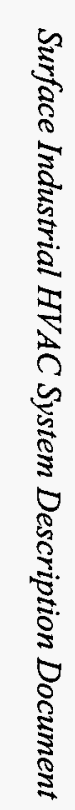




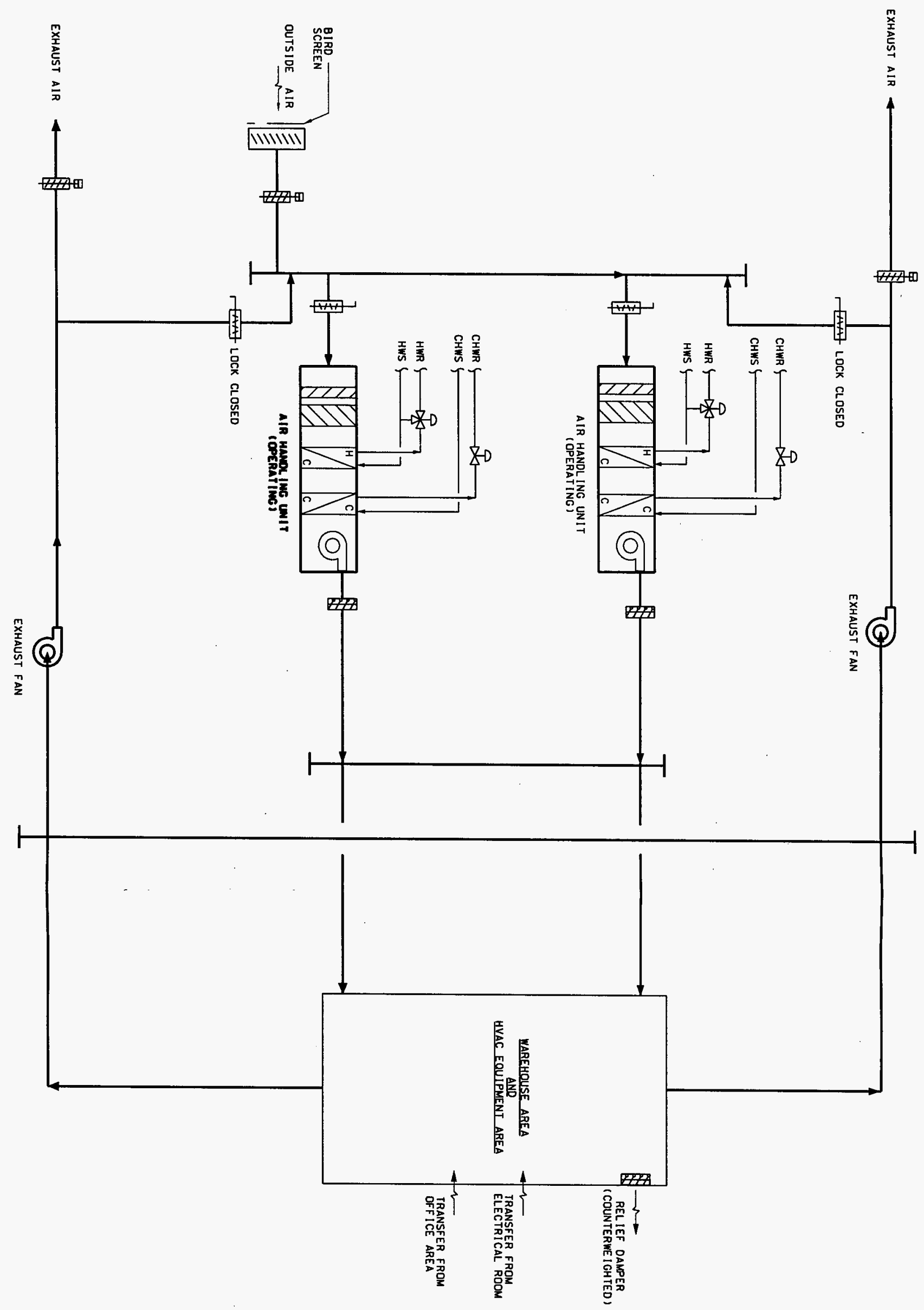

芯

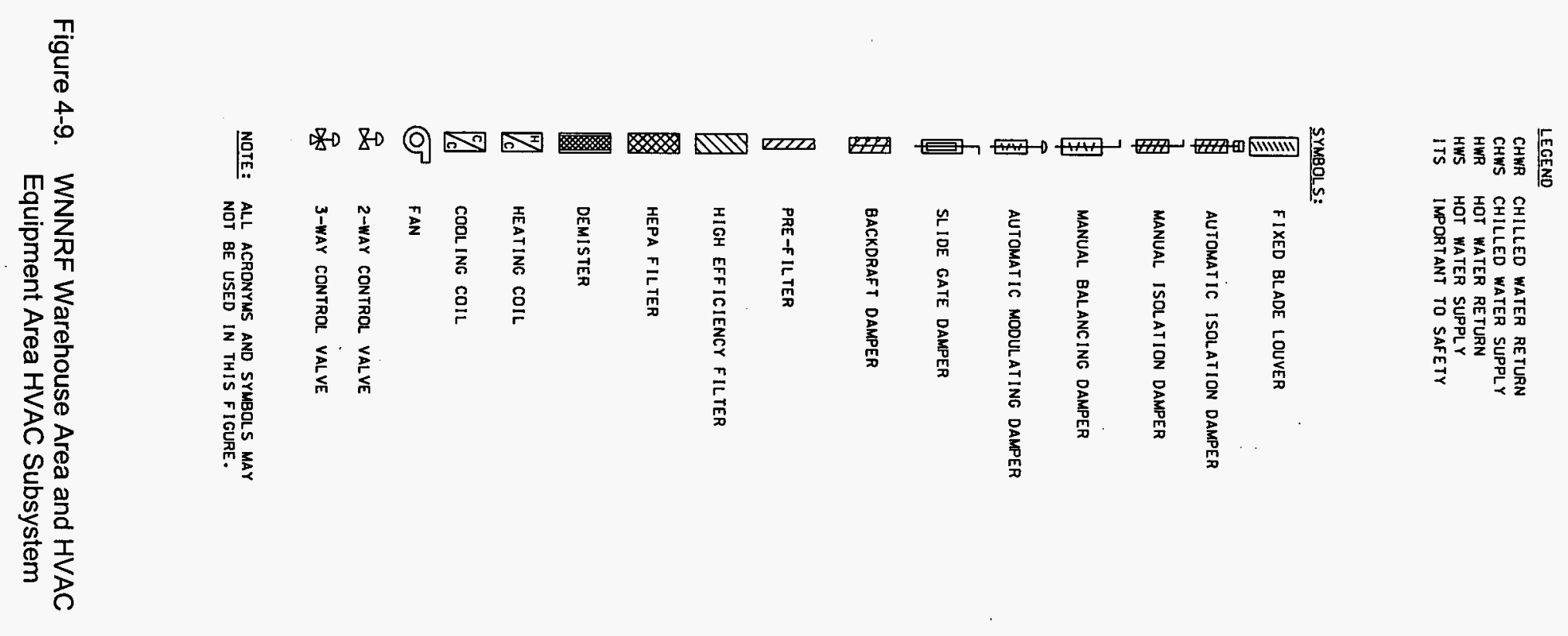




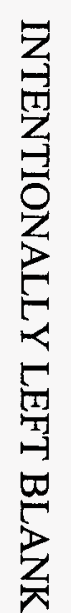



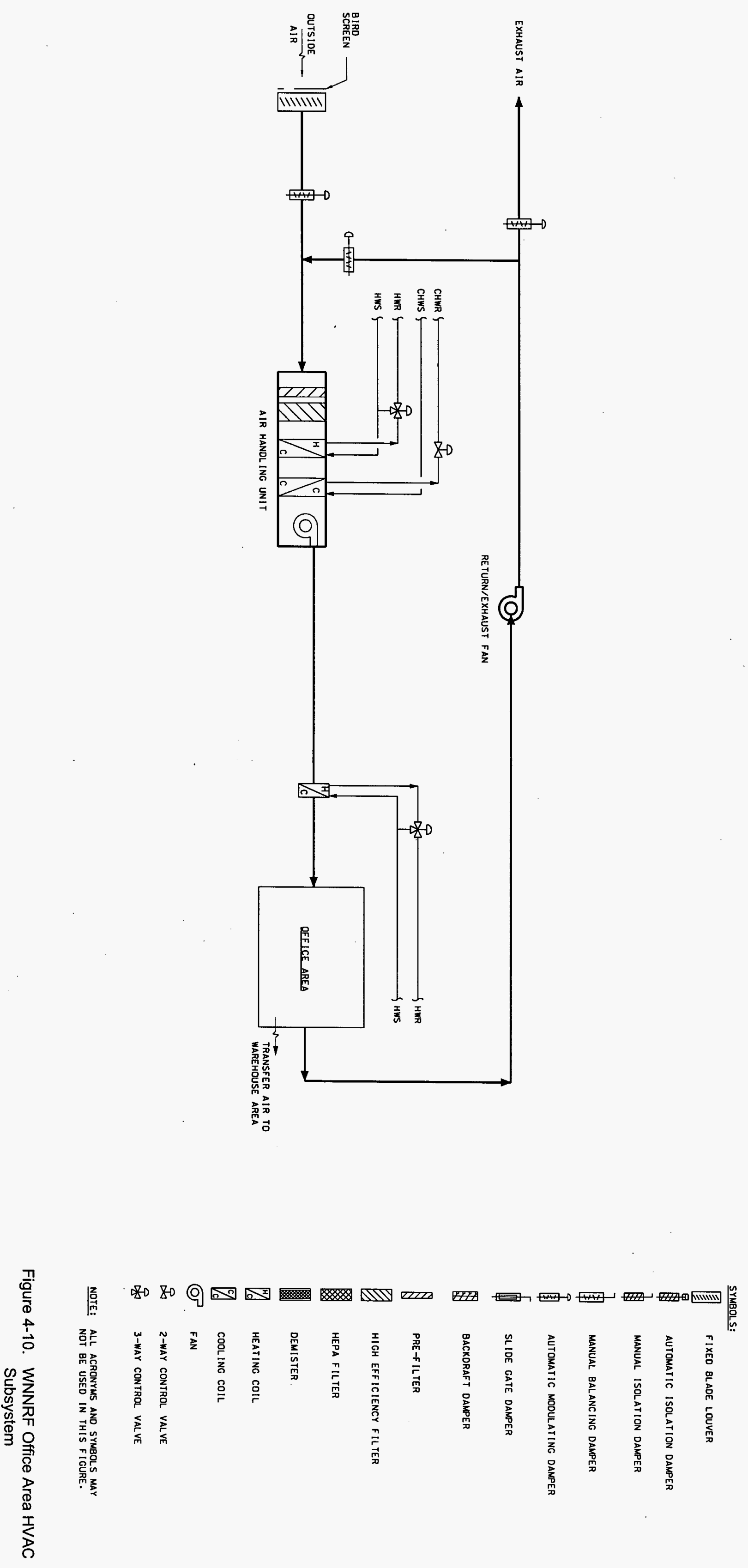
龺 


\section{HVAC Subsystem Components Description}

The TCRRF and WNNRF HVAC subsystems consist of components dedicated to supplying air to or exhausting air from the facility. The supply subsystem components consist of air-handling units with supply fans, outdoor air intake louvers, and supply air distribution. The supply air distribution consists of ductwork, reheat coils, air-balancing devices, and isolation dampers. The exhaust subsystem components consist of exhaust HEPA Filter Plenum, exhaust fans, isolation dampers, air-balancing devices, and ductwork. The TCRRF and WNNRF HVAC subsystems and related design data are listed in Table 4-3 and are described below:

Supply Air-Handling Units--Each supply air-handling unit consists of air filters, cooling coils, heating coils, and a supply fan.

- Filters-The air-filtration section for the supply air-handling units consist of prefilters and high-efficiency filters. The nominal size of each prefilter element is $24^{\prime \prime} \times 24^{\prime \prime} \times 4^{\prime \prime}$, and the nominal size of the high-efficiency filter element is 24 " $\times 24^{\prime \prime} \times 36^{\prime \prime}$. Each prefilter and high-efficiency filter element is rated at $2,000 \mathrm{cfm}$. The prefilter elements are high capacity pleated panel filters and have an efficiency rating of 25 to 30 percent when evaluated in accordance with ANSI/ASHRAE 52.1-1992 [DIRS 164197]. The high-efficiency filters are replaceable, extended surface multipocket style filters made of microfine glass fiber media and have an efficiency rating of 80 to 90 percent when evaluated in accordance with ANSI/ASHRAE 52.1-1992 [DIRS 164197].

- Cooling Coils-The cooling coils are constructed of copper tubes with fins mechanically bonded to the tubes. The tube bundles are enclosed in a steel frame and include vent and drain connections. The coils are arranged for counter-flow design using chilled water. The cooling coils are in accordance with ARI Std 410 [DIRS 164310].

- Heating Coils-The heating and reheat coils are constructed of copper tubes with helically wound, permanently bonded, smooth soldered, coated copper fins. The coils are designed for heating air with hot water. The reheat coils are duct mounted to provide supplemental heat to areas where additional heating is required. The heating coils are in accordance with ARI Std 410 [DIRS 164310].

Supply Fans and Exhaust Fans-The supply fans for the air-handling units and the exhaust fans for the exhaust HEPA Filter Plenum are directly driven or belt driven, heavy-duty centrifugaltype fans with backward inclined or airfoil blades. The supply and exhaust fans are designed in accordance with ASME AG-1-2003 [DIRS 166908], Section BA. The fan performance testing is in accordance with ANSI/AMCA 21099 [DIRS 153079]. 
Dampers-The design and construction of the dampers are in accordance with ASME N509-1989 [DIRS 115139], Article 5.9, and ASME AG-1-2003 [DIRS 166908].

- Isolation Dampers-Isolation dampers, butterfly dampers, or parallel-blade-type dampers are used where a means of isolating the system or portion of a system from a flow path is required. These dampers are pneumatically operated and are designed to automatically fail in the safe position.

- Volume Dampers-Volume (balancing) dampers, opposed-blade-type, are used to provide a means of system balancing. In general, these dampers are manually operated.

- Backdraft Dampers-Backdraft dampers are used to maintain the proper direction of airflow or prevent reversal of airflow where required. Backdraft dampers are equipped with adjustable counterweights.

- Fire Dampers-Fire dampers are curtain-type dampers located in fire barriers, as necessary, to maintain the fire ratings of the barriers. ' Fire dampers are equipped with fusible links to close the damper at elevated temperature.

Exhaust HEPA Filter Plenum-The exhaust HEPA filter plenum consists of demister, prefilters, and HEPA filters. The materials of construction are in accordance with ASME AG-1-2003 [DIRS 166908].

- HEPA filter plenum housing-The design and construction of the HEPA filter plenum housing is in accordance with ASME AG 12003 [DIRS 166908], Section HA. The HEPA filter plenum housing is made of continuously welded stainless steel or coated carbon steel, and provided with service access doors, explosion proof lights, filter test connections (test ports) for pressure gauges, and drain connections.

- Demisters-The demisters (moisture separators) in the HEPA Filter Plenum are used to protect the HEPA filters from damage or loss due to entrained moisture in the air stream. The demister pads are constructed of glass fiber or corrosion resistant wire (e.g., stainless steel) with stainless steel frame and conform to the requirements of ASME N509-1989 [DIRS 115139], Article 5.4, and ASME AG-1-2003 [DIRS 166908], and are certified to UL 9001994 [DIRS 166725].

- Prefilters-The prefilters are installed upstream of the first stage HEPA filter to remove large airborne particulate, thereby reducing the particulate loading on the HEPA filters and extending their service life. The prefilters have an average atmospheric dust-spot efficiency of 80 percent in accordance with ANSI/ASHRAE 52.1 1992 [DIRS 164197]. The prefilter elements are replaceable, glass fiber media that conform to the requirements of ASME AG-1-2003 [DIRS 166908]. 
- HEPA Filters-The HEPA filters remove particulate contaminants from the air stream. The HEPA filters have a minimum removal efficiency of 99.97 percent on particles measuring $0.3 \mathrm{~mm}$ or larger. The HEPA filter elements are Type $\mathrm{B}$, consisting of glass fiber media that conforms to the requirements of ASME N509-1989 [DIRS 115139], Articles 5.1 and 5.6.3, and ASME AG-1-2003 [DIRS 166908]. The framing system is designed to accommodate a $24 " \times 24 " \times 12$ " filter element. The HEPA filters are size 7 rated at 1,500 cfm per filter element, with Type IID (stainless steel) frame material.

Ductwork-The supply, return, and exhaust ductwork is fabricated and installed in accordance with SMACNA 1995 [DIRS 158927]. The supply and return ductwork are generally constructed of galvanized steel with outside thermal insulation, while the exhaust ductwork is uninsulated.

\subsubsection{FHF HVAC System}

The FHF HVAC subsystem serving the nonconfinement zones of FHF, clean areas not served by the surface nuclear HVAC subsystems, are the support rooms and offices, and the electrical equipment rooms HVAC subsystem. The subsystems are provided with a recirculation HVAC system. The subsystems provide conditioned air for cooling, heating, and ventilation to ensure air quality meets standards required for the safety, health, and comfort of occupational workers, and it is designed to maintain a slight positive pressure in the nonconfinement areas relative to atmosphere or adjacent confinement areas.

FHF Electrical Equipment Room HVAC Subsystem-The electrical motor control center rooms, and battery rooms HVAC subsystem block flow diagram is shown in Figure 4-12. The HVAC subsystem serving the electrical equipment rooms (electrical motor control center room, and battery room) consists of two 100 percent recirculating supply air-handling units (one operating and one backup) and associated ductwork, dampers, registers, and controls. Each supply air-handling unit consists of prefilters, high-efficiency filters, heating coil, cooling coil, and supply fan.

The recirculating fan coil units provide supplemental cooling to the Train A and Train B electrical motor control center rooms. Each fan coil unit consists of prefilters, high-efficiency filters, chilled water cooling coil, and a supply fan.

The central plant heating and cooling subsystem provides hot and chilled water to the air-handling unit heating and cooling coils. The backup air-cooled water chiller and chilled water pump, powered from the backup electrical power system, will supply chilled water to the supplementary fan coil unit cooling coils when the central plant heating and cooling subsystem is not available.

The electrically operated components of the electrical equipment room HVAC subsystem are powered from the normal, and, if required, backup electrical power system from standby diesel generators.

The battery rooms are provided with exhaust fans with explosion proof motors (one operating and one backup) that exhaust to the atmosphere to prevent hydrogen buildup in the battery rooms. 


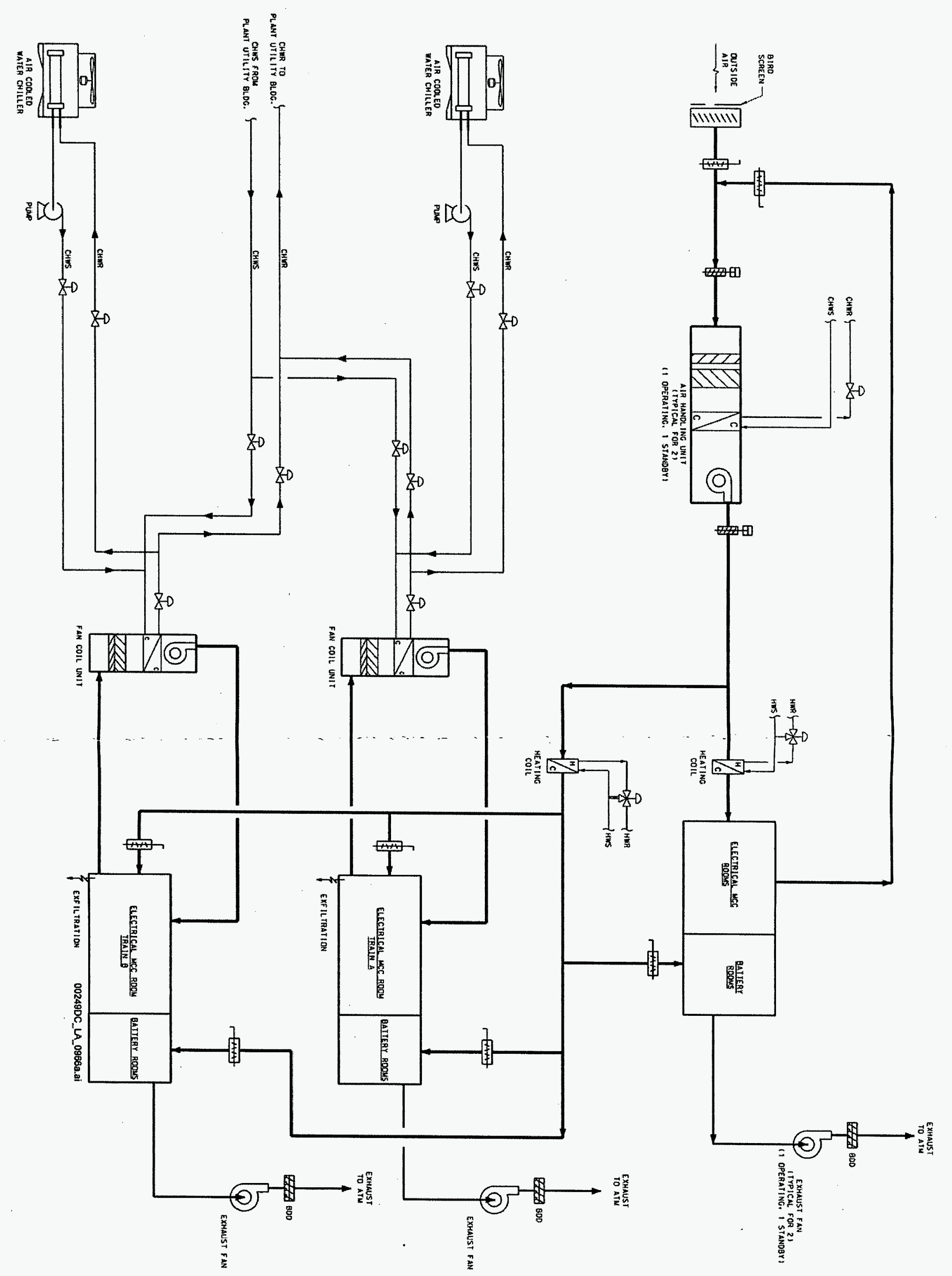


FHF Support Rooms and Offices HVAC Subsystem-The support rooms and offices HVAC subsystem block flow diagram is shown in Figure 4-13. The subsystem consists of two supply air-handling units, two return air fans, two exhaust fans with one operating and one as a backup exhaust fan, and associated ductwork, dampers, registers, and controls. Each supply air-handling unit consists of prefilters, high-efficiency filters, cooling coil, and supply fan. The heating coil is provided in the supply duct to the area. The central plant heating and cooling subsystem provides hot and chilled water to the air-handling unit and cooling coils and heating coil in ductwork. The electrically operated components of the support rooms and offices HVAC subsystem are powered from the normal electrical power system.

\section{HVAC Subsystem Components Descriptions}

The FHF nonconfinement HVAC subsystem consists of components dedicated to supplying air to or exhausting air from the facility. The supply subsystem components consist of air-handling units with supply fan, outdoor air intake louvers, and supply air distribution. The supply air distribution consists of ductwork, reheat coils, air-balancing devices, and isolation dampers.

The major components of the FHF nonconfinement HVAC subsystems related design data are shown in Table 4-4. The major components are described as follows.

Supply Air-Handling Units-Each supply air-handling unit consists of outdoor air intake filters, cooling coils, and heating and reheating coils. The water coils and piping are located outside the moderator exclusion area.

The outdoor air intake filter section for the supply air-handling units consists of prefilters and high-efficiency filters. The prefilters elements are high capacity pleated panel filters and have an efficiency rating of 25 to 30 percent when evaluated in accordance with ANSI/ASHRAE 52.1-1992 [DIRS 164197]. The nominal size of each prefilter element is $24 " \times 24$ " $\times 4$ ". The high-efficiency filters are replaceable, extended surface multipocket style filters made of microfine glass fiber media and have an efficiency rating of 80 to 90 percent when evaluated in accordance with ANSI/ASHRAE 52.1-1992 [DIRS 164197]. The nominal size of each high-efficiency filter element is $24 " \times 24 " \times 36 "$.

The cooling coil is constructed of copper tubes and fins mechanically bonded to the tubes. The tube bundles are enclosed in a steel frame with vent and drain connections. The coils are arranged for counterflow design using chilled water. The cooling coils are in accordance with ARI 410 [DIRS 164310].

The heating coils and reheat coils are constructed of copper tubes with helically wound, permanently bonded, smooth soldered, coated copper fins. The coils are designed for heating air with hot water. The reheat coils are duct-mounted to provide supplemental heat to areas where additional heating is required. The heating coils are in accordance with ARI 410 [DIRS 164310]. 
Supply Fans and Exhaust Fans-The supply fans for the air-handling units and the exhaust fans for the exhaust HEPA Filter Plenum are either directly driven or belt driven, heavy-duty centrifugal-type fans with backward inclined or airfoil blades. The fan performance testing is in accordance with ANSI/AMCA 210-99 2000 [DIRS 153079].

Dampers-The design and construction of the dampers are in accordance with ASME N509 [DIRS 115139] and ASME AG-1-2003 [DIRS 166908].

Isolation dampers are used where a means of isolating the system or portion of a system from a flow path is required. Butterfly dampers or parallel-blade-type dampers are used. These dampers are pneumatically operated and are designed to automatically fail in the safe position.

Volume (balancing) dampers, opposed-blade-type, are used as necessary to provide a means of system balancing. In general, these dampers are manually operated.

Backdraft dampers are used, where required, to maintain the proper direction of airflow or to prevent reversal of the airflow. Backdraft dampers are equipped with adjustable counterweights.

Fire dampers are curtain-type dampers located in fire barriers, as necessary, to maintain the fire ratings of the barriers. Fire dampers are equipped with fusible links to close the damper at elevated temperature.

Ductwork-The supply and exhaust ductwork is fabricated and installed in accordance with SMACNA 1995 [DIRS 158927]. The supply ductwork is generally constructed of galvanized steel with outside thermal insulation. The exhaust ducts are made of galvanized steel and are uninsulated.

Controls and Instrumentation-The FHF HVAC subsystem parameters are monitored and controlled by temperature, pressure, and airflow instrumentation. Temperature-indicating controllers automatically regulate the operation of the heating and cooling coils. Operations of the supply, exhaust, and return fans are controlled from the central control center.

\subsubsection{Central Control Center Facility HVAC Subsystems}

The CCCF HVAC subsystems serve the central control center area (central control center, communication room, corridors, break-room, janitor room, rest rooms, fire protection room, HVAC equipment room \#1, and the electrical equipment room \#1). The CCCF HVAC subsystems also serves the safeguard area (safeguard room, janitor room, restrooms, HVAC equipment room \#2, and electrical room \#2). The subsystems are provided with a recirculation type HVAC system for each area. The subsystems provide conditioned air for cooling, heating, and ventilation to ensure air quality meets standards required for the safety, health, and comfort of the occupational workers and is designed to maintain a slight positive pressure relative to atmosphere. 

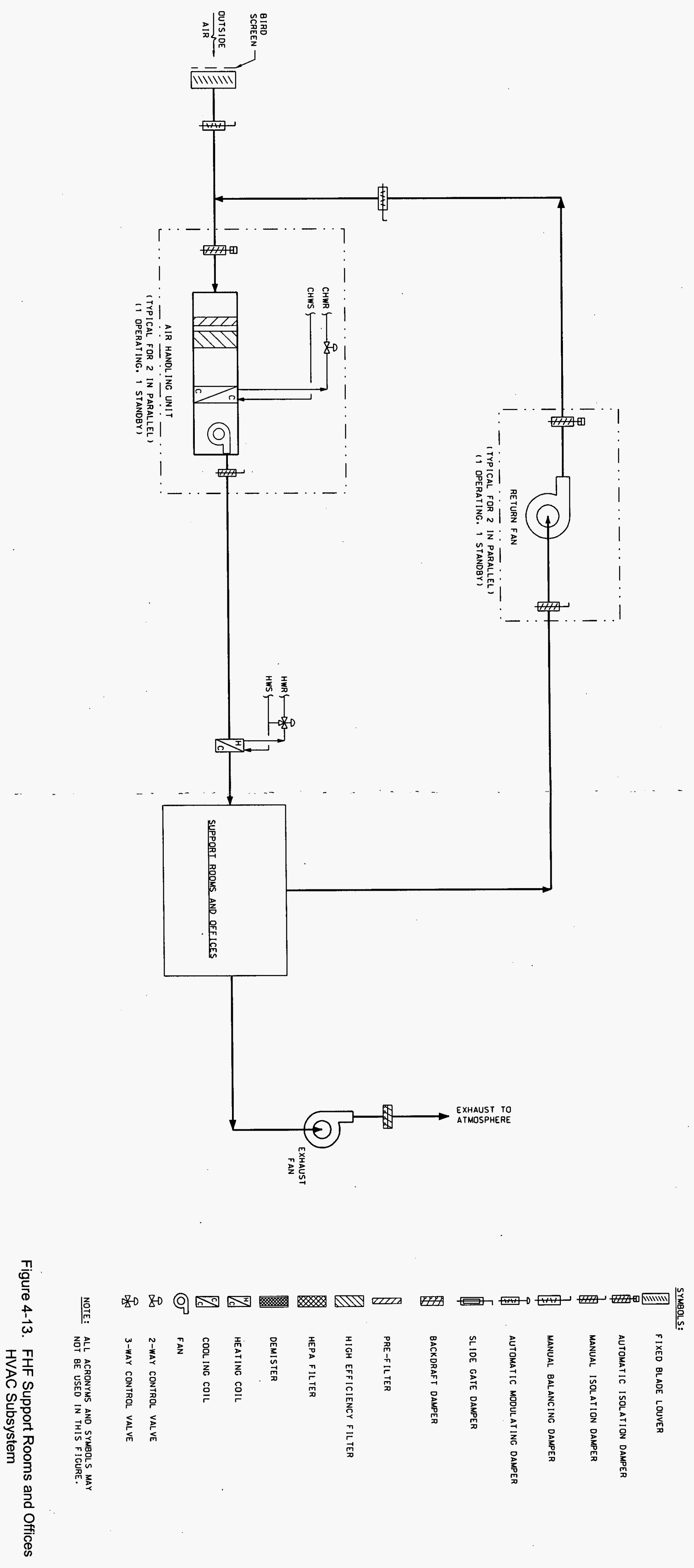


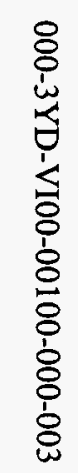

z

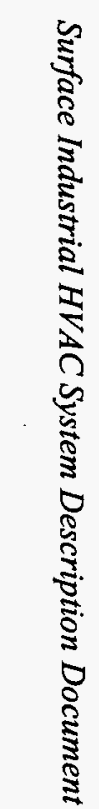




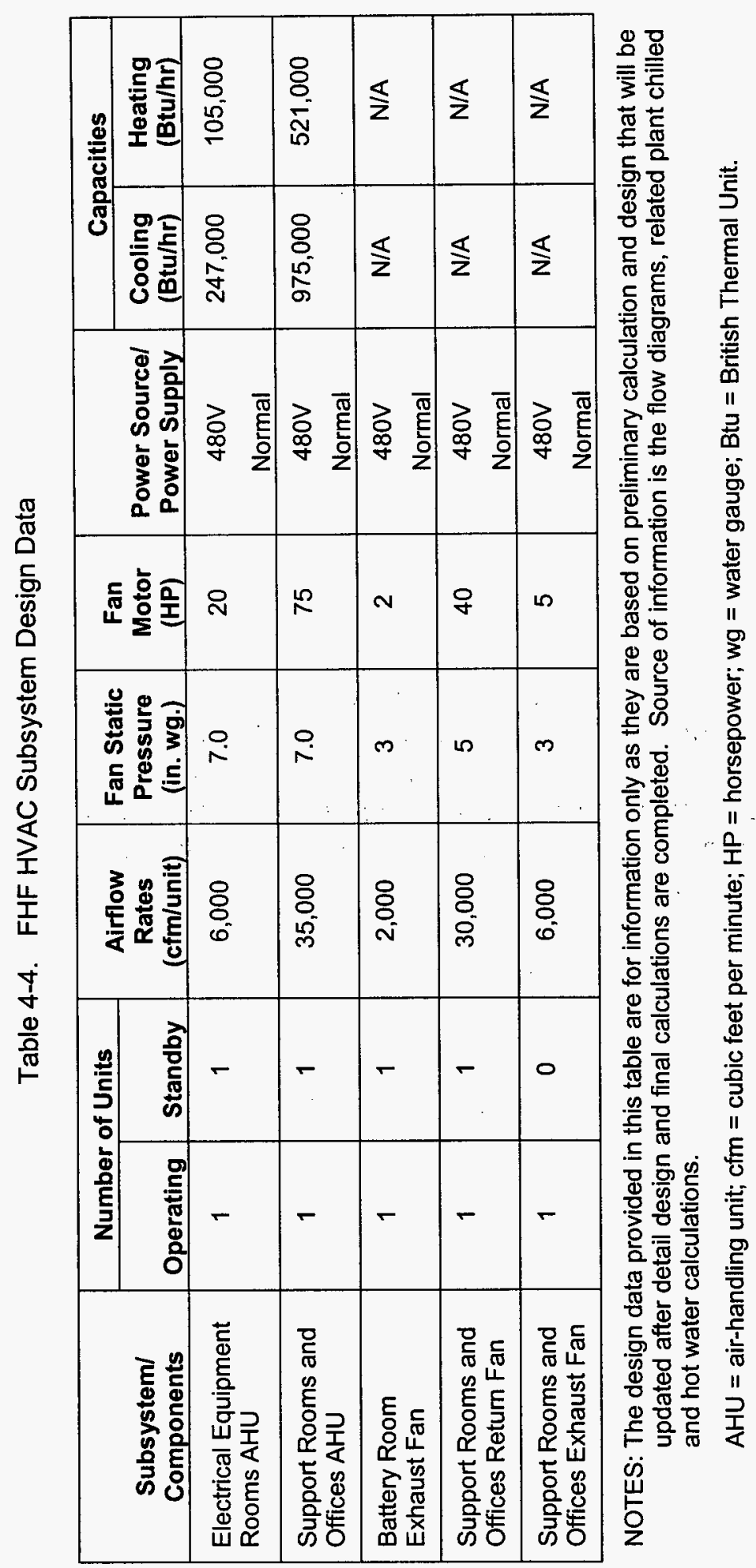


The CCCF HVAC subsystems consist of the following subsystems:

\section{Central Control Center HVAC Subsystem}

The central control center HVAC subsystem block flow diagram is shown in Figure 4-14. The central control center HVAC subsystem is designed to provide redundancy in the supply air-handling units, two sources of cooling medium, normal and emergency electrical power sources, and redundant air intake with detection and alarms. The central control center HVAC subsystem consists of two 100 percent recirculating supply air-handling units (one operating and one backup), two 100 percent exhaust fans (one operating and one backup), a backup air-cooled water chiller and chilled water pump, and associated ductwork, dampers, registers and controls. Each supply air-handling unit consists of prefilters, high-efficiency filters, heating coil, cooling coil, and supply fan. The electrically operated components of the control and computer room HVAC subsystem are powered from the normal and emergency electrical power system as explained below.

The central plant heating and cooling subsystem will provide the hot water and chilled water to the air-handling unit heating and cooling coils. During loss of the normal electrical power, or, when the central plant heating and cooling subsystem is not available, the backup air-cooled water chiller and chilled water pump powered from the emergency or normal electrical power system will supply the required chilled water to the supply air-handling unit cooling coils.

Two outdoor air intakes, located approximately 100 feet apart, are provided for the central control center HVAC subsystem, with one outdoor air intake dedicated for normal operation and the other intake to be used during an event sequence condition. The makeup outdoor air intakes are provided with smoke detectors, radiation detectors, and low-leakage isolation dampers. One of the makeup outdoor air intakes is provided with a HEPA filter unit for use during event sequences to filter the outdoor air prior to mixing it with return air from the control and computer room. If smoke or high radiation levels are detected in the outside air intake, the normal path of outside air intake is closed, and the outside air is directed to the alternate air intake and passed through a HEPA filter unit. The outdoor air filter unit consists of prefilter, high-efficiency filter, HEPA filter, supply fan and electric heating coil for heating of outside air in winter when required.

The central control center HVAC subsystem is non-ITS. However, if needed, it will be designed with augmented quality conforming to DOE/RW-0565, Augmented Quality Assurance Program $(A Q A P)$ (DOE 2004 [DIRS 171341]) during the detail design. 


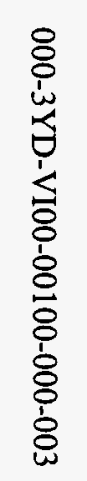

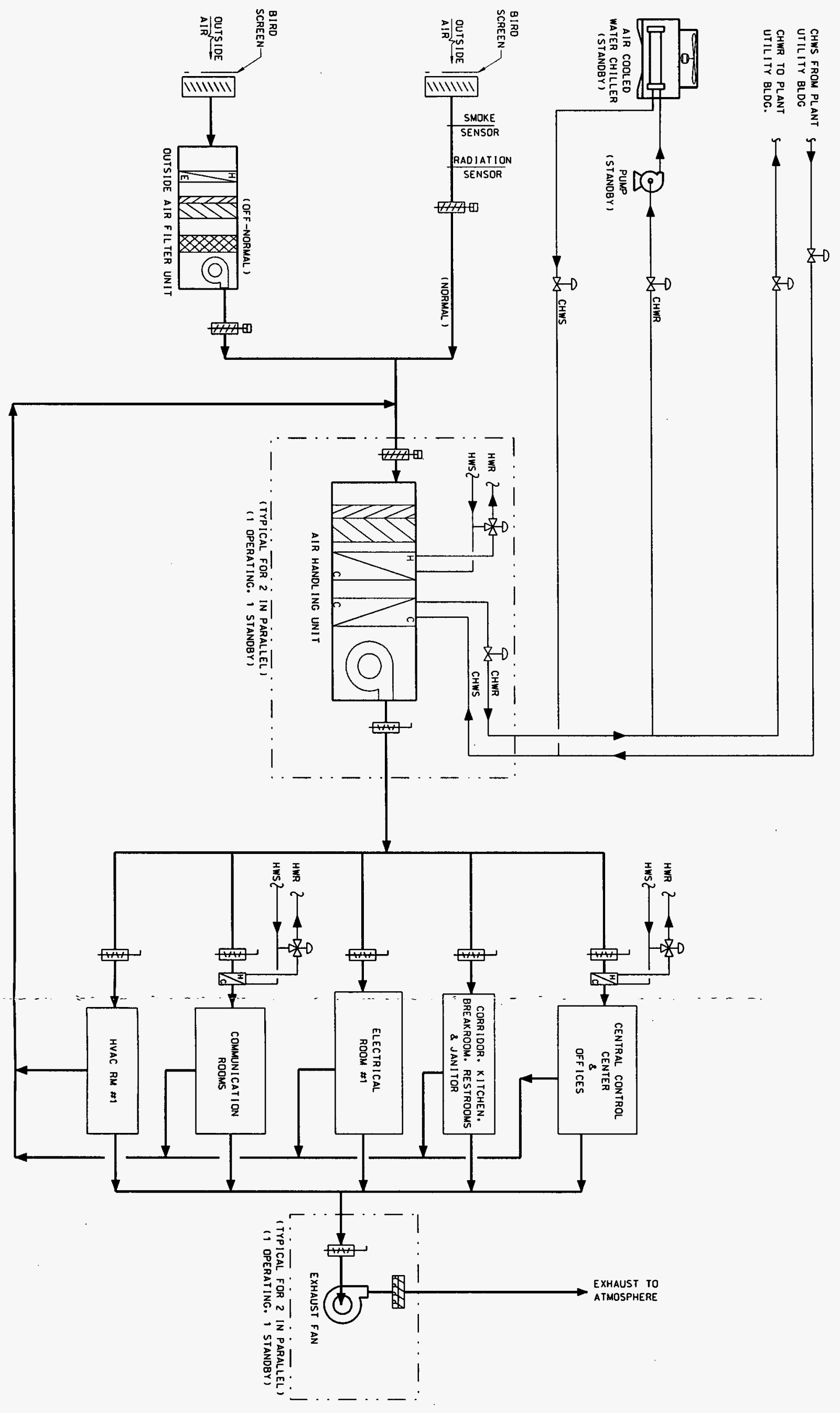

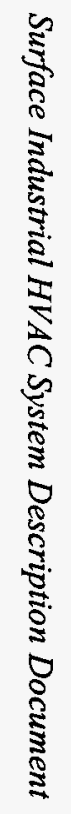

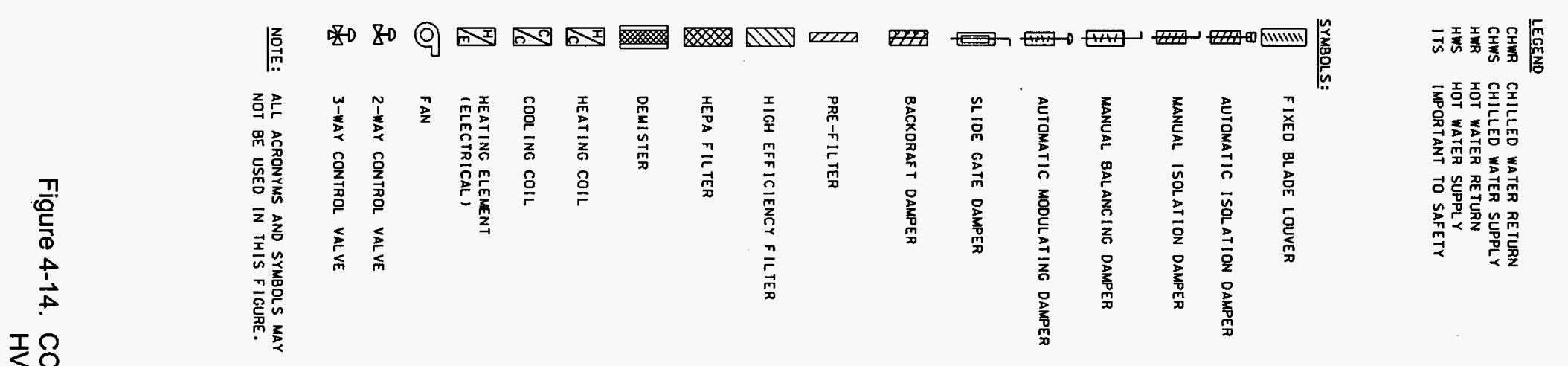

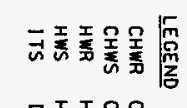

5 


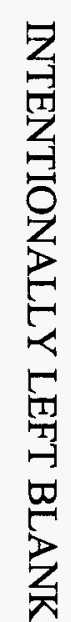




\section{Safeguard Area HVAC Subsystem}

The safeguard area HVAC subsystem block flow diagram is shown in Figure 4-15. The safeguard area HVAC subsystem is designed to provide redundancy in the supply air-handling units, two sources of cooling medium, normal and emergency electrical power sources, and redundant air intake with detection and alarms. The safeguard area HVAC subsystem consists of two 100 percent recirculating supply air-handling units (one operating and one backup), two 100 percent exhaust fans (one operating and one backup), a backup air-cooled water chiller and chilled water pump, and associated ductwork, dampers, registers, and controls. Each supply air-handling unit consists of prefilters, high-efficiency filters, heating coil, cooling coil, and supply fan. The electrically operated components of the safeguard HVAC subsystem are powered from the normal and emergency electrical power system as explained below.

The central plant heating and cooling subsystem provides the hot water and chilled water to the air-handling unit heating and cooling coils. During loss of the normal electrical power, or, when the central plant heating and cooling subsystem is not available, the backup air-cooled water chiller and chilled water pump powered from the emergency or normal electrical power system will supply the required chilled water to the supply air-handling unit cooling coils.

Two outdoor air intake, located approximately 100 feet apart, are provided for the safeguard area HVAC subsystem, with one outdoor air intake dedicated for normal operation and the other intake to be used during an event sequence condition. The makeup outdoor air intakes are provided with smoke detectors, radiation detectors, and low-leakage isolation dampers. One of the makeup outdoor air intakes is provided with a HEPA filter unit for use during event sequences to filter the outdoor air prior to mixing it with return air from the control and computer room. If smoke or high radiation levels are detected in the outside air intake, the normal path of outside air intake is closed, and the outside air is directed to the alternate air intake and passed through a HEPA filter unit. The outdoor air filter unit consists of prefilter, high-efficiency filter, HEPA filter, supply fan and electric heating coil for heating of outside air in winter when required.

\section{HVAC Subsystem Components Description}

The CCCF HVAC system consists of components dedicated to supply air to or exhaust air from the facility. The supply subsystem components consist of air-handling units with supply fan, outdoor air intake louvers, and supply air distribution. The supply air distribution consists of ductwork, reheat coils, pressure control dampers, air-balancing devices, and isolation dampers. The CCCF HVAC subsystems and the related design data are shown in Table 4-5. The components are described below.

Supply Air-Handling Units-Each supply air-handling unit consists of outdoor air intake filters, heating coils, and cooling coils. The air-filtration section for the supply air-handling units consists of prefilters and high-efficiency filters. The nominal size of each prefilter element is 24 " $\times 24$ " $\times 4$ ", and the nominal size of the high-efficiency filter element is 24 " $\times 24$ " $\times 36^{\prime \prime}$. Each prefilter and high-efficiency filter element is rated at $2,000 \mathrm{cfm}$. The prefilter elements are high capacity pleated panel filters and have an efficiency rating of 25 to 30 percent when evaluated in accordance with ANSI/ASHRAE 52.1-1992 [DIRS 164197]. The high-efficiency 
filters are replaceable, extended surface multipocket style filters made of microfine glass fiber media and have an efficiency rating of 80 to 90 percent when evaluated in accordance with ANSI/ASHRAE 52.1-1992 [DIRS 164197].

The cooling coils are constructed of copper tubes and fin mechanically bonded to the tubes. The tube bundles are enclosed in a steel frame and include vent and drain connections. The coils are arranged for counterflow design using chilled water. The cooling coils are in accordance with ARI 410 [DIRS 164310].

The heating coils and reheat coils are constructed of copper tubes with helically wound, permanently bonded, smooth soldered-coated copper fins. The coils are designed for heating air with hot water. The reheat coils are duct mounted to provide supplemental heat to areas where additional heating is required. The heating coils are in accordance with ARI 410 [DIRS $164310]$.

Outside Air Filter Unit-The outside air filter unit consists of electric heating coil, prefilters, high-efficiency filters, and HEPA filters. The design and construction of the HEPA Filter Plenum are in accordance with the guidance provided in of Regulatory Guide 1.140 [DIRS 158855], and ASME AG-1-2003 [DIRS 166908].

The HEPA filter plenum housings are made of continuously welded stainless steel or coated carbon steel provided with service access doors, explosion proof lights, filter test connections (test ports), connections for pressure gauges, and drain connections. The HEPA filter plenum housing method of construction is in accordance with ASME AG-1-2003 [DIRS 166908], Section HA.

Electric heating coil is provided for heating of outside air in winter when required. The prefilters are installed upstream of the HEPA filter to remove large airborne particulate, thereby reducing the particulate loading on the HEPA filters and extending their service life. The prefilters have an average atmospheric dust-spot efficiency of 80 percent in accordance with ANSI/ASHRAE 52.1-1992 [DIRS 164197]. The prefilter elements are replaceable, glass fiber media and conform to the requirements of ASME AG-1-2003 [DIRS 166908], Section FB.

The HEPA filters function to remove particulate contaminants from the air stream. The HEPA filters have a minimum removal efficiency of 99.97 percent on particles measuring $0.3 \mathrm{~mm}$ or larger. The HEPA filter elements are Type B consisting of glass fiber media and conform to the requirements of ASME N509 [DIRS 115139], Article 5.1 and 5.6.3, and ASME AG-1-2003 [DIRS 166908], Section FC. The framing system is designed to accommodate a 24 " $\times 24$ " $\times 12^{\prime \prime}$ filter element. The HEPA filters are size 7 rated at $1500 \mathrm{cfm}$ per filter element, with Type IID (stainless steel) frame material.

Supply Fans and Exhaust Fans-The supply fans for the air-handling units and the exhaust fans for the exhaust HEPA Filter Plenum are either directly driven or belt driven, heavy-duty centrifugal-type fans with backward inclined or airfoil blades. The supply and exhaust fans are designed in accordance with ASME N509 [DIRS 115139], Article 5.7 and ASME AG-1-2003 [DIRS 166908], Section BA. The fan performance testing is in accordance with ANSI/AMCA 210-99 [DIRS 153079]. 


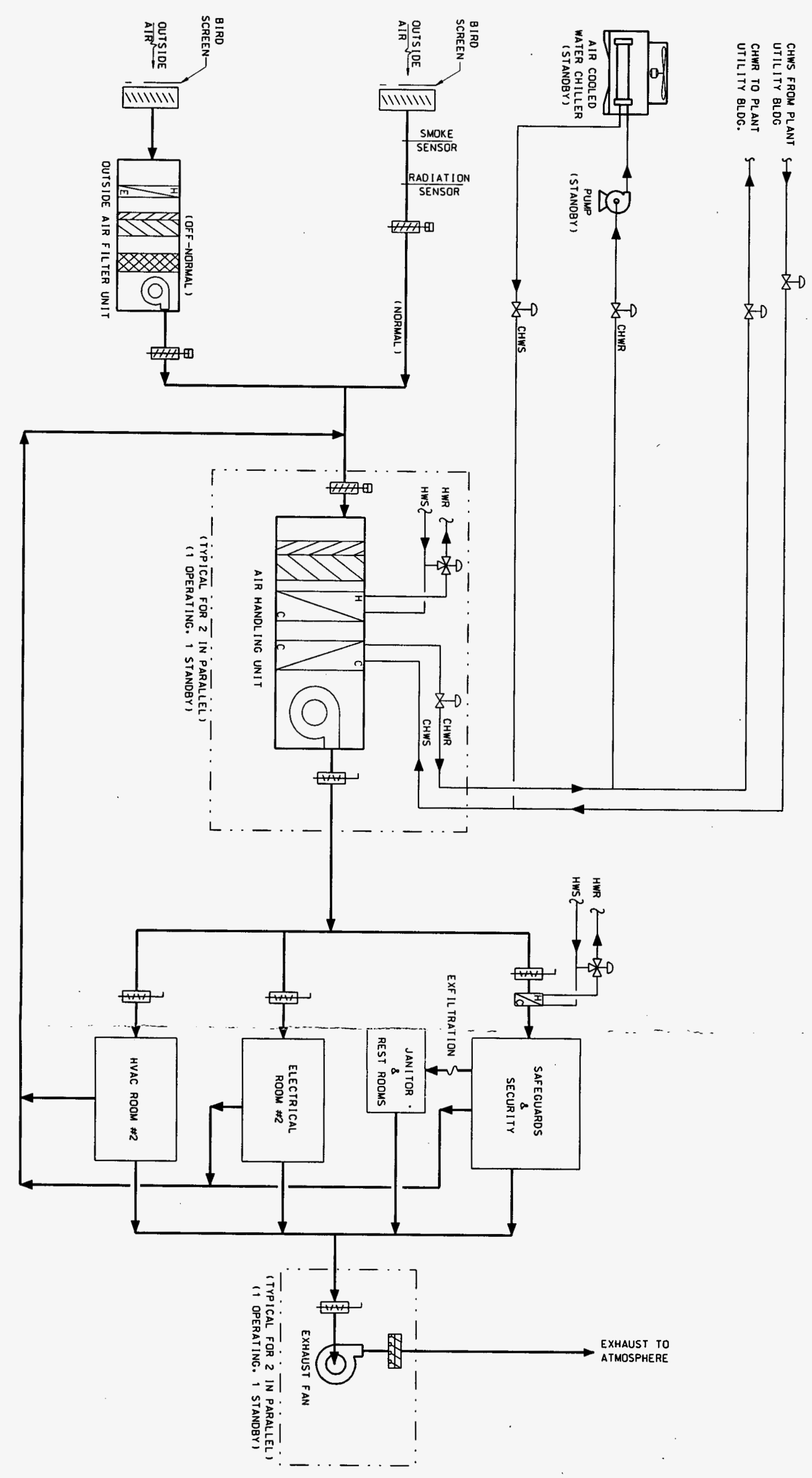

$\dot{\leftrightarrow}$

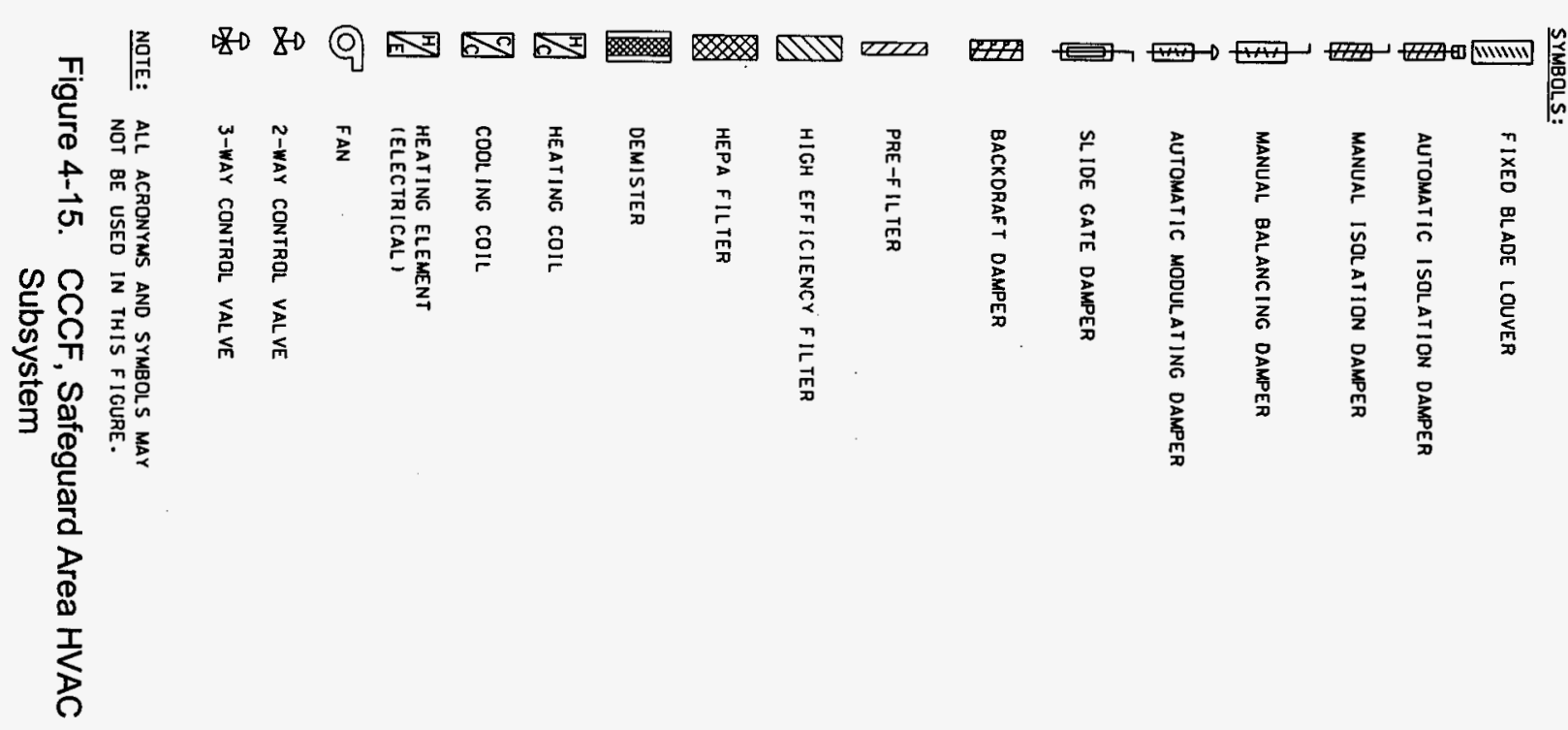

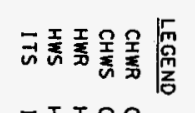

공독올을 


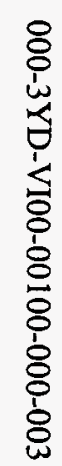

勇 


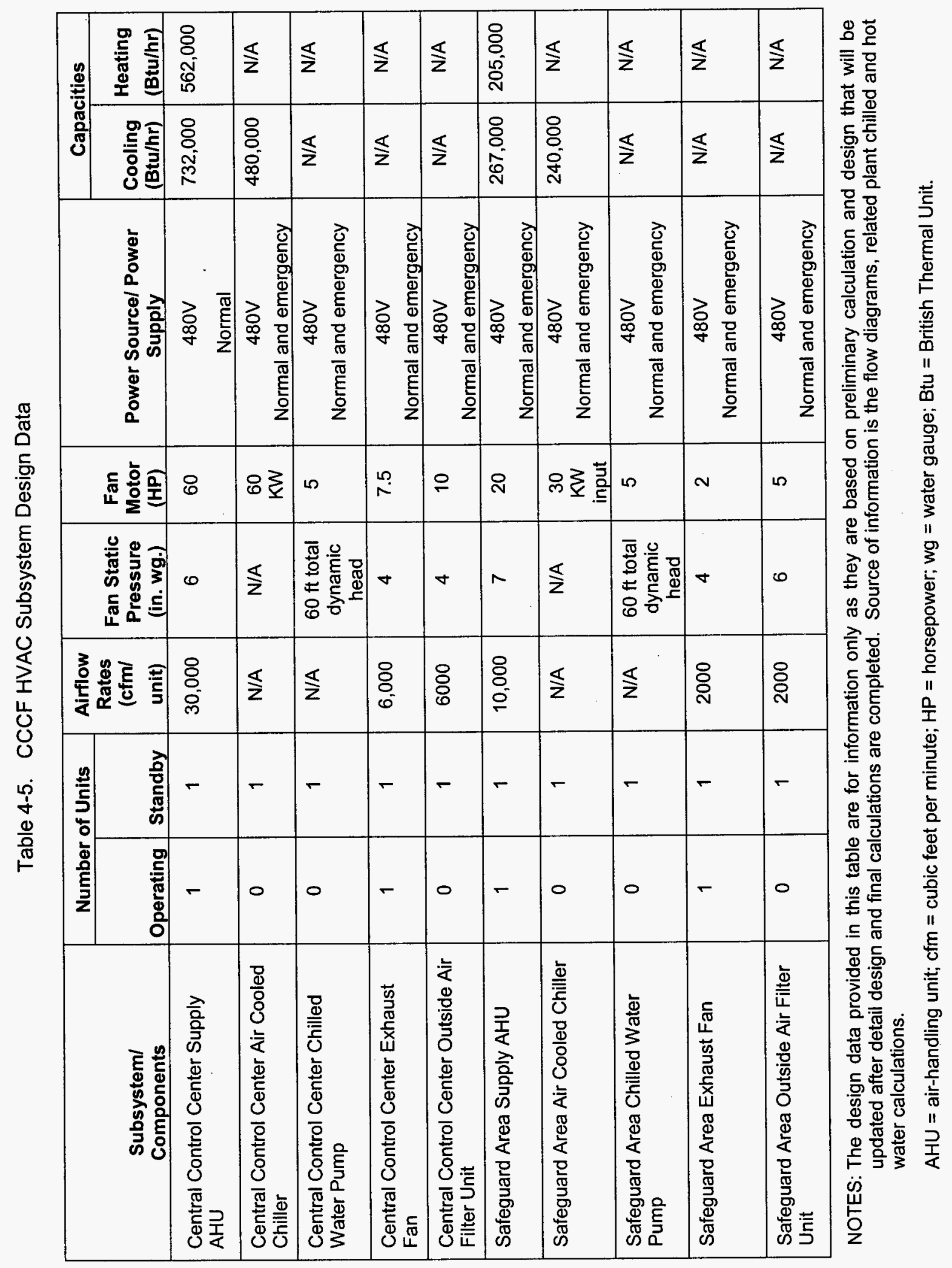


Dampers-The design and construction of the dampers are in accordance with Article 5.9 of ASME N509 [DIRS 115139] and Section DA of ASME AG-1-2003 [DIRS 166908].

Isolation dampers are used where a means of isolating the system or portion of a system from a flow path is required; butterfly dampers or parallel-blade-type dampers are utilized. These dampers are pneumatically operated and are designed to automatically fail in the safe position.

Volume (balancing) dampers, opposed-blade-type, are utilized, as necessary, to provide a means of system balancing. In general, these dampers are manually operated.

Backdraft dampers are employed, where required, to maintain the proper direction of airflow, or prevent reversal of airflow. Backdraft dampers are equipped with adjustable counterweight.

Fire dampers are the curtain-type dampers located in fire barriers, as necessary, to maintain the fire ratings of the barriers. Fire dampers are equipped with fusible links to close the damper at elevated temperature.

Ductwork-The supply and exhaust ductwork is fabricated and installed in accordance with SMACNA 1995 [DIRS 158927]. The supply ductwork is generally constructed of galvanized steel with outside thermal insulation. The exhaust ducts are sized to maintain sufficient transport velocities to prevent particulate contaminants from settling out of the air stream. The exhaust ducts are made of galvanized steel and are uninsulated.

\subsubsection{BOP and other Miscellaneous HVAC Facilities}

The HVAC system design and configuration for various miscellaneous facilities are similar.

The miscellaneous plant facilities are provided with industrial type of HVAC systems. They are classified as not ITS, not ITWI and non-SC. This classification is based on event sequence categorization, and event sequence dose consequence analyses, which indicate that no event sequences have been identified that take credit for BOP and miscellaneous plant facilities HVAC subsystem.

The miscellaneous plant facilities HVAC systems are designed to maintain proper environmental conditions (temperature, pressure, and relative humidity) in the facility. The system provides conditioned air for cooling, heating, and ventilation to meet the air quality standards required for the safety, health, and comfort of workers. They also maintain a slightly positive differential pressure relative to ambient pressure to minimize infiltration of unconditioned air and dust into the facility. It also maintains environmental conditions for reliable operation of equipment and components, and it removes heat dissipated from heat producing equipment.

BOP and miscellaneous plant facilities HVAC systems consist of following subsystems:

- Administration Facility HVAC Subsystem

- Security Stations HVAC Subsystems

- Utilities Facility HVAC Subsystems

- Switchgear Facilities HVAC Subsystems

- Generator Facilities Heating and Ventilation Systems 
- Fire Water Facilities Heating and Ventilation Systems

- Fire, Rescue, and Medical Facility HVAC Subsystem

- Warehouse/Central Receiving HVAC Subsystem

- Craft Shops HVAC Subsystems

- Heavy Equipment Maintenance Facility HVAC Subsystem

- Vehicle Maintenance and Motor Pool HVAC Subsystem

- Visitor Center HVAC Subsystem.

- Gate 510 Facilities HVAC Subsystem

Details of the miscellaneous plant facilities HVAC system will be included as the design evolves.

\subsubsection{Boundaries and Interfaces}

The surface industrial HVAC system interfaces with the following systems:

- Structural building system-The structural building system (DTFs, CHF, TCRRF, WNNRF, FHF, CCCF and BOP) is the main interface for the surface industrial HVAC system. This interface is required for confinement zoning to maintain the required pressure, temperature and humidity conditions, HVAC equipment foundation and supports.

- Electrical power system-To provide reliable power to electrically operated system and components.

- HVAC plant heating and cooling systems-To provide chilled water and hot water to the system's air-handling unit and duct mounted heat exchangers for the different areas of the facility.

- Plant services-To provide instrument air to pneumatic controls.

- Fire protection system-To provide protection to personnel and SSCs.

- DCMIS-For continuous monitoring and control of the system.

- Safeguard and security system-For physical barriers requirements for security.

- Surface nuclear HVAC system-For maintaining pressure differential between confinement and nonconfinement zones.

- Low level waste management system-For managing and disposing the waste generated during operation and maintenance of the surface industrial HVAC system.

\subsubsection{Physical Locations and Layout}

The facilities (DTF, CHF, FHF, TCRRF, WNNRF, CCCF and BOP) are configured to provide the space and layout necessary to integrate the surface industrial HVAC subsystems, system components, and other support systems. 
The outdoor air intakes are located as close as possible to the air-handling units, and as far as possible from building exhaust or from other sources of contamination.

The surface industrial HVAC equipment rooms are located such that potentially contaminated air will not be recirculated back through the outdoor air intakes. The air-conditioning units with filters, coils, and supply fans are located in the HVAC equipment rooms of the respective facilities.

The arrangement of the HVAC supply and exhaust equipment is shown in floor plan and general arrangement drawings.

\subsubsection{Principles of Operation}

The surface industrial HVAC system provides conditioned air for cooling, heating, and ventilation to ensure meeting the air quality standard required for the safety, health, and comfort of the occupational workers.

During normal operating conditions, the system operates by drawing outdoor air through the intake plenums and mixes with the recirculation air, which is filtered through the supply air-conditioning prefilters and high-efficiency filters, and conditioned for distribution to the different areas of nonconfinement zone. The air supplied to the nonconfinement zones is conditioned by the cooling coils and heating coils supplied with chilled water and hot water from the HVAC plant heating and cooling system. The supply air temperature from the air-conditioning units is maintained by modulating the water flow through the associated control valves of either the chilled water coils or hot water coils. Temperature controllers with sensors located in various spaces maintain the desired room temperatures. The supply ductwork for each zone is provided with hot water reheat coils (supplied with hot water from the HVAC plant heating and cooling system) actuated by thermostats, to meet the temperature requirement for comfort and process needs. Exhaust air from the nonconfinement areas is discharged to the outside environment by exhaust fans and associated ductwork. The surface industrial HVAC system provides outdoor air of no less than 10 percent of the total system airflow rate, or as required, to maintain proper indoor air quality and slight positive pressure in the nonconfinement areas relative to the atmosphere or to adjacent confinement areas. This slight pressurization will minimize infiltration of unconditioned air or dust during normal operation.

\subsubsection{System Reliability/Safety Features}

The surface industrial HVAC subsystem is designed, constructed, and installed to ensure that the system will remain operational to perform its function.

The bypass dampers to provide the passive (natural) ventilation for fuel element staging area HVAC subsystem in the DTF and canister staging area HVAC subsystem in CHF are designed to fail open upon loss of power or upon fan failure and the associated exhaust fan isolation dampers fail closed. The related ductwork is designed to remain intact to allow natural airflow. This portion of surface industrial HVAC system is designed not to collapse, and be operational with a DBGM-1 event sequence. 
The surface industrial HVAC system components located outdoors are designed to operate at extreme environmental conditions to ensure system readiness and continued operation. The supply air intakes are protected from the environmental elements such as snowfall, precipitation, sand, and smoke. As appropriate, the intake and exhaust openings are provided with tornado missile barriers to preclude entry of a missile into the building.

The surface industrial HVAC system has smoke detectors to shutoff the supply fans and exhaust fans to prevent recirculation of smoke into the occupied areas of the facility in the event of a fire. Ductwork penetrations in fire barriers are provided with heat activated fire dampers that close to confine the fire and prevent the spread of contamination through the ductwork. The exhaust HEPA filter plenums are provided with fire detectors.

\subsubsection{System Control Features}

The surface industrial HVAC system parameters are monitored and controlled by temperature, pressure, and flow instrumentation. Operation of heating and cooling coils is automatically regulated by temperature indicating controllers. Fans are controlled from the central control center. The system monitoring, status indication, and alarm functions are shown in Table 4-1.

The logic for the automatic operation of the surface nuclear HVAC system will be provided in a later revision of this SDD.

- The instrumentation for the surface industrial HVAC subsystem are provided, either locally or in the central control center, in accordance with ASME AG-1-2003 [DIRS 166908] and ASME N509-1989 [DIRS 115139].

The general control concepts for the surface industrial HVAC subsystem areas are:

- The supply air-handing units are directly controlled from individual direct digital controllers. The exhaust fans are interlocked with the associated air-handling units. When the air-handling units are proven on, the associated exhaust fans will run.

- The supply air-handing units are provided with supply air temperature sensor connected to a direct digital controller. The set points are set, or automatically reset by operator choice, to optimally adjust the supply air temperature based on actual building load. The supply air temperature's set point is varied between $65^{\circ} \mathrm{F}$ and $55^{\circ} \mathrm{F}$.

- The duct-mounted hot water reheat coils in the supply ductwork are controlled by their own controller. Each controller is connected to a wall mounted electronic temperature sensor. The controller compares the heating set point with the space temperature and determines a heating control signal to operate the modulating hot water valve. 


\subsection{OPERATIONS}

\subsubsection{OPERATIONS For the DTF Staging Area HVAC Subsystem}

\subsubsection{Initial Configuration (Pre-startup)}

Pre-startup and initial configuration will be developed after the design is finalized.

\subsubsection{System Startup}

The exhaust system receives the start signal from the ITS PLC Control Station located in the HVAC Equipment Room. Upon receiving start signal, the exhaust fan isolation dampers will open. Upon confirmation that the isolation dampers are fully open (by limit switches), the exhaust fans will start automatically. Two exhaust fans (no standby) are required for normal operation.

\subsubsection{Normal Operation}

During normal operation, the ventilation of the DTF staging area is provided by the forced ventilation system using two exhaust fans. Temperature indicators are provided in the staging area and at the exhaust duct to monitor temperatures and indicate alarm on high temperature. Differential pressure indicators are provided to monitor staging area room pressure and alarms on high differential pressure.

\subsubsection{Off-Normal Operation}

Upon loss of forced ventilation (active cooling) due to loss of power or fan failure, the flow switch will detect low flow and the associated isolation dampers for the forced ventilation system will close. Upon loss of active cooling, the interlock will open the isolation damper for the passive ventilation system to provide natural ventilation in the staging area by stack effect.

On resumption of normal power, the isolation damper for the passive ventilation system will close and the isolation damper for exhaust fans will open. The exhaust fans are manually started as described in Section 4.3.1 - System Startup.

\subsubsection{System Shutdown}

Exhaust fans are manually stopped. Upon stopping the exhaust fans, the associated isolation dampers will close and passive ventilation isolation damper will open. The passive ventilation isolation damper can be closed manually if desired. 


\subsubsection{OPERATIONS for Surface Industrial HVAC Systems}

\subsubsection{Initial Configuration (Pre-startup)}

Pre-startup and initial configuration will be developed after the design is finalized.

\subsubsection{System Startup}

When starting up the surface industrial HVAC subsystem, as part of the automatic startup sequence in the control system, the fans are started in a sequence to ensure that the required pressurization in the nonconfinement zones is maintained.

Startup procedures will be developed after the detail design is completed as part of Operation Startup Strategy.

\subsubsection{Normal Operation}

The surface industrial HVAC system is designed to operate continuously throughout the year. The system capacities meet or exceed the requirements for filtration, ventilation, heating, and cooling under normal operating conditions. Design margins are included to account for unforeseen conditions. The occupied areas of the facility are designed for a minimum of four air changes per hour. The amount of air circulation is provided to meet room temperature requirements or for effective contamination control. The nominal indoor design temperature is shown in Table 3-1 of this SDD.

\subsubsection{Off-Normal Operation}

Control of temperature and humidity is not required during event sequence conditions, including loss of power, release of radioactive materials, and equipment failure.

A preclosure safety analysis has been performed for the repository in accordance with the requirements of 10 CFR Part 63 [DIRS 173164]. This analysis includes evaluation of internal and external hazards, event sequence analyses (including the role of HVAC SSCs during an event sequence), consequence analysis, and the safety classification of SSCs. Based on this analysis, the surface industrial HVAC system is ITS and SC.

Portions of the staging area HVAC subsystem that provide passive (natural) ventilation to the fuel element or canister staging area are classified as ITS and SC. The related ductwork is designed to remain intact to allow natural airflow. This portion of surface industrial HVAC system is designed not to collapse and be operational with a DBGM-1 event sequence. 
Although not required to maintain acceptable onsite and offsite doses, the backup units are provided in some areas as defense-in-depth in the event that a particulate release occurs during waste handling operations. During an event sequence, the actuations identified below will occur. These actions minimize contamination of the surface industrial HVAC system and the facility in the event of a radiological release.

- The normally operating support rooms and offices HVAC subsystem supply and exhaust fans are de-energized.

- The control, safeguard, and computer room HVAC subsystem will continue to operate to provide the required cooling in the control, computer room, and safeguard areas. The backup air-cooled chiller will provide the chilled water required by the cooling coils when the central plant heating and cooling system is not available. The outside air filter will provide clean air to the control centers. The backup electrical power subsystem will provide the power required by the control and computer room HVAC subsystem electrical components.

- The electrical equipment room HVAC subsystem in DTF and FHF will continue to operate. The supplementary fan coil units for the Train A and Train B electrical rooms will continue to operate to provide the required cooling in the electrical equipment rooms. The backup air-cooled chiller will provide the chilled water required by the supplementary fan coil units cooling coils when the central plant heating and cooling system is not available.

\subsubsection{System Shutdown}

The surface industrial HVAC system can be shut down if the system is not required to operate or support the operation of the facilities during an event sequence, including loss of power, smoke or fire, release of radioactive materials, and equipment failure.

For planned maintenance and shutdown, the surface industrial HVAC systems are taken out of service in the reverse of the starting order. If any system fails during normal operation, the shutdown sequence is the same as that for removal from service, and any systems having a higher contamination potential than the failed system will remain in operation.

\subsubsection{Safety Management Program and Administrative Controls}

No administrative or procedural safety controls are required to prevent or mitigate the effects of Category 1 or Category 2 event sequences. Actuation of the isolation dampers and operation of the backup equipment are automatic. Manual initiation is available as a defense-in-depth feature.

The safety management program in place is the integrated safety management system. 


\subsection{TESTING AND MAINTENANCE}

\subsubsection{Temporary Configuration}

Separate testing and maintenance programs and temporary configurations will be developed for the surface industrial HVAC system.

\subsubsection{Safety Required Surveillances}

The technical specifications for surveillance requirements, such as checks, inspection, calibrations, and functional testing that are deemed necessary and sufficient for safe operation of the surface industrial HVAC system based on its safety classification will be identified after the detail design.

The DTF staging area HVAC subsystems will list and define the technical specifications and surveillance requirements to check, inspect, calibrate, and functionally test operation of inlet and outlet dampers, ductwork and related instrumentation.

\subsubsection{Non-Safety Inspections and Testing}

Procedures will be developed to define and describe surveillances, inspections, and testing requirements. The procedures will be based on manufacturer's recommendations and final system configuration.

The HEPA filters are replaced when the differential pressure reaches 1.8 to 2 -in. water gauge, a condition that may occur due to dust or particulate loading.

A system air balance, system test, and system adjustments to design conditions are conducted in the course of the repository preoperational test program. Instruments are calibrated in accordance with the repository maintenance program. Components requiring preventive maintenance are located in accessible areas to permit periodic inspection during normal repository operation. Automatic controls are tested for actuation at the proper setpoint. Alarm functions are checked for operability.

For subsystems that are provided with HEPA filters as defense-in-depth, the following test may be performed as required.

- The method of leak testing of ductwork is in accordance with ASME AG-1-2003 [DIRS 166908], Sections SA and TA, and ASME N510-1989, Testing of Nuclear Air Treatment Systems [DIRS 115203], Section 6.

- Testing methods for the fans is in accordance with ANSI/AMCA 210-99 [DIRS 153079] and with ASME AG-1-2003 [DIRS 166908], Section BA, Article BA-5000. 
- The HEPA filters are factory-tested in accordance with the guidance provided in Regulatory Guide 1.140, Design, Inspection, and Testing Criteria for Air Filtration and Adsorption Units of Normal Atmosphere Cleanup Systems in Light-Water-Cooled Nuclear Power Plants [DIRS 158855]. The HEPA filters are tested with monodispersed dioctyl phthalate aerosol to demonstrate a minimum particulate removal efficiency of no less than 99.97 percent for $0.3-\mathrm{mm}$ particulates. The prefilters or moisture eliminators do not undergo factory or in-place testing because no credit is taken for removal of particulates by the prefilters.

- In-place leak testing of the HEPA filter plenum is performed in accordance with Regulatory Guide 1.140 [DIRS 158855], ASME AG-1-2003 [DIRS 166908], Section TA, and ASME N510-1989 [DIRS 115203]. A functional test of the HEPA filter and charcoal adsorbers is performed whenever a filter element is replaced. A preoperational test is conducted to verify that negative pressure exists in the waste handling areas when the ventilation system is in operation. Regularly scheduled surveillance testing of the exhaust HEPA filter plenum is performed as part of the maintenance program to ensure that the system is functioning properly.

Additional procedures will be developed to define and describe surveillances, inspections, and testing requirements. The procedures will be based on manufacturer recommendations and final system configuration.

\subsubsection{Maintenance}

The surface industrial HVAC system is designed to be operational for 50 years. Components with a shorter life span are designed and installed to permit replacement with minimal effect on operations while maintaining personnel exposure ALARA. Provisions are made for the routine maintenance of the HVAC components in order to maximize their operational life. Instrumentation is provided to facilitate maintenance, troubleshooting, and surveillance testing. Procedures are provided to permit testing, maintenance, and repair of components. There are no specific operator training requirements associated with the surface industrial HVAC system. 


\section{REFERENCES}

\subsection{DOCUMENTS CITED}

103124 NRC (U.S. Nuclear Regulatory Commission) 1987. Standard Review Plan for the Review of Safety Analysis Reports for Nuclear Power Plants. NUREG-0800. LWR Edition. Washington, D.C.: U.S. Nuclear Regulatory Commission. TIC: 203894.

140225 DOE (U.S. Department of Energy) 1999. Design Specification. Volume 1 of Preliminary Design Specification for Department of Energy Standardized Spent Nuclear Fuel Canisters. DOE/SNF/REP-011, Rev. 3. Washington, D.C.: U.S. Department of Energy, Office of Spent Fuel Management and Special Projects. TIC: 246602.

154039 YMP (Yucca Mountain Site Characterization Project) 2000. Environmental Management Plan. YMP/93-04, Rev. 4. Las Vegas, Nevada: Yucca Mountain Site Characterization Office. ACC: MOL.20000831.0064.

155970 DOE (U.S. Department of Energy) 2002. Final Environmental Impact Statement for a Geologic Repository for the Disposal of Spent Nuclear Fuel and High-Level Radioactive Waste at Yucca Mountain, Nye County, Nevada. DOE/EIS-0250. Washington, D.C.: U.S. Department of Energy, Office of Civilian Radioactive Waste Management. ACC: MOL.20020524.0314; MOL.20020524.0315; MOL.20020524.0316; MOL.20020524.0317; MOL.20020524.0318; MOL.20020524.0319; MOL.20020524.0320.

163179 BSC (Bechtel SAIC Company) 2003. Energy Conservation Compliance Design Guide for Yucca Mountain Project Surface and Subsurface Facilities. 000-3DGOSS0-00100-000-00A. Las Vegas, Nevada: Bechtel SAIC Company. ACC: ENG.20030509.0003.

166275 Canori, G.F. and Leitner, M.M. 2003. Project Requirements Document. TER-MGRMD-000001 REV 02. Las Vegas, Nevada: Bechtel SAIC Company. ACC: DOC.20031222.0006.

167254 DOE (U.S. Department of Energy) 2003. Emergency Management Plan. PLN-CRWEM-000001 REV 01 ICN 03. Las Vegas, Nevada: U.S. Department of Energy, Office of Repository Development. ACC: DOC.20031215.0002.

167313 BSC (Bechtel SAIC Company) 2004. Preliminary Hazards Analysis for License Application Study. 000-30R-HPYK-00100-000-00A. Las Vegas, Nevada: Bechtel SAIC Company. ACC: ENG.20040610.0002.

170557 Curry, P.M. 2004. Project Functional and Operational Requirements. TDR-MGRME-000003 REV 02. Las Vegas, Nevada: Bechtel SAIC Company. ACC: DOC.20040714.0003. 
170938 BSC (Bechtel SAIC Company) 2004. Thermal Analysis of the Canister Pits and Staging Area. 190-MAC-VN00-00400-000-00A. Las Vegas, Nevada: Bechtel SAIC Company. ACC: ENG.20040716.0001.

171190 BSC (Bechtel SAIC Company) 2005. Q-List. 000-30R-MGR0-00500-000-001. Las Vegas, Nevada: Bechtel SAIC Company. ACC: ENG.20050217.0010.

171341 DOE (U.S. Department of Energy) 2004. Augmented Quality Assurance Program $(A Q A P)$. DOE/RW-0565, Rev. 0. Washington, D.C.: U.S. Department of Energy, Office of Civilian Radioactive Waste Management. ACC: DOC.20040813.0001.

171512 BSC (Bechtel SAIC Company) 2005. Nuclear Safety Design Bases for License Application. 000-30R-MGR0-00400-000-001. Las Vegas, Nevada: Bechtel SAIC Company. ACC: ENG.20050308.0004.

171539 DOE (U.S. Department of Energy) 2004. Quality Assurance Requirements and Description. DOE/RW-0333P, Rev. 16. Washington, D.C.: U.S. Department of Energy, Office of Civilian Radioactive Waste Management. ACC:

DOC.20040907.0002. Replacement for 171386

171599 BSC (Bechtel SAIC Company) 2004. Project Design Criteria Document. 000-3DRMGR0-00100-000-003. Las Vegas, Nevada: Bechtel SAIC Company. ACC: ENG.20041124.0001.

171778 BSC (Bechtel SAIC Company) 2004. DTF 1 Thermal Analysis of the Staging Cell. 110-00C-VN00-00200-000-00A. Las Vegas, Nevada: Bechtel SAIC Company. ACC: ENG.20040730.0001.

\subsection{CODES, STANDARDS, REGULATIONS, AND PROCEDURES}

102564 ANSUANS-57.7-1988. American National Standard Design Criteria for an Independent Spent Fuel Storage Installation (Water Pool Type). Revision of ANSI/ANS 57.7-1981. La Grange Park, Illinois: American Nuclear Society. TIC: 238870 .

103093 ANSI/ANS-57.9-1992. Design Criteria for an Independent Spent Fuel Storage Installation (Dry Type). La Grange Park, Illinois: American Nuclear Society. TIC: 3043.

10402664 FR 30851. Greening the Government through Efficient Energy Management. Executive Order 13123. Readily available

115139 ASME N509-1989. Nuclear Power Plant Air-Cleaning Units and Components. New York, New York: American Society of Mechanical Engineers. TIC: 240273.

115203 ASME N510-1989. Testing of Nuclear Air Treatment Systems. New York, New York: American Society of Mechanical Engineers. TIC: 239028. 
17316410 CFR 63. 2004 Energy: Disposal of High-Level Radioactive Wastes in a Geologic Repository at Yucca Mountain, Nevada. ACC: MOL.20050323.0071.

150357 DOE-STD-1027-92. 1992. Hazard Categorization and Accident Analysis Techniques for Compliance with DOE Order 5480.23, Nuclear Safety Analysis Reports. Washington, D.C.: U.S. Department of Energy. TIC: 205819.

153079 ANSI/AMCA 210-99. 2000. Laboratory Methods of Testing Fans for Aerodynamic Performance Rating. Arlington Heights, Illinois: Air Movement and Control Association International. TIC: 249168.

157789 ASHRAE (American Society of Heating, Refrigerating \& Air-Conditioning Engineers) 2001. 2001 ASHRAE Handbook, Fundamentals. Inch-Pound Edition. Atlanta, Georgia: American Society of Heating, Refrigerating and Air-Conditioning Engineers. TIC: 249910.

157791 ANSUASHRAE 55(55a)-1995. 1995. Thermal Environmental Conditions for Human Occupancy, with Addendum. Atlanta, Georgia: American Society of Heating, Refrigerating and Air-Conditioning Engineers. TIC: 252273; 252574.

158855 Regulatory Guide 1.140, Rev. 2. 2001. Design, Inspection, and Testing Criteria for Air Filtration and Adsorption Units of Normal Atmosphere Cleanup Systems in LightWater-Cooled Nuclear Power Plants. Washington, D.C.: U.S. Nuclear Regulatory Commission. Readily available.

158858 Regulatory Guide 5.65. 1986. Vital Area Access Controls, Protection of Physical Security Equipment, and Key and Lock Controls. Washington, D.C.: U.S. Nuclear Regulatory Commission. Readily available.

15891210 CFR 434. 2002. Energy: Energy Code for New Federal Commercial and MultiFamily High Rise Residential Buildings. Readily available.

158913 DOE O 430.2A. 2002. Departmental Energy and Utilities Management. Washington, D.C.: U.S. Department of Energy. Readily available.

158927 SMACNA (Sheet Metal and Air Conditioning Contractors' National Association) 1995. HVAC Duct Construction Standards Metal and Flexible. 2nd Edition. Chantilly, Virginia: Sheet Metal and Air Conditioning Contractor National Association. TIC: 232331.

160955 NFPA 90A. 2002. Standard for the Installation of Air-Conditioning and Ventilating Systems. 2002 Edition. Quincy, Massachusetts: National Fire Protection Association. TIC: 253687.

161103 ANSI/UL-555-2001. 2002. Standard for Fire Dampers. Northbrook, Illinois: Underwriters Laboratory. TIC: 253697. 
161567 DOE O 450.1. 2003. Environmental Protection Program. Washington, D.C.: U.S. Department of Energy. Readily available.

164197 ANSI/ASHRAE 52.1-1992. 1992. Gravimetric and Dust-Spot Procedures for Testing Air-Cleaning Devices Used in General Ventilation for Removing Particulate Matter. Atlanta, Georgia: American Society of Heating, Refrigerating and Air Conditioning Engineers. TIC: 254102.

164296 ANSU/ASHRAE 62-2001. 2001. Ventilation for Acceptable Indoor Air Quality. Atlanta, Georgia: American Society of Heating, Refrigerating and Air-Conditioning Engineers. TIC: 254101.

164310 ARI Std 410. 2002. Forced-Circulation Air-Cooling and Air-Heating Coils, with Addendum. Arlington, Virginia: Air-Conditioning and Refrigeration Institute. TIC: 254106.

166725 UL 900. 1999. Air Filter Units. 6th Edition. Northbrook, Illinois: Underwriters Laboratories. TIC: 255495.

166908 ASME AG-1-2003. Code on Nuclear Air and Gas Treatment. New York, New York: American Society of Mechanical Engineers. TIC: 255464.

169128 IEEE Std 484TM-2002. 2003. IEEE Recommended Practice for Installation Design and Installation of Vented Lead-Acid Batteries for Stationary Applications. New York, New York: Institute of Electrical and Electronics Engineers. TIC: 256025.

171798 ASHRAE (American Society of Heating, Refrigerating and Air-Conditioning Engineer 2003. 2003 ASHRAE ${ }^{\circledR}$ Handbook, Heating, Ventilating, and AirConditioning Applications. Inch-Pound Edition. Atlanta, Georgia: American Society of Heating, Refrigerating and Air-Conditioning Engineers. TIC: 256642.

171799 ASHRAE (American Society of Heating, Refrigerating and Air-Conditioning Engineer 2004. 2004 ASHRAE® Handbook, Heating, Ventilating, and AirConditioning Systems and Equipment. Inch-Pound Edition. Atlanta, Georgia: American Society of Heating, Refrigerating and Air-Conditioning Engineers. TIC: 256641 .

171846 ASME (American Society of Mechanical Engineers) 2004. 2004 ASME Boiler and Pressure Vessel Code. 2004 Edition. New York, New York: American Society of Mechanical Engineers. TIC: 256479.

AP-3.11Q, Technical Reports

AP-EM-002, Land Access and Environmental Compliance

AP-EM-007, Hazardous Material Approval and Tracking

AP-EM-009, Pollution Prevention Assessments and Sustainable Design 
AP-EM-010, Environmental Baseline Review

AP-ESH-004, Occupational Safety and Health Program

AP-ESH-006, Protection Program for Radon

LP-3.26Q-BSC, System Description Documents

LP-3.30Q-BSC, Hazards Analysis System

LP-ESH-010-BSC, Onsite Emergency Management

LP-ESH-019-BSC, Silica Protection

LP-ESH-037-BSC, Emergency Preparedness and Response

LP-SA-001Q-BSC, Determination of Importance and Site Performance Protection Evaluations

\subsection{DATA TRACKING NUMBERS}

None at this time.

\subsection{SOFTWARE CODES}

None at this time. 
INTENTIONALLY LEFT BLANK. 


\section{APPENDIX A \\ GLOSSARY}

Canister

\section{Design Bases}

Basis

Function

Performance Acceptance Criteria

\section{Requirement}

The structure surrounding some forms of waste (e.g., high-level radioactive waste immobilized in glass logs or ceramic disks within cans) that facilitates handling, storage, and transportation. Canistered waste will be placed in waste packages prior to emplacement.

Information that identifies the specific functions performed by an SSC of a facility and the specified range of values chosen for controlling the parameters that are the referenced boundaries for the design of the SSC. The design bases are statements that identify and support why a design requirement is established.

Statements that refer to design requirements for SSCs and identify why the requirement exists, why it is specified in a particular manner, and why a specified value is used. The design bases provide information that identifies the specific functions performed by the SSCs of a facility and the specified range of values chosen for controlling the parameters that are the referenced boundaries for the design of the SSCs.

The statement of the purpose of a system or component.

Statements that provide the verifiable measures of how well the design specification has been achieved or limits against which the actual performance capability of the as-built-system can be evaluated.

A specification of what the design solution must do.

Requirement statements should also include a statement of how well the specification is to be achieved so as to permit verification. In some cases, there are several different criteria for measuring the success of the achievement of the specification and these would be listed as performance acceptance criteria. 
Safety Function: No Failure

Safety Function: Controlled Failure
The "no failure" safety function is assigned to various SSCs (e.g., limiters, collars, dampers) assigned to either a DBGM-1 or DBGM-2 level. The no failure safety function has the following performance goal during and after a seismic event:

The SSC will continue its designated safety function after a seismic event without significant degradation in the performance or requirement for repair. For structural elements, the load response shall be essentially elastic due to the seismic event.

The "controlled failure" safety function is assigned in special instances to SSCs (e.g., ventilation stacks) to preclude potential interactions with SSCs that are ITS. The controlled failure safety function has the following performance goals for ventilation stacks during and after a seismic event:

Failure of an SSC due to a seismic event shall not obstruct an open flow path to the environment of the corresponding ventilation system.

Failure of an SSC shall not impede the safety function of another SSC that is ITS. 


\section{APPENDIX B \\ LIST OF KEY SYSTEM CHARTS, DIAGRAMS, DRAWINGS, AND LISTS}

Following is the list of drawings that helps the implementation of the design requirement of this SDD and is issued separately through the document center. (Note: The DI number identifies these documents; numeric or letter revision designators are not included in the document number).

1. 110-M50-VI00-00101-000, DTF 1 Recirculating Non-Confinement HVAC System Block Flow Diagram

2. 110-M50-VNP0-00202-000, DTF 1 Primary Confinement Staging Area HVAC System Ventilation Flow Diagram

3. 190-M50-VI00-00101-000, CHF Electrical Room and Support Area HVAC Ventilation Flow Diagram

4. 190-M50-VI00-00102-000, CHF Staging Area HVAC System

5. 14A-M50-VI00-00101-000, TCRRF Non Confinement HVAC Block Flow Diagram

6. 150-M50-VI00-00101-000, Waste Package Receipt Facility Block Flow Diagram

7. 210-M50-VI00-00101-000, FHF Electrical Room and Support Area HVAC Ventilation Flow Diagram

8. 240-M50-VI00-00101-000, CCCF, Central Control Center HVAC Ventilation Flow Diagram

9. 240-M50-VI00-00201-000, CCCF, Safeguard HVAC Ventilation Flow Diagram

10. 25A-M50-VPH0-00201-000, Plant Hot Water Process Flow Diagram

11. 25A-M50-VPC0-00101-000, Plant Chilled Water Process Flow Diagram.

Following is the list of calculations that helps the implementation of the design requirement of this SDD:

1. 110-MAC-VN000-00100-000, DTF Ventilation Air Calculation

2. 110-MAC-VP000-00100-000, DTF Heating and Cooling Load Calculation

3. 110-MAC-VN000-00300-000, DTF Equipment Sizing and Selection Calculation

4. 110-MAC-VN000-00200-000, DTF Ventilation Air Pressure Loss Calculation

5. 130-M1C-VN000-00100-000, RF Confinement Zoning Analysis 
6. 130-MAC-VN000-00100-000, RF Ventilation Air Calculation

7. 130-MAC-VP000-00100-000, RF Heating and Cooling Load Calculation

8. 130-MAC-VN000-00300-000, RF Equipment Sizing and Selection Calculation

9. 130-MAC-VN000-00200-000, RF Ventilation Air Pressure Loss Calculation

10. 190-M1C-VN000-00100-000, CHF Confinement Zoning Analysis

11. 190-MAC-VN000-00100-000, CHF Ventilation Air Calculation

12. 190-MAC-VP000-00100-000, CHF Heating and Cooling Load Calculation

13. 190-MAC-VN000-00300-000, CHF Equipment Sizing and Selection Calculation

14. 190-MAC-VN000-00200-000, CHF Ventilation Air Pressure Loss Calculation

15. 140-MAC-VN000-00100-000, TCRRF Ventilation Air Calculation

16. 140-MAC-VP000-00100-000, TCRRF Heating and Cooling Load Calculation

17. 140-MAC-VN000-00300-000, TCRRF Equipment Sizing and Selection Calculation

18. 140-MAC-VN000-00200-000, TCRRF Ventilation Air Pressure Loss Calculation

19. 240-MAC-VI00-00100-000, CCCF HVAC Load and Equipment Sizing Calculation.

20. 25A-MEC-VP00-00100-000, Plant Chilled and Hot Water Calculation and Related Equipment Sizing

21. 110-00C-VNO0-00200-000, DTF 1 Thermal Analysis of the Staging Cell

22. 190-MAC-VN00-00400-000, CHF Thermal Analysis of the Staging Area. 


\section{APPENDIX C \\ LIST OF SYSTEM PROCEDURES}

No procedures have been identified for the surface industrial HVAC system. 
INTENTIONALLY LEFT BLANK 